This is an electronic reprint of the original article. This reprint may differ from the original in pagination and typographic detail.

Author(s): Honkala, Karoliina

Title: $\quad$ Tailoring oxide properties: An impact on adsorption characteristics of molecules and metals

Year: $\quad 2014$

Version:

Please cite the original version:

Honkala, K. (2014). Tailoring oxide properties: An impact on adsorption

characteristics of molecules and metals. Surface Science Reports, 69(4), 366-388.

https://doi.org/10.1016/j.surfrep.2014.09.002

All material supplied via JYX is protected by copyright and other intellectual property rights, and duplication or sale of all or part of any of the repository collections is not permitted, except that material may be duplicated by you for your research use or educational purposes in electronic or print form. You must obtain permission for any other use. Electronic or print copies may not be offered, whether for sale or otherwise to anyone who is not an authorised user. 


\title{
Tailoring oxide properties: an impact on adsorption characteristics of molecules and metals
}

\author{
K. Honkala ${ }^{1}$ \\ ${ }^{1}$ Department of Chemistry, Nanoscience Center,P.O. Box 35, \\ University of Jyväskylä, FIN-40014 Jyväskylä, Finland
}

(Dated: September 12, 2014) 


\begin{abstract}
Both density functional theory calculations and numerous experimental studies demonstrate a variety of unique features in metal supported oxide films and transition metal doped simple oxides, which are markedly different from their unmodified counterparts. This review highlights, from the computational perspective, recent literature on the properties of the above mentioned surfaces and how they adsorb and activate different species, support metal aggregates, and even catalyse reactions. The adsorption of $\mathrm{Au}$ atoms and clusters on metal-supported $\mathrm{MgO}$ films are reviewed together with the cluster's theoretically predicted ability to activate and dissociate $\mathrm{O}_{2}$ at the $\mathrm{Au}-$ $\mathrm{MgO}(100) / \mathrm{Ag}(100)$ interface, as well as the impact of an interface vacancy to the binding of an $\mathrm{Au}$ atom. In contrast to a bulk $\mathrm{MgO}$ surface, an $\mathrm{Au}$ atom binds strongly on a metal-supported ultra-thin $\mathrm{MgO}$ film and becomes negatively charged. Similarly, Au clusters bind strongly on a supported $\mathrm{MgO}(100)$ film and are negatively charged favouring 2D planar structures. The adsorption of other metal atoms is briefly considered and compared to that of Au. Existing computational literature of adsorption and reactivity of simple molecules including $\mathrm{O}_{2}, \mathrm{CO}, \mathrm{NO}_{2}$, and $\mathrm{H}_{2} \mathrm{O}$ on mainly metal-supported $\mathrm{MgO}(100)$ films is discussed. Chemical reactions such as $\mathrm{CO}$ oxidation and $\mathrm{O}_{2}$ dissociation are discussed on the bare thin $\mathrm{MgO}$ film and on selected $\mathrm{Au}$ clusters supported on $\mathrm{MgO}(100) /$ metal surfaces. The Au atoms at the perimeter of the cluster are responsible for catalytic activity and calculations predict that they facilitate dissociative adsorption of oxygen even at ambient conditions. The interaction of $\mathrm{H}_{2} \mathrm{O}$ with a flat and stepped $\mathrm{Ag}$-supported $\mathrm{MgO}$ film is summarized and compared to bulk MgO. The computational results highlight spontaneous dissociation on $\mathrm{MgO}$ steps. Furthermore, the impact of water coverage on adsorption and dissociation is addressed. The modifications, such as oxygen vacancies and dopants, at the oxide-metal interface and their effect on the adsorption characteristics of water and Au are summarized. Finally, more limited computational literature on transition metal (TM) doped $\mathrm{CaO}(100)$ and $\mathrm{MgO}(100)$ surfaces is presented. Again, $\mathrm{Au}$ is used as a probe species. Similar to metal-supported $\mathrm{MgO}$ films, $\mathrm{Au}$ binds more strongly than on undoped $\mathrm{CaO}(100)$ and becomes negatively charged. The discussion focuses on rationalization of $\mathrm{Au}$ adsorption with the help of Born-Haber cycle, which reveals that the so called redox energy including the electron transfer from the dopant to the Au atom together with the simultaneous structural relaxation of lattice atoms is responsible for enhanced binding. In addition, adsorption energy dependence on the position and type of the dopant is summarized.
\end{abstract}


PACS numbers: 


\section{INTRODUCTION}

Metal oxides have long been considered as potential materials for large variety of applications ranging from gas sensing and protective coatings to electrodes in fuel cells, heterogeneous photo(electro) catalyst, and bio-compatible materials ${ }^{1}$. Compared to any other material class both crystallographic and electronic properties of oxides display diverse behaviour, e.g., electronic conductivity ranges from wide-gap insulators to materials with conductivity comparable to metals ${ }^{2}$. The characteristics of oxides can be tailored to improve desired properties in various ways by introducing structural modifications like steps and grain boundaries, adding impurity atoms as dopants, or removing atoms from the structure ${ }^{1,2}$. In particular, point defects such as oxygen vacancies determine optical, electronic and transport properties of insulating oxides, and they usually dominate the chemistry of its surface ${ }^{3}$. While transition metal oxides are utilized for their catalytic properties, simple oxides such as $\mathrm{MgO}$ or $\mathrm{CaO}$ are intrinsically inert owing to their very deep valence band and very high conduction band; thus, they are less exploited in applications. However, simple oxides are interesting model systems whose properties have been thoroughly investigated ${ }^{1,4}$ and therefore they form an ideal platform to explore the impact of different tailoring strategies to improve their reactivity. One way to achieve this is to prepare oxides as metal grown thin films, which provides an unique approach to modify structural, electronic and chemical properties as a function of film thickness extensively, which is discussed in the reviews of Prof. H.J. Freund, Prof. G. Pacchioni, and Prof. N. Nilius ${ }^{5-8}$. From the experimental point of view metal supported thin-film systems create specific technical challenges to be tackled. The significant benefit of ultra-thin arrangement of insulating oxides is that they can be studied with scanning tunneling microscopy (STM), which is not possible for their bulk counterparts. Ultra-thin oxide films such as $\mathrm{MgO}^{6,9}, \mathrm{NiO}^{10}, \mathrm{CaO}^{11}, \mathrm{Al}_{2} \mathrm{O}_{3}{ }^{12,13}, \mathrm{FeO}^{14-16}$, and $\mathrm{SiO}_{2}{ }^{17}$ have been extensively studied. A comprehensive overview of metal-supported transition metal oxide films can be found in reference ${ }^{18}$. Possible applications of metal supported ultra-thin oxide films can be divided into two groups: support materials and active players in chemical conversions. Gold clusters on metal supported ultra-thin films show distinct features compared to clusters on bulk films ${ }^{5}$ and calculations predict that the perimeter of these particles is highly reactive e.g., activating oxygen readily ${ }^{19}$. Supported films can also directly act as a catalyst for $\mathrm{CO}$ oxidation ${ }^{20,21}$ and dissociate $\mathrm{H}_{2}{ }^{22}$. Furthermore, metal-supported ultra-thin 
films are reactive towards water dissociation ${ }^{23}$.

Other ultra-thin insulating materials grown on metal surfaces include e.g., $\mathrm{NaCl}$ on $\mathrm{Cu}(111)$, which is used as a substrate to explore charge transport to nanostructures including $\mathrm{Au}$ adatoms ${ }^{24-26}$. While the stoichiometry and atomic structure of ultra-thin $\mathrm{MgO}$ corresponds that of the bulk $\mathrm{MgO}$, this is not always the case. The most prominent example of this is an ultra-thin alumina film over a NiAl support for which determination of atomic structure turned out to be particularly challenging owing to a complex atomic structure. From the interplay between STM experiments and density functional theory (DFT) calculations, the peculiar alumina structure was revealed and it corresponds to $\mathrm{Al}_{10} \mathrm{O}_{13}$ being oxygen deficient with respect to bulk $\mathrm{Al}_{2} \mathrm{O}_{3}{ }^{12}$. Recently, the studies on thin film systems have extended to solid oxide solution thin films on a metal substrate. In the case of NiO$\mathrm{MgO} / \mathrm{Mo}$ it was found that the metal support increases the relative stability of the Ni solute at the oxide film ${ }^{27}$.

Both experiments and calculations show that metal substrate grown thin oxide layers introduce variable new phenomena. First and foremost charge transfer between electronegative adsorbates such as $\mathrm{O}_{2}$ and $\mathrm{Au}$, and an oxide-metal interface is generally found to significant activate an adsorbate and it depends on the film thickness ${ }^{8}$. The occurrence of charge transfer to an $\mathrm{Au}$ atom on a Ag-supported $\mathrm{MgO}$ film was first predicted by DFT computations $^{28}$. The charge transfer was verified by employing STM measurements to analyse the samples containing $\mathrm{Au}$ atoms deposited on a $\mathrm{MgO}(3 \mathrm{ML}) / \mathrm{Ag}(100)$ surface at low coverage and temperature ${ }^{29}$. The results highlight the formation of ordered Au adsorption structures owing to charge transfer from the substrate. This picture can be further complicated by the presence of defects and low coordinated sites. The substrate's response to a charged adsorbate comprises the relaxation of lattice atoms near an adsorption site to accommodate the extra charge ${ }^{30}$. Film thickness also affects the metal-oxide interface adhesion, which can be further modified by suitable transition metal dopants ${ }^{31}$.

An alternative approach to modify the properties of oxides is to introduce dopant atoms into a host oxide. This can be achieved by replacing a small fraction of the cations in an oxide with different guest cations. Dopants modify the electronic structure and chemical characteristics of an oxide ${ }^{32}$ via exchanging electrons with host oxides and adsorbed species. However, dopant atoms can have either lower or higher valence compared to a cation they substitute and this dictates their impact on host oxide characteristics. In the latter case, the 
influence of a dopant resembles that of a metal support in the ultra-thin oxide film. However, the number of spare electrons depends on the concentration of dopants and the fact that the dopants can be mobile, unlike the metal support. There is a large body of studies, where the impact of substutional doping on catalytic properties of oxides has been examined for example see references $i^{32,33}$. In many cases it has been shown that the reactivity has improved upon doping. Among the studied systems Li-doped $\mathrm{MgO}$ has received the most attention owing to its use as a catalyst for oxidative methane coupling to ethane that is often labeled as Holy Grail in catalysis ${ }^{34-36}$. Despite extensive research on this topic, many questions have remained open, and there is not a conclusive understanding of the role of the catalyst, let alone its structure. In the case of CaO, STM studies demonstrate that tiny amounts of Mo embedded into the oxide introduce similar features as metal-supported ultra-thin $\mathrm{MgO}$ films namely, Au atoms become negatively charged ${ }^{37,38}$ and Au aggregates favour the $2 \mathrm{D}$ growth mode ${ }^{39}$. Calculations predict enhanced binding of Au adatoms, which is due to electron transfer from Mo to the adsorbate and substantial lattice relaxations near the dopant originating from increased attraction between more positively charged Mo and surrounding anions ${ }^{40}$. Notwithstanding the similarities, TM-doped simple oxides and metal-supported ultra-thin oxide systems show fundamental differences as impact of dopant is more localised compared to metal support, and a number of electrons that the dopant can provide is very limited, which means that the dopant concentration is a new adjustable parameter.

\section{PREPARATION AND PROPERTIES OF MODIFIED SIMPLE OXIDES}

Here the preparation of oxide systems is briefly discussed and for a more detailed discussion on the preparation and experimental studies of ultra-thin films and simple doped oxides refer to previous reviews ${ }^{5,6,8}$. Ultra-thin-oxide layers are synthesized by the vaporization of metals such as $\mathrm{Mg}$ in a background of molecular oxygen on a metal support and they typically have smaller optimal lattice parameters than bulk oxides ${ }^{41}$. By far the most extensively studied ultra-thin oxide film is $\mathrm{MgO}$ for which the best support is either a $\operatorname{Ag}(100)$ or $\mathrm{Mo}(100)$ surface owing to small lattice mismatch, which amounts to $3 \%$ and $5.4 \%$, for $\mathrm{Ag}$ and Mo respectively. In the thin film structure $\mathrm{O}$ anions are preferably located above $\mathrm{Ag} / \mathrm{Mo} \mathrm{atoms}^{42}$ as displayed in Figure 1. Already a 3ML-thick MgO film on a Ag-support 

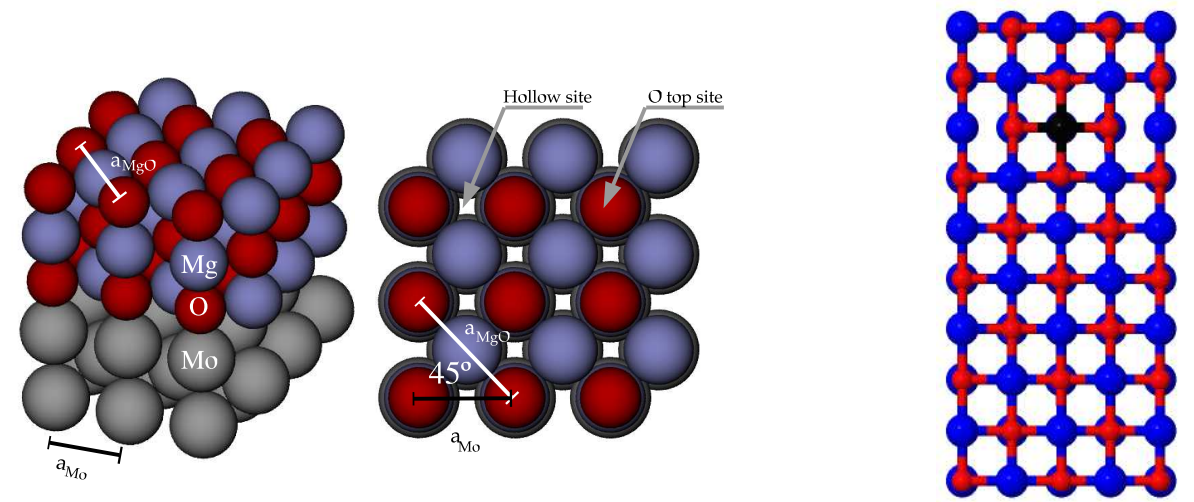

FIG. 1: Left: The side and top view of the 3ML thick $\mathrm{MgO}(100)$ film on a $\mathrm{Mo}(100)$ surface. The size of the computational surface unit cell is $(3 \times 3)$, and $a_{M o}$ and $\mathrm{a}_{\mathrm{MgO}}$ correspond to the lattice parameters of $\mathrm{Mo}$ and $\mathrm{MgO}$, respectively ${ }^{43}$. Right: The side view of a $10 \mathrm{ML}$ thick $\mathrm{CaO}$ slab with a dopant cation in the third layer. Atomic color codes: blue (Mg), red (O), and black (dopant).

is sufficient to reproduce the band gap of bulk $\mathrm{MgO}^{9}$.

Crucial to the characteristics of metal-supported ultra-thin oxide materials is the interaction between a metal substrate and an oxide film, which affects both the geometric and electronic properties of the system. Furthermore, even a small lattice mismatch, like the one for $\mathrm{MgO} / \mathrm{Mo}$, introduces strain effects into the oxide during the film growth. This leads to substantial lattice relaxations and formation of complex network of abundant dislocation lines as demonstrated by STM experiments ${ }^{44,45}$. They are not only important for film morphology but drastically modify the electronic structure since they are rich in point defects and impurities, and able to trap substantial amount of excess charges. To the best of my knowledge, no computational studies exist for understanding dislocation lines in thin films systems. Theoretical studies for bulk $\mathrm{MgO}$ demonstrates the importance of electron trapping in extended defects ${ }^{46}$.

Calculations show that $\mathrm{MgO}$ layers attach loosely to the $\mathrm{Ag}(100)$ surface, whereas the interaction between the regular $\mathrm{MgO}$ and $\mathrm{Mo}$ is stronger, owing to larger covalency contribution of the oxygen anions and $\mathrm{Mo}^{28,42,47}$. This is seen in calculated MgO-metal distances, which are shorter for $\mathrm{MgO}-\mathrm{Mo}$ than for $\mathrm{MgO}-\mathrm{Ag}$ systems ${ }^{28,48}$. The existing experimental data indicates that $\mathrm{MgO}-\mathrm{Ag}$ distance varies between $2.37 \AA$ and $2.53 \AA^{49-51}$. The calculated equilibrium $\mathrm{MgO}$-metal distance depends naturally on the substrate metal, and the choice of 
the exchange correlation functional. While PBE and RPBE functionals tend to exaggerate the $\mathrm{MgO}-$ metal distance ${ }^{52}$, the inclusion of van der Waals interactions reduces the $\mathrm{MgO}-\mathrm{Ag}$ distance to $2.5 \AA^{52}$, which is in line with experiments ${ }^{49,50}$. For a single $\mathrm{MgO}$ layer calculations give $0.2(0.1) \AA$ rumpling (either cations or anions are closer to the metal surface) on a $\mathrm{Mo}(\mathrm{Ag})$ support $^{42,48}$ but already in a bilayer system rumpling drops substantially being only $0.1 \AA$ for the Mo support. The detailed analysis of the MgO-metal interface attributed rumpling to a structural response to the interfacial charge transfer and formation of the interfacial dipole ${ }^{53}$.

Structural characteristics at the interface impact strongly on electronic properties of a system, which is seen as changes in work function of support metal studied extensively both experimentally ${ }^{54-56}$ and theoretically ${ }^{57-59}$. Three different factors are identified to be responsible for observed changes owing to presence of the ultra-thin oxide film ${ }^{59,60}$. These include (i) the suppression of electron density spillover from the metal due to Coulomb repulsion by anions in oxide, which depends on the oxide-metal distance, (ii) charge transfer from oxide (metal) to metal (oxide), and (iii) interfacial rumpling. All of these factors modify the dipole moment at the interface and the work function, which in turn impacts on charge transfer to an adsorbate. In addition, different types of imperfections at the interface may also affect the work function. For $\mathrm{MgO} / \mathrm{Ag}$ a substantial 1.1-1.4 eV decrease in the work function has been measured and compared to the pristine $\operatorname{Ag}(100)$ surface ${ }^{61,62}$. Calculations predict that the decreased values range from 1 to $1.4 \mathrm{eV}$ depending on the applied functional ${ }^{52,63}$.

Unlike line defects, the abundance of surface point defects such as oxygen vacancies in ultra-thin $\mathrm{MgO}$ films is very limited being about $0.1 \%{ }^{64}$. Frequency-modulated dynamic force microscopy and STM have assigned these defects to regular $\mathrm{F}^{0}$ (two electrons) and singly occupied $\mathrm{F}^{+}$(one electron) surface vacancies ${ }^{54}$. Moreover, the concentration of oxygen vacancies can be artificially increased by bombarding the $\mathrm{MgO}$ films. Fabricated defects have been distinguished on the $\mathrm{MgO}$ surface employing variety of experimental techniques. While the electron paramagnetic resonance method ${ }^{65}$ is sensitive only to $\mathrm{F}^{+}$vacancies and electron energy $\operatorname{loss}^{66,67}$ and optical spectroscopes ${ }^{68}$ can separate the vacancies only with support from computations, are $\mathrm{F}^{0}$ and $\mathrm{F}^{+}$vacancies directly distinguishable in STM by their appearance in topographic images and different spectroscopic signatures ${ }^{65,69}$. Despite the control reached over the stoichiometry at the surface of metal-supported ultra-thin films, it 
is difficult to ensure that no vacancies are buried at the oxide-support metal interface as their experimental identification is challenging and therefore experimental studies on interfacial vacancies are $\operatorname{sparse}^{70}$.

Well-ordered transition metal (TM) doped oxides such as $\mathrm{CaO}$ are prepared by adding transition metal atoms into $\mathrm{Ca} / \mathrm{O}$ vapor grown as a tens of monolayers thick film on a metal support, where the topmost layers are synthesized without dopant atoms to prevent their segregation to the surface ${ }^{71}$. Mo doped $\mathrm{CaO}$ can also be formed by diffusion of Mo from the Mo substrate used for oxide growth. Figure 1 displays a typical structure setting used in computations. The presence of the dopant in the oxide matrix can be confirmed experimentally e.g., with Auger spectroscopy ${ }^{71}$. Formally TM ions adopt the oxidation state $2+$ in $\mathrm{MgO}$ or $\mathrm{CaO}$. In reality they can exist in various oxidation states, which can be easily changed. However, if a dopant adopts a different oxidation state, defect states must appear to maintain electroneutrality. The comparison of the impact of doping simple oxides with transition metal atoms $\mathrm{Cr}$ and $\mathrm{Mo}$ in $\mathrm{MgO}$ and $\mathrm{CaO}$ has been addressed by DFT calculations employing both PBE and hybrid functionals PBE0 and HSE06 ${ }^{72}$. Calculations show that in Mo-doped $\mathrm{CaO}$ Mo favours a low-spin state with formal oxidation state $2+$ and the impurity atom introduces a small $4 \%$ contraction to the metal-oxygen distance. Cr also adopts a $2+$ oxidation state. In this case, the high spin state is thermodynamically preferred and lattice relaxations are small and mainly restricted to the nearest neighbour oxygen atoms owing to the similar radius of a host atom. The relative stability of different oxidation state-vacancy structures were analyzed with the help of atomistic thermodynamics at the PBE level. While $\mathrm{Cr}^{3+}$ in $\mathrm{MgO}-\mathrm{V}_{m}$ (= one cation vacancy in the system) is the most stable structure under all reaction conditions, the oxidation state of $\mathrm{Mo}-\mathrm{CaO}$ depends sensitively on the oxygen chemical potential ranging from $\mathrm{Mo}^{3+}$ to $\mathrm{Mo}^{5+}$ with decreasing chemical potential ${ }^{72}$.

\section{ADSORPTION OF ATOMS, MOLECULES AND CLUSTERS ON ULTRA- THIN FILMS}

\section{A. Adsorption of individual Au atoms and clusters}

Unlike bulk $\mathrm{Au}$, nanosized Au exhibits high catalytic activity for various reactions ${ }^{73-76}$. In the pioneering work of Haruta and Hutchings, it was found that Au nanoparticles can 
catalyze $\mathrm{CO}$ oxidation to $\mathrm{CO}_{2}$ at low temperature ${ }^{75,77}$ and acetylene hydrochlorination ${ }^{75,78,79}$. Later, Au nanoparticles were found to be active in reactions such as propylene epoxidation ${ }^{80}$, hydrogenation of unsaturated hydrocarbons ${ }^{81}$ and nitrocompounds ${ }^{82}$, oxidation of diols ${ }^{83}$ and alcohols ${ }^{84}$, and the water-gas shift reaction ${ }^{85}$. Different properties have been suggested to be important for catalytic activity of $\mathrm{Au}$ including size and structure of particles ${ }^{86}$, lowcoordinated step and corner sites $^{87}$, and the charge state of the active Au species ${ }^{88-91}$. The catalytic activity of nano Au has been suggested to be sensitive with respect to the support material $^{92}$. However, the recent discovery of high catalytic activity of Au clusters on a inert substrate indicates that the reducibility of a support is not a critical factor ${ }^{93}$. DFT calculations suggest that $\mathrm{MgO}$-supported $\mathrm{Au}$ particles are unable to activate a molecular oxygen, binding it weakly and having a high activation energy for dissociation ${ }^{94}$. However, tiny Au clusters containing only few metal atoms on the same support display high catalytic activity towards $\mathrm{CO}$ oxidation ${ }^{88,95}$. The perimeter sites at the Au-support interface have been suggested as active sites for $\mathrm{CO}$ oxidation on a $\mathrm{TiO}_{2}$ support $^{96-98}$. At the interface, the low-coordinated sites in a $\mathrm{Au}$ particle have been found to be pivotal for $\mathrm{O}_{2}$ activation ${ }^{99,100}$. The studies on the adsorption of a $\mathrm{Au}$ adatom on a metal-supported $\mathrm{MgO}$ films highlight the difference in chemical characteristics of supported $\mathrm{MgO}$ films and bulk $\mathrm{MgO}$ surfaces.

On the basis of DFT calculations, it was predicted that $\mathrm{Au}$ atoms on $\mathrm{MgO}(100) / \mathrm{Mo}(100)$ are negatively charged and their binding to the surface is stronger ${ }^{28}$ than on a bulk-like $\mathrm{MgO}(100)$, where atoms stay neutral ${ }^{94}$ and have adsorption energy of $\sim-0.7 \mathrm{eV}^{48}$. On the supported thin film the adsorption site also changes: on the bulk $\mathrm{MgO}$ the $\mathrm{Au}$ atom is located on atop of an oxygen anion and on ultra-thin $\mathrm{MgO}$ a hollow $/ \mathrm{Mg}$ site is preferred ${ }^{48}$. The prediction of Au charging and the change in adsorption site were experimentally verified with STM measurements ${ }^{29,101}$.

Calculations from Honkala and Häkkinen show that Au adsorption energy depends sensitively on film thickness being strongest on the thinnest film, Figure 2 with the exception that a $2 \mathrm{ML}$-thick $\mathrm{MgO}$ film binds Au more strongly than a $1 \mathrm{ML}$-thick film ${ }^{48}$. In the case of $5 \mathrm{MgO}$ layers on the $\mathrm{Mo}(100)$ surface, the Au adsorption energy on the O-top site is still twice as large as on the bulk-like $\mathrm{MgO}(100)$ surface. Figure 3 presents a density difference plot, projected on the plane that includes the $\mathrm{Au}$ adatom, displaying a rich polarization pattern for the 5ML-thick $\mathrm{MgO}$ film all the way from the $\mathrm{MgO} / \mathrm{Mo}$ interface throughout the oxide. Additionally, substantial charge accumulation around $\mathrm{Au}$ is seen as well as charge 


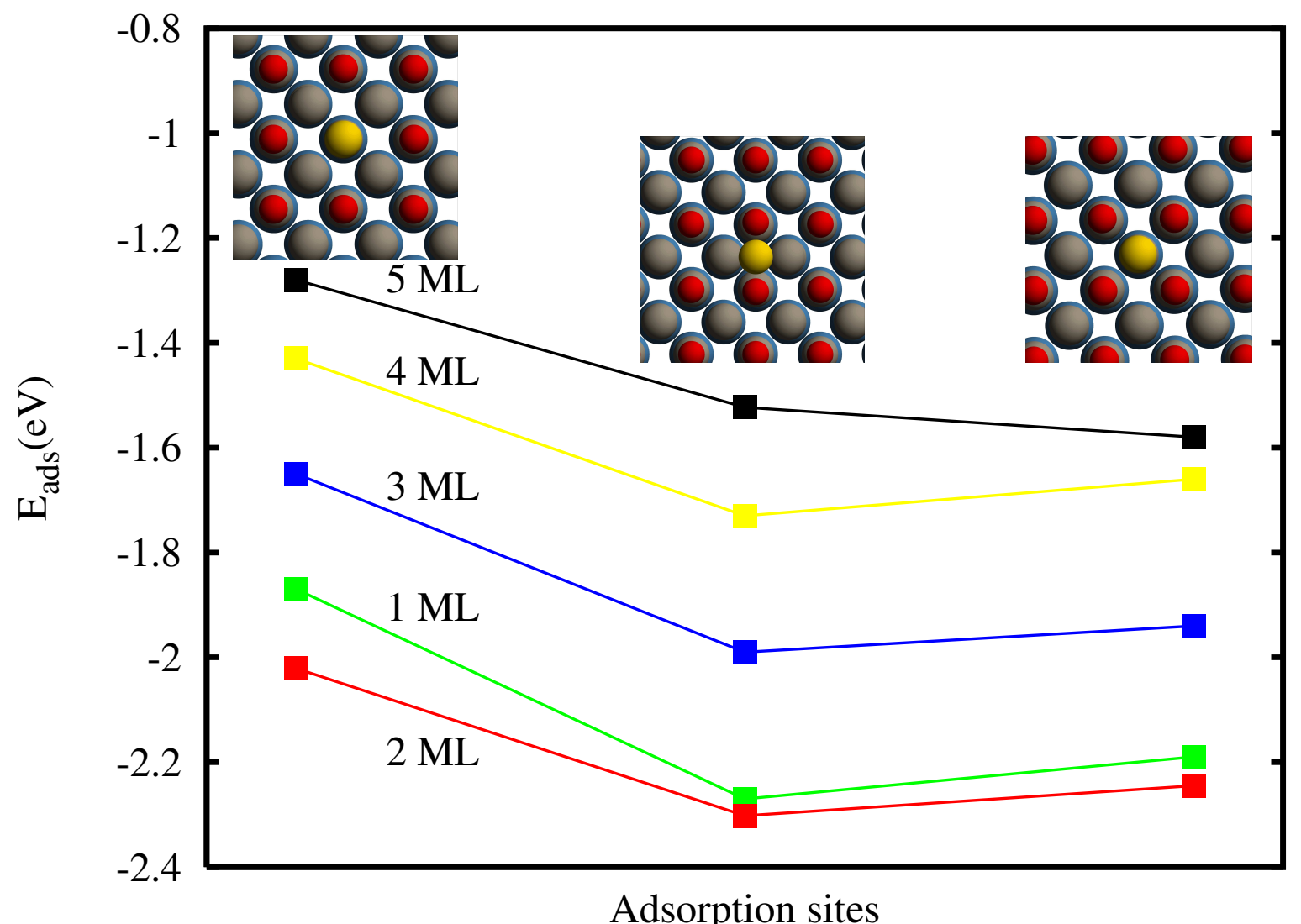

FIG. 2: Au adsorption energy at O-top, hollow and Mg-top sites on a Mo-supported $\mathrm{MgO}$ film with the film thickness ranging from 1 to $5 \mathrm{ML}$. Atomic color codes: yellow $(\mathrm{Au})$, blue $(\mathrm{Mo})$, red $(\mathrm{O})$, and grey $(\mathrm{Mg})$. Solid lines are just to guide the eye. Figure adapted with permission from Ref. ${ }^{48}$.

depletion at the surface.

On the 20ML-thick film, the most stable site is O-top and the difference in adsorption energy between single crystal and supported $\mathrm{MgO}$ systems is only about $0.2 \mathrm{eV}$, that is the supported film binds slightly more strongly ${ }^{102}$. If the Mo lattice constant is used for the single crystal $\mathrm{MgO}$ the difference reduces to $0.1 \mathrm{eV}$, which is within the limit of accuracy in DFT calculations. The Bader charge analysis ${ }^{103,104}$ shows that with increasing film thickness the $\mathrm{Au}$ charging decreases, which is in line with decreasing electron tunneling with increasing film thickness. This is also supported by the projected density of states as the $\mathrm{Au} 6 \mathrm{~s}$ state moves toward the Fermi level with an increasing number of $\mathrm{MgO}$ layers and is singly occupied in the case of 20 layer system. On a bulk-like $\mathrm{MgO}$ surface the adsorption energy 


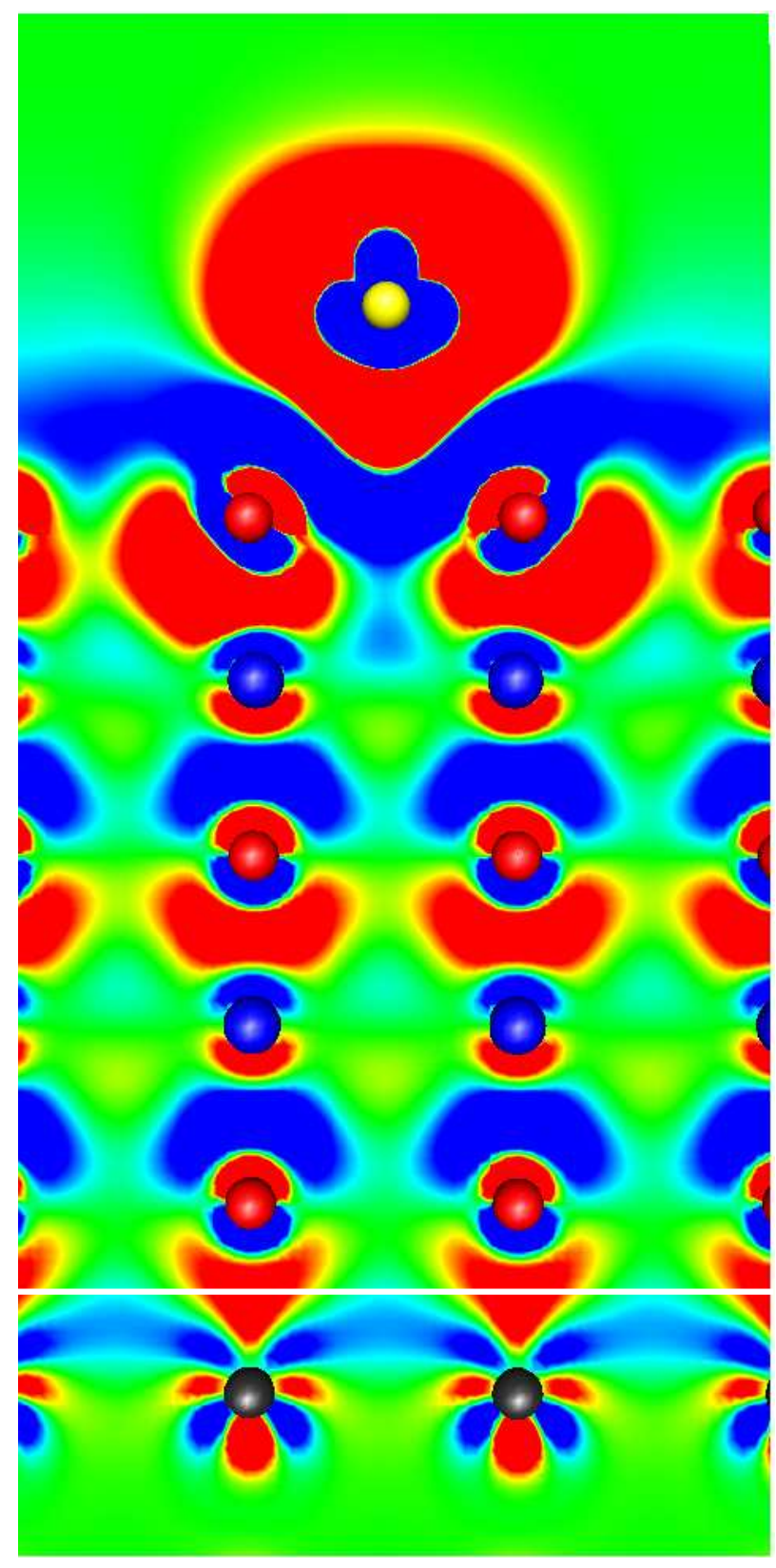

FIG. 3: Density difference plot for a Au atom at the hollow site on 5ML-thick $\mathrm{MgO} / \mathrm{Mo}$. Blue (red) regions indicate charge depletion (accumulation).

Yellow, red, blue, and black balls mark $\mathrm{Au}, \mathrm{O}, \mathrm{Mg}$, and Mo atoms, respectively. The $\mathrm{MgO}-\mathrm{Mo}$ interface is marked with the white line. The scale is $\left( \pm 0.003 \mathrm{e} / \mathrm{bohr}^{3}\right)$. Figure adapted with permissions from Ref. ${ }^{48}$. 
of metal atoms converges fast with film thickness ${ }^{105}$. Calculations predict that the preferred adsorption site changes at the $10 \mathrm{ML}$ - thick film of supported $\mathrm{MgO}^{102}$. This qualitatively agrees with experimental observations for $\mathrm{Au} / \mathrm{MgO} / \mathrm{Ag}$, where the change in adsorption site takes place between three and eight $\mathrm{MgO}$ layers ${ }^{101}$.

$\mathrm{Au}$ charging introduces pronounced oxide relaxations, called polaronic distortion, around the adsorbate, which help to stabilize the state occupied by an extra electron. XPS experiments demonstrate the large deviation in the phonon structure of ultra-thin films and bulk oxides $^{106}$, which is associated to enhanced structural flexibility of the film being pivotal for structural relaxations to occur. In the case of $\mathrm{Au}$ on $2 \mathrm{ML} \mathrm{MgO} / \mathrm{Ag}$, the $\mathrm{Mg}$ cation to which $\mathrm{Au}$ is bound to relaxes as much as $0.44 \AA$ outwards according to calculations, and on the other hand the $\mathrm{O}$ anion below the cation relaxes $0.2 \AA$ but toward the support metal ${ }^{30}$. The energy contribution of this relaxation is substantial being $\sim 0.7 \mathrm{eV}$ for $\mathrm{MgO}(3 \mathrm{ML}) / \mathrm{Mo}$ and $\sim 0.95 \mathrm{eV}$ for $\mathrm{MgO}(3 \mathrm{ML}) / \mathrm{Ag}^{102}$. An unrelaxed substrate leads to weaker polarization, reduced charge transfer, and weaker adsorption. Thus, charging of Au is crucial to enhanced $\mathrm{Au}$ adsorption on the supported thin film. As the charge on the adsorbate originates from the metal-support interface, the work function of the combined metal-oxide system should be an important parameter. To understand how the work function variation affects adsorption energy of $\mathrm{Au}$, the following systems were investigated: one $\mathrm{Au}$ atom on $2 \mathrm{ML}$ thick film on $\mathrm{Mo}, \mathrm{Pd}, \mathrm{Pt}, \mathrm{Ag}, \mathrm{Au}$ surfaces $^{102}$. In these calculations the equilibrium lattice constant was employed for each metal, introducing unequal strain to the supported $\mathrm{MgO}$ film that can potentially impact on the obtained results. Figure 4a) shows calculated work functions for the clean (100) metal surfaces and for metal-supported 2ML thick MgO films. For the studied metals the work function ranges from $4.1 \mathrm{eV}(\mathrm{Mo})$ to $5.6 \mathrm{eV}(\mathrm{Pt})$. The presence of $\mathrm{MgO}$ film reduces the work function by $\sim 2 \mathrm{eV}$ owing to polarization at the interface. Figure 4b) displays the variation of Au adsorption energy. In general, the tendency is that the low work function is associated to more exothermic adsorption energy but the values are scattered. The adsorption energies range from $\sim-2.1 \mathrm{eV}$ on a Mo-supported $\mathrm{MgO}$ film to $~$ -0.6 eV on $\mathrm{Pd}$-supported $\mathrm{MgO}$ film. This highlights the fact that the selection of a support metal is an adjustable parameter that can modify the binding strength of an Au atom in addition to the thickness of the film. Interestingly, the Bader charge analysis shows that the amount of charge transferred to $\mathrm{Au}$ is almost independent of the supporting metal and the work function ${ }^{102}$. 

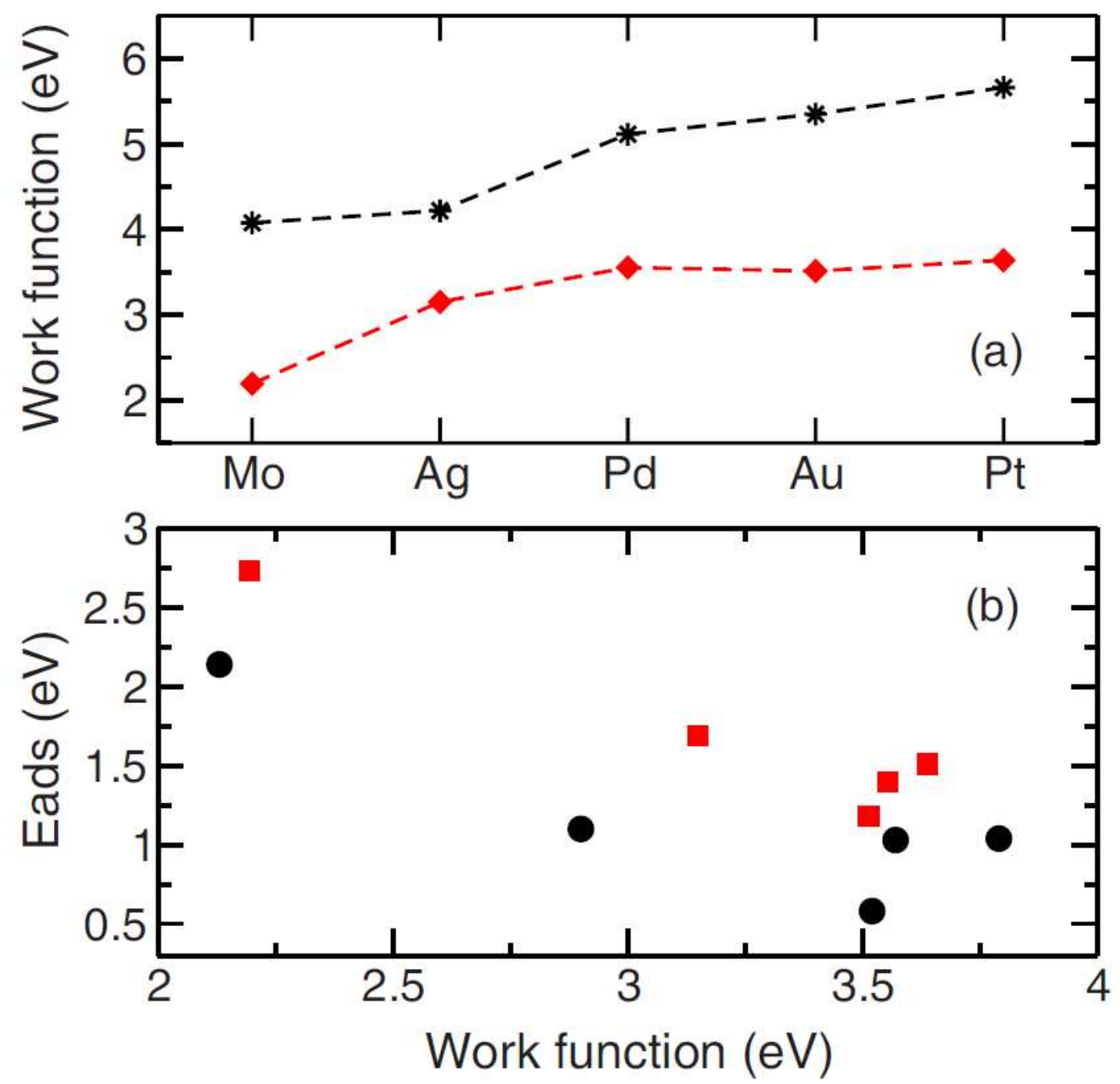

FIG. 4: (a) Calculated work functions for Mo, Ag, Pd, Au and Pt surfaces (stars) and corresponding values for metal-supported $\mathrm{MgO}(2 \mathrm{ML})$ systems (diamonds).(b) Adsorption energies for $\mathrm{Au}$ (circles) and $\mathrm{NO}_{2}$ (squares) as a function of work function. Note, that here positive adsorption energy values stand for exothermic adsorption. Figure adapted with permission from Ref. ${ }^{102}$.

The large modifications in adsorption owing to the metal support are not limited to Au or other transition metal single atoms, but significant changes are also seen in Au cluster geometries, charge states, and adsorption energies on metal-supported MgO films ${ }^{107-111}$. For comparison, on bulk $\mathrm{MgO}$ the smallest $\mathrm{Au}_{N}(\mathrm{~N}=2-6)$ clusters favour minimal wetting with 
one or two Au atoms in contact with oxide ions ${ }^{28,94,108,112,113}$. The internal atomic structure follows the calculated structures of corresponding neutral gas-phase species ${ }^{114}$. The binding is rather weak with adsorption energies ranging from $-0.6 \mathrm{eV}$ to $-1.4 \mathrm{eV}$ showing no clear size dependence ${ }^{108}$. The nature of the weak $\mathrm{Au}-\mathrm{MgO}$ interaction has been characterised to be of polarization type ${ }^{115}$.

From an interplay between STM experiments and DFT calculations it was shown that in the size regime of 2-6 atoms, the most stable Au clusters are linear chains on an $\mathrm{Ag}$ supported $\mathrm{MgO}$ film ${ }^{109}$. The smallest Au aggregates also adopt linear structures on $\mathrm{MgO} / \mathrm{Mo}$ substrates $^{111}$ as shown in Figure 5. For $\mathrm{Au}_{1-3}$ only chain isomers are stable and their adsorption energies vary from $-1.3 \mathrm{eV}$ to $-2.8 \mathrm{eV}$ on $\mathrm{MgO} / \mathrm{Mo}(100)$. The adsorption energies of planar $\mathrm{Au}_{4-6}$ range from $-1.1 \mathrm{eV}$ to $-2.1 \mathrm{eV}^{108}$ while the chain structures of the same size bind 1.2-1.5.eV stronger ${ }^{111}$. The Bader charge analysis shows that the charge state of the adsorbed cluster depends on the atomic structure and impacts on adsorption energy. The linear $\mathrm{Au}_{1-3}$ and planar $\mathrm{Au}_{4-6}$ aggregates are singly charged whereas the $\mathrm{Au}_{4-6}$ chains are doubly charged. The singly charged isomers are structurally similar to their anionic gas-phase counterparts ${ }^{43,108}$ while linear cluster shapes do not have counterpart in the gasphase or on a single crystal $\mathrm{MgO}$ surface. Charging behaviour of $\mathrm{Au}_{2-6}$ chains on supported $\mathrm{MgO}$ films is independent of the support metal either Mo or $\mathrm{Ag}^{109}$. On $\mathrm{Al}_{2} \mathrm{O}_{3} / \mathrm{NiAl}$, the charging effect is larger as $\mathrm{Au}_{3}$ contains already two and $\mathrm{Au}_{5-6}$ three extra electrons ${ }^{117}$. The electronic states of Au chains can be analyzed by means of one dimensional quantum well state model. In such a model, the electronic structure of the aggregates is determined by a potential well to which $6 \mathrm{~s}^{1}$ valence electrons of individual $\mathrm{Au}$ atoms are delocalized and confined. Au chains on $\mathrm{Al}_{2} \mathrm{O}_{3}(2 \mathrm{ML}) / \mathrm{NiAl}(110)$ display a particle in a box-type of behaviour as shown by experiments and calculations ${ }^{117}$. Figure 6 exhibits similar behaviour for $\mathrm{Au}$ chains on $\mathrm{MgO}(3 \mathrm{ML} / \mathrm{Mo})$, where $\mathrm{HOMO}$ and LUMO states of $\mathrm{Au}_{3}$ and $\mathrm{Au}_{6}$ chains are shown together with the 1D harmonic oscillator potential and the probability density of corresponding eigenstates. The LUMO state of $\mathrm{Au}_{3}$ has three lobes and two nodes and the HOMO orbital has two lobes and one node. These equal to the HOMO and LUMO states of the $1 \mathrm{D}$ harmonic oscillator with 4 electrons, each $\mathrm{Au} 6$ s orbital donates one electron while the fourth electron comes from the substrate. This is in line with Bader charge of -1.03 for the adsorbed chain. In the case of $\mathrm{Au}_{6}$, the LUMO state has 5 lobes and 4 nodes whereas the HOMO state has 4 lobes and 3 nodes. This stands for the $1 \mathrm{D}$ harmonic oscillator with 

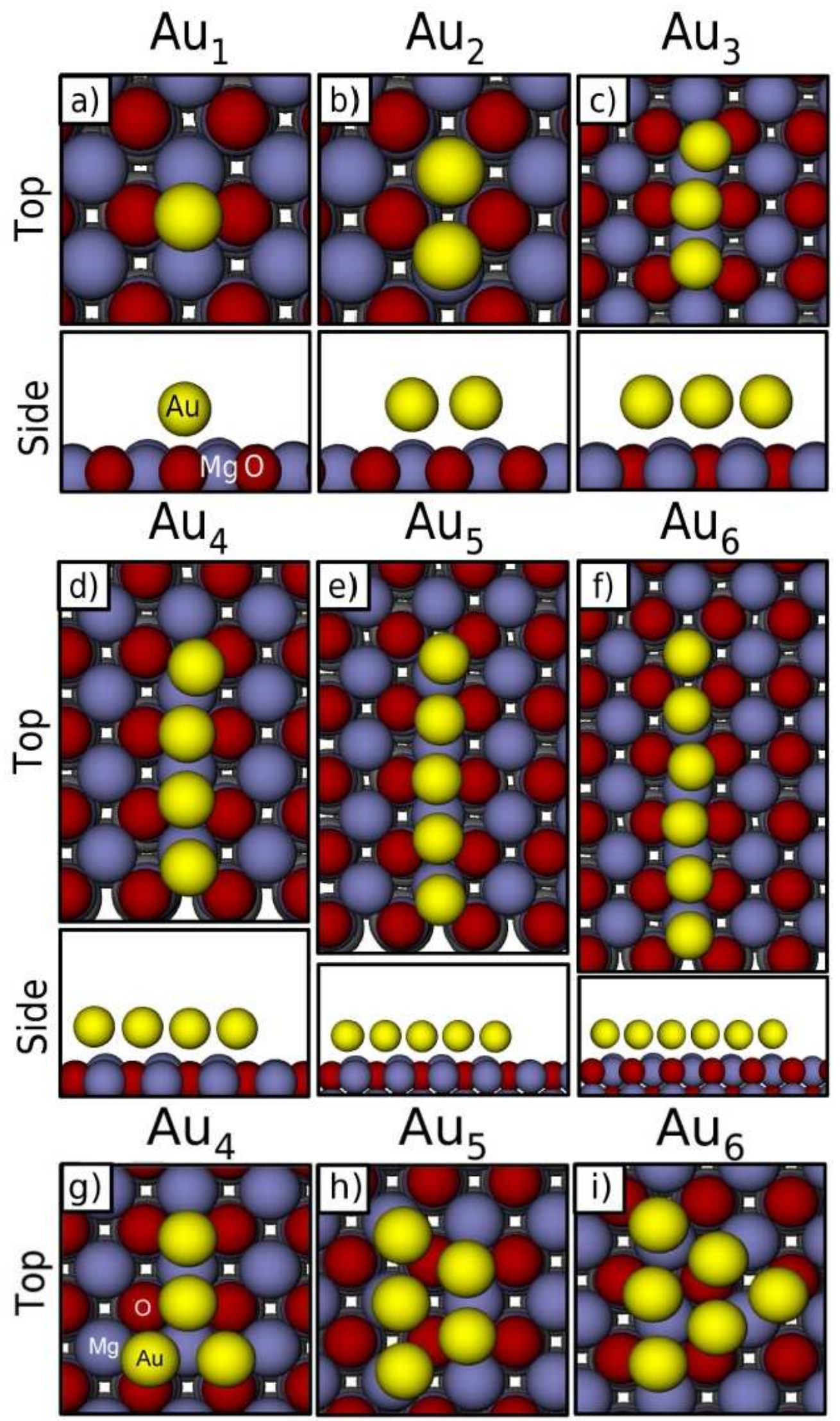

FIG. 5: The top and side view of the most stable $\mathrm{Au}_{1-6}$ adsorption geometries on MgO-supported Mo are given ${ }_{16}$ a-f, and the top view of less stable $2 \mathrm{D}$ planar structures for $\mathrm{Au}_{4}, \mathrm{Au}_{5}$, and $\mathrm{Au}_{6}$ are presented in g-i. $\mathrm{Au}$ atoms are yellow and $\mathrm{Mg}$ and $\mathrm{O}$ atoms are blue and red, respectively. Mo atoms are not shown. Figure adapted with permission from Ref. ${ }^{116}$. 
eight electrons. Six out of eight electrons originates from $\mathrm{Au}$ atoms while the other two electrons are from the substrate. Again, this agrees nicely with the calculated Bader charge, which is -2.39 e for $\mathrm{Au}_{6}{ }^{111}$.

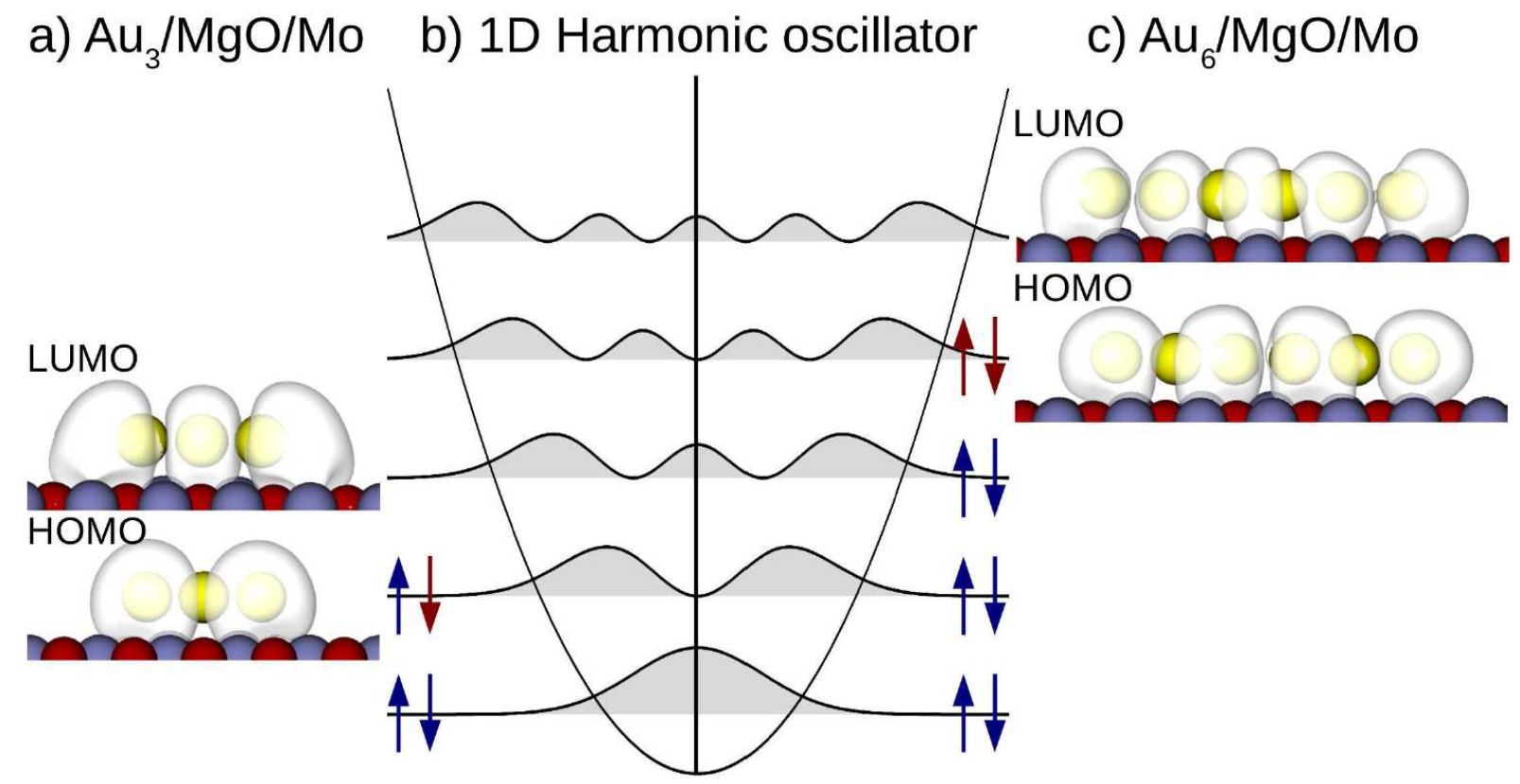

FIG. 6: The spatial appearance of the HOMO and LUMO states of $\mathrm{Au}_{3}$ panel a and $\mathrm{Au}_{6}$ panel c on $\mathrm{MgO}(3 \mathrm{ML}) / \mathrm{Mo}$ together with their connection to a $1 \mathrm{D}$ quantum well model panel $b$. The blue arrows stand for the valence electrons from the atomic Au 6s states and the red arrows correspond the electrons transferred from the substrate. Figure adapted with permission from Ref. ${ }^{116}$.

The tendency of Au clusters to prefer 2D structures over 3D structures was first predicted by DFT calculations for $\mathrm{Au}_{n}(\mathrm{n}=8,16,20)$ on Mo-supported $\mathrm{MgO}^{107}$ and later verified experimentally with STM on an Ag-supported $\mathrm{MgO}$ film as a function of the film thickness ${ }^{101}$. The strong interaction with the surface introduces reoptimization and straining in the internal cluster geometry. Calculations show the favourably of planar structures compared to 3D ones on the 2 ML thick film, but with increasing film thickness Au adhesion to the substrate weakens leading eventually to the preference of 3D structures ${ }^{107}$. STM experiments demonstrate that the cluster geometry is sensitive to the film thickness, and 3D clusters are seen on the 8 ML-thick film whereas $2 \mathrm{D}$ clusters are present on the $3 \mathrm{ML}$ thick film ${ }^{101}$. DFT calculations 
predicted charge transfer to be present also on larger clusters ${ }^{107,118}$. While the direct experimental verification of charge transfer is challenging the 2D shape of the adsorbed cluster has been taken as an indirect indication of a charge transfer process. To further explore the internal electronic structure and charger transfer of small $\mathrm{MgO} / \mathrm{Ag}$-supported $\mathrm{Au}$ clusters, a combined STM-DFT study was undertaken ${ }^{119}$. Similar to Au chains, larger Au clusters prefer to maximize their contact area with the support and become negatively charged with the calculated average charge transfer of $-0.2 \mathrm{e} / \mathrm{an} \mathrm{Au}$ atom. Charged Au aggregates need to reduce substantial electron-electron repulsion originating from excess charges. This can be achieved by separating extra electrons over long distances, which results, for example, in the localization of electrons at the edges of the islands and leads to a further stabilization effect of linear and planar structures ${ }^{120}$.
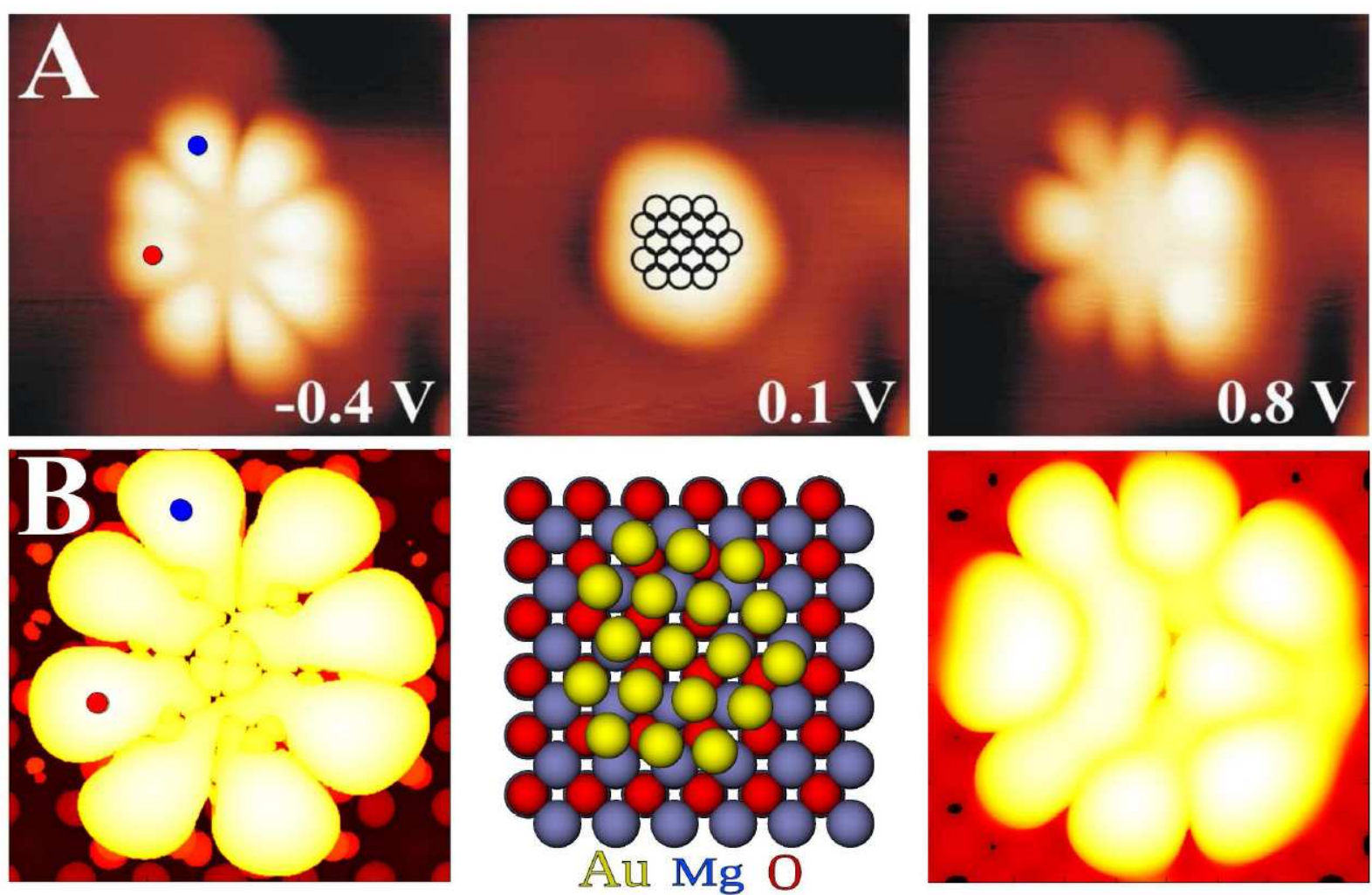

FIG. 7: Panel A) Measured STM images of a selected Au cluster on Ag-supported $\mathrm{MgO}$ at bias voltage $-0.4 \mathrm{~V}$ (HOMO), $-0.1 \mathrm{~V}$, and +0.8V (LUMO). Panel B) The calculated STM images of HOMO and LUMO states $\mathrm{Au}_{18} / \mathrm{MgO}(2 \mathrm{ML}) / \mathrm{Ag}$. The atomic structure of the calculated system is shown in the middle. Figure adapted with permission from Ref. ${ }^{119}$. 
Figure 7 A) displays measured constant-current-mode topographic STM images of a selected Au cluster on an Ag-supported 2ML-thick MgO film. At low bias a featureless bright image appears because tunneling is not in resonance with any cluster states. Adjusting the bias to appropriate values, flower-like shapes appear and the increase in cluster height is seen. Both effects suggest that the STM contrast is dictated by electronic structure of a cluster whose exact atomic structure remains unknown. Theoretically, the electronic structure of a planar cluster can be predicted employing the 2D harmonic oscillator potential model, which confines the atomic $6 \mathrm{~s}$ valence electrons ${ }^{118}$. The eigenstates of the $2 \mathrm{D}$ harmonic oscillator $(\mathrm{HO})$ can be characterised by their principal quantum number together with the projection of angular momentum on the normal vector of the plane, m. Thus, the states have $\mathrm{n}-1$ radial nodes and $|\mathrm{m}|$ angular nodes. The atomic nomenclature of the states is adopted, which means that e.g., the $2 \mathrm{P}$ state has one radial node and two angular nodes. Moreover, states such as $1 \mathrm{~F}$ exhibit a very flower-like appearance. Again, each Au atom brings in one $6 \mathrm{~s}$ electron, therefore the number of atoms in a cluster can be obtained by analyzing the nodal structure of frontier orbitals in a cluster within the 2D HO model.
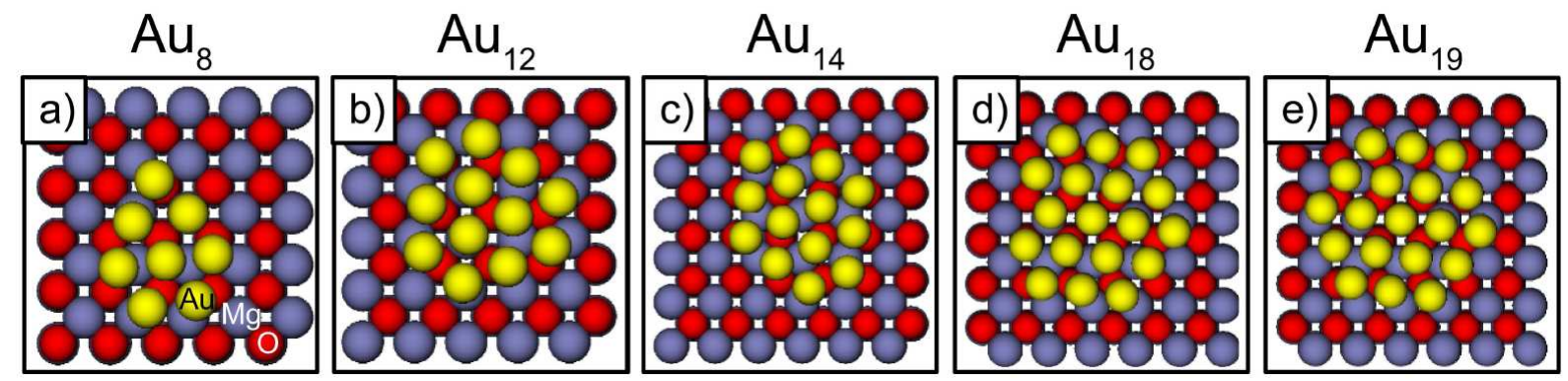

FIG. 8: Selected highly symmetric candidate structures for $\mathrm{Au}_{8-20}$ clusters addressed by DFT calculations. Figure adapted with permission from Ref. ${ }^{116}$.

To resolve the atomic structure of these clusters, an extensive DFT search for possible structures was carried out at size regime of 6-20 Au atoms per a cluster. The aim was to find clusters having similar HOMO and LUMO states as seen in STM images of unknown species. The candidate cluster sizes were selected so that the $2 \mathrm{D} \mathrm{HO}$ model predicts that their HOMO and LUMO states resemble those seen in experiments. Furthermore, since flower-like shapes are typical for symmetric planar clusters the computational search focused on these structures. Similar to 1D Au chains Au clusters might have additional electrons not originating from 6 s states. Figure 8 collects some of the selected cluster sizes and shapes 
calculated. All of them experience thin-film effects that is having a planar geometry with formation energies ranging from $-2.1--2.5 \mathrm{eV} /$ atom. The charge analysis suggests that the smallest species are doubly charged, and the large ones can accommodate 3-4 electrons. Calculations assign that $\mathrm{Au}_{18}$ contains altogether 21.5 electrons: 18 from 6 s states and 3.5 from the support. Within the 2D HO model it was not possible to unambiguously distinguish the charge state. However, comparison of calculated HOMO and LUMO states of $\mathrm{Au}_{18}$ shown in Figure 7B match perfectly with the HOMO and LUMO states of unknown species in Figure 7A. The final confirmation was obtained by comparing the measured and calculated $d I / d V$ spectra from the same spot on the cluster showing the same sequence of states and intensity modulation ${ }^{119}$. Calculations show that simulated STM images are highly sensitive to the number and arrangement of $\mathrm{Au}$ atoms in the cluster ${ }^{116}$ and therefore the unknown cluster was identified as $\mathrm{Au}_{18}$ and not to $\mathrm{Au}_{20}^{-2}$, which according to the charge analysis should not even exist as adsorbed $\mathrm{Au}_{20}$ gains 4 electrons. The electronic structure of larger, ultrathin film-supported, clusters containing 50-200 atoms has been analyzed combining STM measurements, a theoretical particle-in-a-box model, and tight-binding DFT calculations showing again a nice agreement between measurements and calculations ${ }^{121}$. Finally, the charge transfer does not always occur from the metal-oxide interface towards the adsorbed $\mathrm{Au}$ as reported for the $\mathrm{FeO} / \mathrm{Pt}(111)$ surface, where $\mathrm{Au}$ atoms form positive ions ${ }^{122}$. The formation of $\mathrm{Au}$ anions on metal supported $\mathrm{MgO}$ films and cations on $\mathrm{FeO} / \mathrm{Pt}(111)$ highlight the influence of the work function on the charge transfer in ultra-thin film systems. While $\mathrm{MgO}$ reduces the work function of both $\mathrm{Mo}$ and $\mathrm{Ag}$ and thus facilitates electron transfer to the 6 s orbital of an $\mathrm{Au}$ atom, quite opposite happens in the case of the $\mathrm{FeO} / \mathrm{Pt}(111)$ system, which has very high work function and the 6s state is pushed above the Fermi level and electron transfers to the surface ${ }^{122}$.

\section{B. Adsorption of other atoms than Au}

Despite $\mathrm{Au}$ adsorption on metal-supported ultra-thin $\mathrm{MgO}$ films have received majority

of interest, the adsorption of other atoms such as $\mathrm{K}, \mathrm{Pd}, \mathrm{Pt}, \mathrm{Ni}, \mathrm{Cu}$, and $\mathrm{Ag}$ have been addressed with DFT computations ${ }^{28,58,123}$. Coinage metals $\mathrm{Cu}$ and Ag exhibit completely different adsorption behaviour on $\mathrm{MgO}$ and $\mathrm{MgO}(2 \mathrm{ML}) / \mathrm{Mo}(100)$ surfaces: on a bulk oxide surface they favour $\mathrm{O}$ anions, while on a metal-supprted thin film all adsorption sites (hollow, 
cation and anion) are almost equally favoured. The presence of Mo enhances the adsorption energies by $0.5 \mathrm{eV}$ and $0.8 \mathrm{eV}$ for $\mathrm{Cu}$ and $\mathrm{Ag}$ atoms, respectively ${ }^{123}$. The analysis of charge states shows that on bare $\mathrm{MgO}$ both species are neutral but become negatively charged on the supported film. Changing the support metal to Ag introduces marked differences compared to Mo: adsorption energies are close to values on bare $\mathrm{MgO}$ and no charge transfer is observed meaning that atoms stay neutral.

At variance with coinage metals, group 10 atoms interact strongly with the bare $\mathrm{MgO}$. They have adsorption energies varying from $-1.44 \mathrm{eV}(\mathrm{Pd})$ to $-2.56 \mathrm{eV}(\mathrm{Pt})$, which favour adsorption on anions and display strong corrugation of the potential energy surface ${ }^{123}$. The Bader charge analysis shows nonzero values owing to the mixing of metal and oxide states. However, it does not indicate charge transfer but merely demonstrates the formation of a covalent polar bond. On $\mathrm{MgO}(2 \mathrm{ML}) / \mathrm{Mo}(100)$, the adsorption of both $\mathrm{Pd}$ and $\mathrm{Ni}$ atoms is enhanced $(\sim 0.4 \mathrm{eV})$ and the Bader, density of states, and magnetic moment analysis suggest the existence of a small charge transfer; yet neither of species cannot be classified as a full anion because of the substantial mixing with the $\mathrm{O} 2 \mathrm{p}$ states and the covalent nature of the bond. Pt becomes a full anion on $\mathrm{MgO} / \mathrm{Mo}(100)$ with adsorption energy of $\sim-3.3 \mathrm{eV}$ on a O-top site, and considerable, $0.3 \AA$, relaxation of the lattice $\mathrm{O}$ underneath. The adsorption characteristics of all three group 10 atoms on $\mathrm{MgO}(2 \mathrm{ML}) / \mathrm{Ag}(100)$ are very similar to those on the bare support highlighting the fact that the nature of atoms can be tailored by varying the substrate. The reason for all of these transition metal atoms being neutral on $\mathrm{MgO}(2 \mathrm{ML}) / \mathrm{Ag}(100)$ is the higher work function $\sim 3 \mathrm{eV}$ compared to $\mathrm{MgO}(2 \mathrm{ML}) / \mathrm{Mo}(100)$ for which the cost to remove an electron is $\sim 2 \mathrm{eV}$.

Finally, the adsorption of a $\mathrm{K}$ atom on $\mathrm{MgO}(2 \mathrm{ML}) / \mathrm{Ag}(100)$ is briefly discussed ${ }^{58}$. The presence of Ag support stabilizes $\mathrm{K}$ adsorption by $\sim 0.3 \mathrm{eV}$ on the most stable O-top position, and large lattice relaxations are seen. Yet, adsorption is very weak being less than $-0.5 \mathrm{eV}$. Interestingly, the $\mathrm{K}$ atom becomes positively charged donating charge to the Ag support. Positive charging is further supported by decrease in a K-O distance by $0.33 \AA$ and decrease in the work function of $\mathrm{K} / \mathrm{MgO}(2 \mathrm{ML}) / \mathrm{Ag}(100)$ system compared to $\mathrm{MgO}(2 \mathrm{ML}) / \mathrm{Ag}(100)$. 


\section{Adsorption of $\mathrm{NO}_{2}$ and $\mathrm{O}_{2}$ molecules}

Enhanced adsorption on metal-supported ultra-thin film is not limited to metal species. The phenomenon is more general in nature and present also for molecules with high electronic affinity such as $\mathrm{O}_{2}$ and $\mathrm{NO}_{2}$. Understanding $\mathrm{NO}_{2}$ adsorption characteristics is important, for example for $\mathrm{NO}_{x}$ storage catalysts to control emissions from combustion in oxygen excess ${ }^{124}$. On bulk-like $\mathrm{MgO} \mathrm{NO}_{2}$ adsorbs weakly and stays neutral ${ }^{125}$, whereas DFT calculations render $\mathrm{NO}_{2}$ adsorption strongly enhanced on metal supported $\mathrm{MgO}^{126}$. The molecule becomes negatively charged forming a $\mathrm{NO}_{2}^{-1}$ anion, which is also singled out by strong structural changes in a $\mathrm{N}-\mathrm{O}$ bond length and a $\mathrm{O}-\mathrm{N}-\mathrm{O}$ angle ${ }^{127}$. Figure 9 displays the most favourable $\mathrm{NO}_{2}$ adsorption geometry on a $\mathrm{MgO}(2 \mathrm{ML}) / \mathrm{Pt}(100)$ surface. Similar adsorption characteristics are seen on a more complex $\mathrm{Al}_{2} \mathrm{O}_{3}$ film supported over $\mathrm{Ag}$, where according to calculations $\mathrm{NO}_{2}$ adsorption energy is enhanced by factor of $5^{13}$. This takes place with concomitant substantial structural relaxations at the metal-oxide interface, where in particular, the Ag-O distance is strongly reduced. Among the studied metal supported ultra-thin oxides, $\mathrm{BaO} / \mathrm{Pt}(100)$ shows the largest stabilization effect and $\mathrm{NO}_{2}$ adsorption energy is about $-2.4 \mathrm{eV}$ on the $2 \mathrm{ML}$ thick film ${ }^{128}$. On $2 \mathrm{ML} \mathrm{Al}_{2} \mathrm{O}_{3}(0001) / \mathrm{Ag}$ and $\mathrm{MgO} / \mathrm{Ag}(100)$ films the corresponding adsorption energies are $-2.0 \mathrm{eV}$ and $-1.8 \mathrm{eV}$, respectively ${ }^{102}$.

The extent of structural relaxations depends on oxide and support metal but also on an adsorbate being more pronounced for $\mathrm{NO}_{2}$ than for $\mathrm{Au}$ even though both species are singly negatively charged ${ }^{102}$. The binding strength of $\mathrm{NO}_{2}$ as a function of increasing film thickness resembles that of $\mathrm{Au}$, since it becomes weaker with increasing film thickness. The unusual feature of the $\mathrm{Al}_{2} \mathrm{O}_{3} / \mathrm{Ag}$ system is that the calculated work function is larger than that of the bare metal, which is in contrast what is found for metal-supported $\mathrm{MgO}^{102}$. The increase results from the different interface structure: while in the case of $\mathrm{MgO}$ the metal atoms are below anions, they are under cations in the $\mathrm{Al}_{2} \mathrm{O}_{3}(0001) / \mathrm{Ag}(111)$ system leading to polarization towards oxide and increase in the work function ${ }^{102}$. The charging of species on metal supported ultra-thin films has been linked to the reduced work function ${ }^{58}$ but the $\mathrm{Al}_{2} \mathrm{O}_{3} / \mathrm{Ag}$ system shows that this is not necessarily the case.

Calculations predict that the stabilization, charging and internal structural modifications of $\mathrm{O}_{2}$ adsorbed on metal supported $\mathrm{MgO}$ resemble that of $\mathrm{NO}_{2}$ and highlight the spontaneous

formation of an activated superoxo species ${ }^{20,111}$ owing to the low work function of the system. 


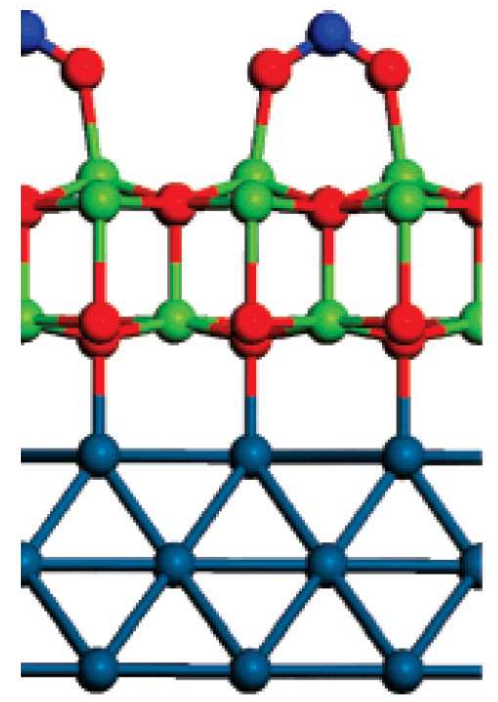

FIG. 9: The most favourable adsorption geometry of $\mathrm{NO}_{2}$ on Pt-supported $\mathrm{MgO}^{127}$. Mo atoms are coloured dark blue, oxygen atoms red, magnesium atoms green, and the bright blue atom stand for a nitrogen atom. Reprinted with permission from Journal of Physical Chemistry B. Copyright 2006 American Chemical Society.

While on a single crystal $\mathrm{MgO}(100)$ surface $\mathrm{O}_{2}$ adsorption is endothermic and the molecule stays neutral, on a metal supported $\mathrm{MgO}(100)$ film $\mathrm{O}_{2}$ adsorption is exothermic, the molecule becomes singly charged, and the $\mathrm{O}-\mathrm{O}$ bond length increases ${ }^{20,111} \cdot \mathrm{O}_{2}$ adopts a parallel adsorption geometry bridging between two $\mathrm{Mg}$ cations with adsorption energy of $-0.82 \mathrm{eV}$ on an $\mathrm{Ag}_{\text {-supported film }}^{20}$. On Mo-supported $\mathrm{MgO}$ the adsorption energy is even more exothermic being $-1.5 \mathrm{eV}^{111}$. The theoretical prediction of $\mathrm{O}_{2}^{-}$formation was confirmed by means of EPR spectroscopy ${ }^{129}$, where an unpaired electron is responsible for the signal. The common feature of the species that show enhanced adsorption on metal-supported ultra-thin films is that they have high enough electronic affinity. Molecules with lower electron affinity such as CO do not show increased stability ${ }^{20}$. 


\section{CHEMICAL REACTIONS OF SIMPLE MOLECULES ON ULTRA-THIN FILMS AND SUPPORTED AU CLUSTERS}

Relatively little attention has been paid on chemical reactions on $\mathrm{MgO}$ due to its inertness compared to more reactive reducible oxides such as $\mathrm{TiO}_{2}$. However, as discussed above ultrathin films display higher chemical reactivity compared to bulk $\mathrm{MgO}$ binding species with high electron affinity more strongly. The question then arises: can thin films systems facilitate chemical reactions?

\section{A. CO oxidation on ultra-thin films}

Recent DFT calculations of Hellman et al. predict that CO oxidation proceeds over an Ag-supported ultra-thin $\mathrm{MgO}(100)$ film with an activation barrier lower than the corresponding barrier on $\mathrm{Pt}(111)^{20}$. While $\mathrm{CO}$ oxidation on $\mathrm{Pt}$ involves $\mathrm{O}_{2}$ dissociation before $\mathrm{CO}$ oxidation ${ }^{130}$, on $\mathrm{MgO} / \mathrm{Ag} \mathrm{O}_{2}$ dissociation is highly unfavourable being endothermic by $1 \mathrm{eV}$. Also $\mathrm{CO}$ adsorption is weak being only $-0.25 \mathrm{eV}$ on bare $\mathrm{MgO} / \mathrm{Ag}$ and $-0.4 \mathrm{eV}$ on the oxygen preadsorbed surface. The calculations give an activation barrier of $0.7 \mathrm{eV}$ if both reactants are adsorbed to the surface prior the reaction but the barrier drops to only $0.3 \mathrm{eV}$ for the Eley-Rideal route, where gas-phase CO reacts directly with the adsorbed molecular oxygen.

For comparison, on $\mathrm{FeO} / \mathrm{Pt}(111)$ a completely different reaction mechanism has been put forward ${ }^{15}$ owing to the high work function of $\mathrm{Pt}$, which prevents the spontaneous formation of $\mathrm{O}_{2}^{-1}$ anions. Calculations predict that $\mathrm{O}_{2}$ dissociation is a relatively easy process, where the adsorption energy of $\mathrm{O}_{2}$ is $-0.7 \mathrm{eV}$ and the dissociation is strongly exothermic with a modest activation barrier of $0.4 \mathrm{eV}$. At high $\mathrm{O}_{2}$ coverage this leads to the transformation of a bilayer film to trilayer $\mathrm{FeO}_{2-x}$ stoichiometry as seen in Auger electron spectroscopy and temperature programmed desorption ${ }^{15}$. A similar transformation is seen when NO is used as an oxidative agent ${ }^{21}$. On $\mathrm{FeO}_{2} / \mathrm{Pt}(111) \mathrm{CO}$ oxidation involves the extraction of lattice oxygen and the barrier for $\mathrm{CO}_{2}$ formation is only $0.2 \mathrm{eV}$ according to DFT calculations ${ }^{15}$. At the end, oxygen vacancies are healed via a reaction with a gas-phase oxygen, which returns the original stoichiometry of the film. A combination of various experimental techniques show that O-rich $\mathrm{FeO}_{2-x}$ films produced by $\mathrm{O}_{2}$ and $\mathrm{NO}$ are virtually identical, the substantial 


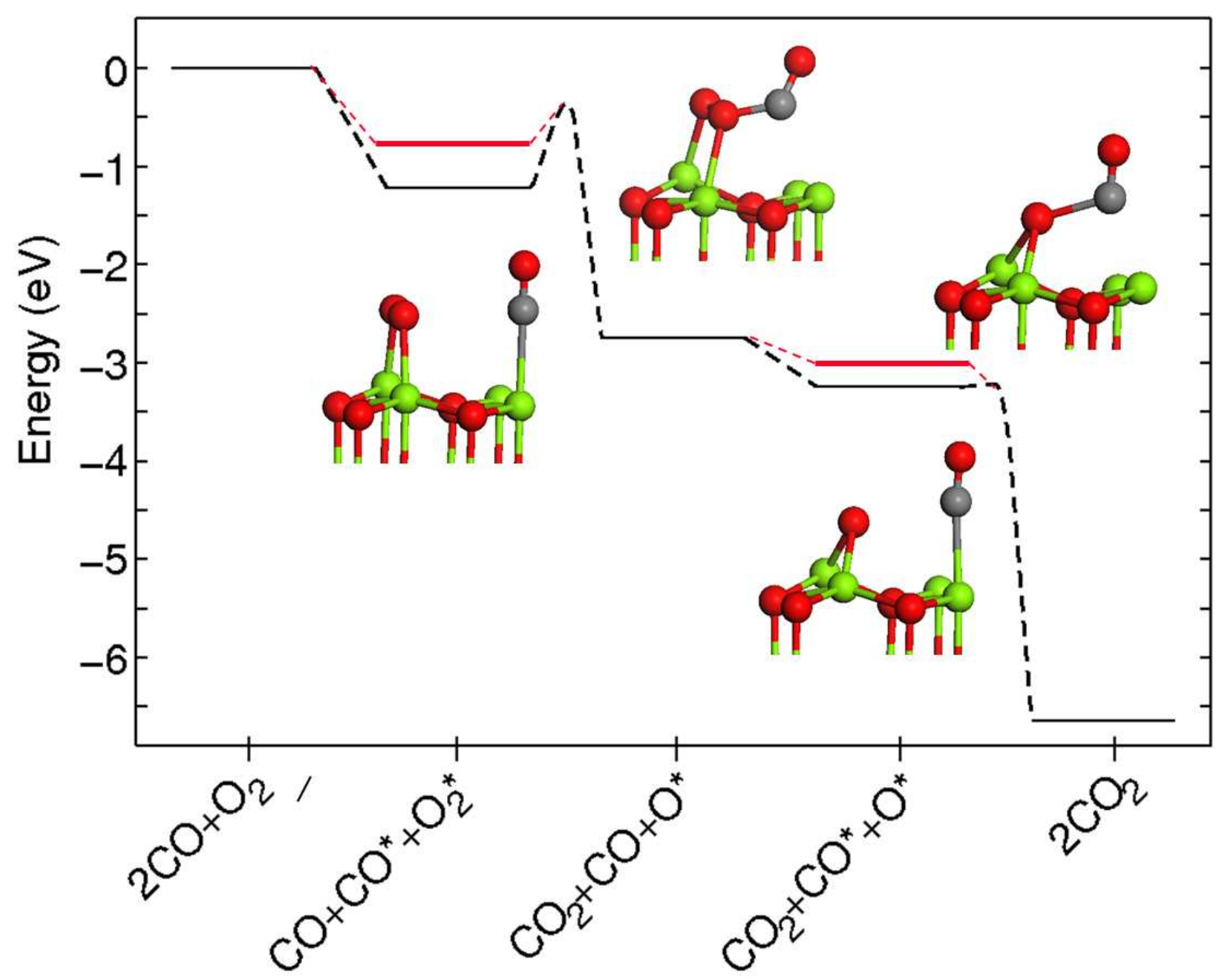

FIG. 10: The potential energy surface for CO oxidation over $\mathrm{MgO}(100) / \operatorname{Ag}(100)^{20}$. The black line corresponds the

Langmuir-Hinshelwood reaction mechanism. The energies related to the Eley-Rideal mechanism are marked with the red bars in reaction steps, where Eley-Rideal and Langmuir-Hinshelwood energies differ. Atomic color codes: green $(\mathrm{Mg}), \operatorname{red}(\mathrm{O})$, and gray $(\mathrm{C})$. Reprinted with permission from Journal of American Chemical Society. Copyright 2009 American Chemical Society.

difference in kinetics of $\mathrm{CO}_{2}$ production from $\mathrm{CO}+\mathrm{O}_{2}$ and $\mathrm{CO}+\mathrm{NO}$ reactions indicate that the healing of oxygen vacancies is the rate-limiting step ${ }^{21}$. DFT calculations demonstrate that this is indeed the case because NO adsorbs N-down on an oxygen vacancy and CO reaction with the "dangling" oxygen is a highly activated process ${ }^{21}$. 


\section{B. Adsorption and reactivity of $\mathrm{O}_{2}$ and $\mathrm{CO}$ on Au clusters supported by ultra-thin}

films

The adsorption and activation of $\mathrm{O}_{2}$ is known to be difficult on $\mathrm{Au}^{131}$, yet its pivotal role in oxidation reactions on an $\mathrm{Au}$ catalyst is undeniable. Therefore, it is natural that first reactivity studies on ultra-thin film supported $\mathrm{Au}$ clusters include molecular oxygen. $\mathrm{O}_{2}$ adsorption and activation on thin-film supported Au clusters has been theoretically analyzed on $\mathrm{Au}_{1-6} / \mathrm{MgO} / \mathrm{Mo}^{111}$ (Figure 11), on $\mathrm{Au}_{14}$ and $\mathrm{Au}_{18} / \mathrm{MgO} / \mathrm{Ag}^{19}$, and on $\mathrm{Au}_{20} / \mathrm{MgO} / \mathrm{Mo}^{132}$. Calculations show that molecular oxygen slightly favours adsorption on the bare $\mathrm{MgO} / \mathrm{Mo}$ surface than on $\mathrm{Au}_{1-6} / \mathrm{MgO} / \mathrm{Mo}^{111}$. While $\mathrm{O}_{2}$ adsorption on the supported $\mathrm{Au}_{2-6}$ chains is exothermic with adsorption energies ranging from $-1.5 \mathrm{eV}$ to $-0.7 \mathrm{eV}$ and weakest adsorption found for $\mathrm{Au}_{4}$, no stable adsorption geometry could be found on a single $\mathrm{Au}$ atom. In general, $\mathrm{O}_{2}$ prefers to adsorb to the end of the $\mathrm{Au}_{2-6}$ chains bridging simultaneously two $\mathrm{Mg}$ cations, similarly to the bare $\mathrm{MgO} / \mathrm{Mo}$. Upon adsorption, $\mathrm{O}_{2}$ gains approximately one electron, O-O bond length elongates to 1.39 - $1.47 \AA$ depending the cluster size, and the O-O bond length correlates linearly to the calculated charge state of the molecule as depicted in Figure $12^{111}$.

Figure 13 shows that $\mathrm{O}_{2}$ adsorption on $\mathrm{MgO} / \mathrm{M}$-supported $\mathrm{Au}$ chains is more exothermic than adsorption on neutral, anionic, and dianionic gas-phase clusters. The clear oscillatory adsorption trend with respect to a number of Au atoms in the chain, that is typical for gasphase or $\mathrm{F}_{s} / \mathrm{MgO}$ adsorbed clusters, is absent. Adsorption and dissociation of multiple $\mathrm{O}_{2}$ molecules was calculated at the edges of a flat $\mathrm{Au}_{14}$ cluster supported by $\mathrm{MgO}(2 \mathrm{ML}) / \mathrm{Ag}^{19}$ and is strongly linked to bridge the materials and pressure gaps to discover potential morphology changes of the catalyst particle under ambient conditions. The $\mathrm{Au}_{14}$ cluster has an idealized $\mathrm{C}_{2 v}$ symmetry with ten atoms at the edge and four inner atoms forming a rhombus-like structure. All the favourable adsorption sites reside at the edge of the cluster as the adsorption on the top of the cluster is endothermic. For all the studied structures adsorption energies range from from $-1.15 \mathrm{eV}$ for a single molecule to $-0.6 \mathrm{eV}$ for the 10 'th molecule. The best adsorption structures for 1, 2, 6, and 10 oxygen molecules are given in Figure 14. Depending on the number of oxygen molecules two adsorption modes are identified: perpendicular and parallel, where either one or two oxygen atoms interact with Au edge atoms. Electronic and geometric adsorption characteristics group into two categories 


\section{$\mathrm{O}_{2} / \mathrm{Au}_{1}$ \\ $\mathrm{O}_{2} / \mathrm{Au}_{2}$ \\ $\mathrm{O}_{2} / \mathrm{Au}_{3}$}
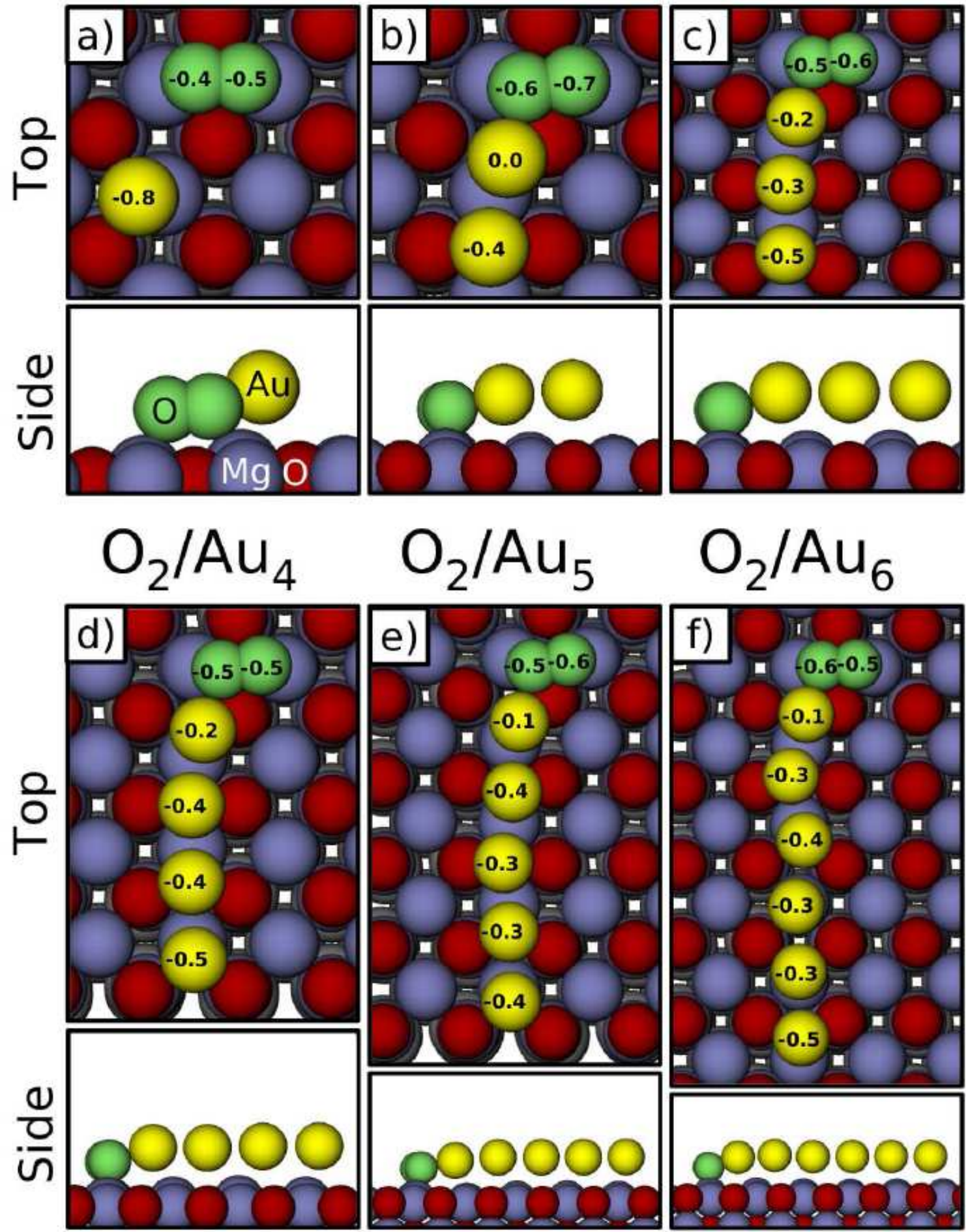

$\mathrm{O}_{2} / \mathrm{Au}_{5}$

$\mathrm{O}_{2} / \mathrm{Au}_{6}$
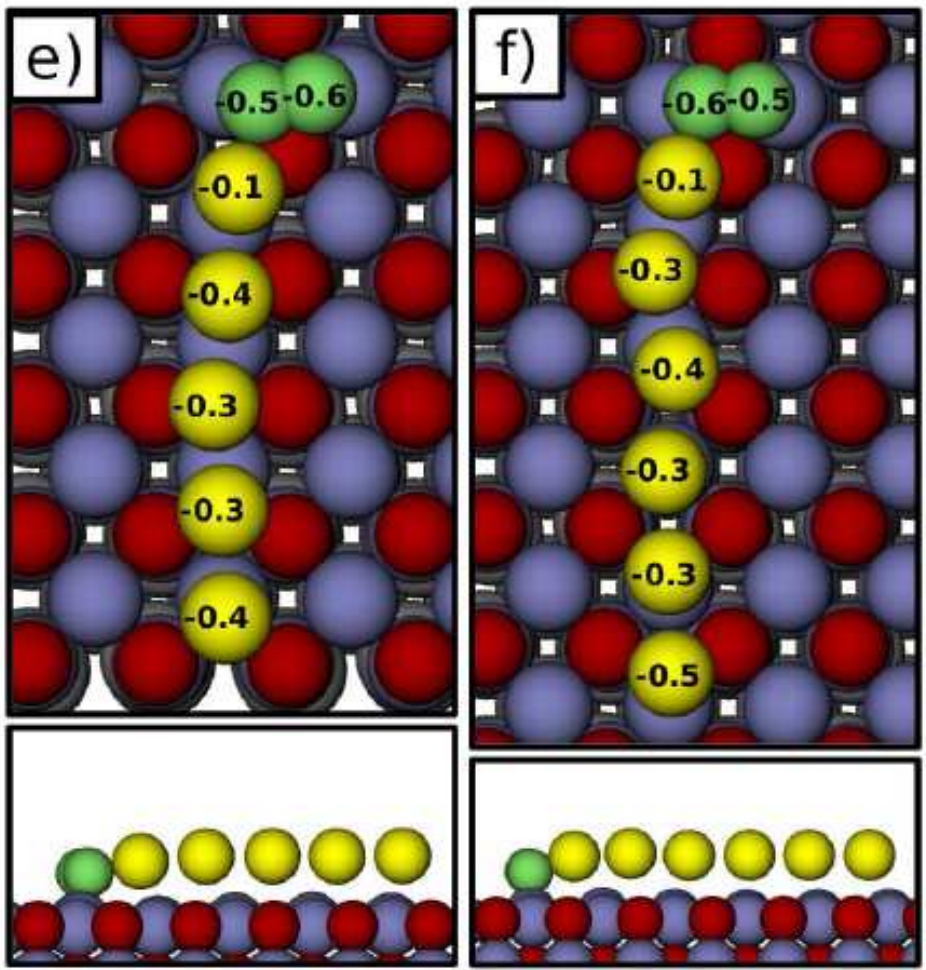

FIG. 11: The top and side views of the optimal geometries for molecular oxygen on $\mathrm{Au}_{1-6}$ aggregates on $\mathrm{MgO}(3 \mathrm{ML}) / \mathrm{Mo}$. the colour coding is as follows $\mathrm{O}_{2}$ green, Au yellow, $\mathrm{Mg}$ blue and lattice $\mathrm{O}$ red. The Bader charges of selected atoms are marked in the atoms. Figure adapted with permissions from Ref. ${ }^{111}$. 


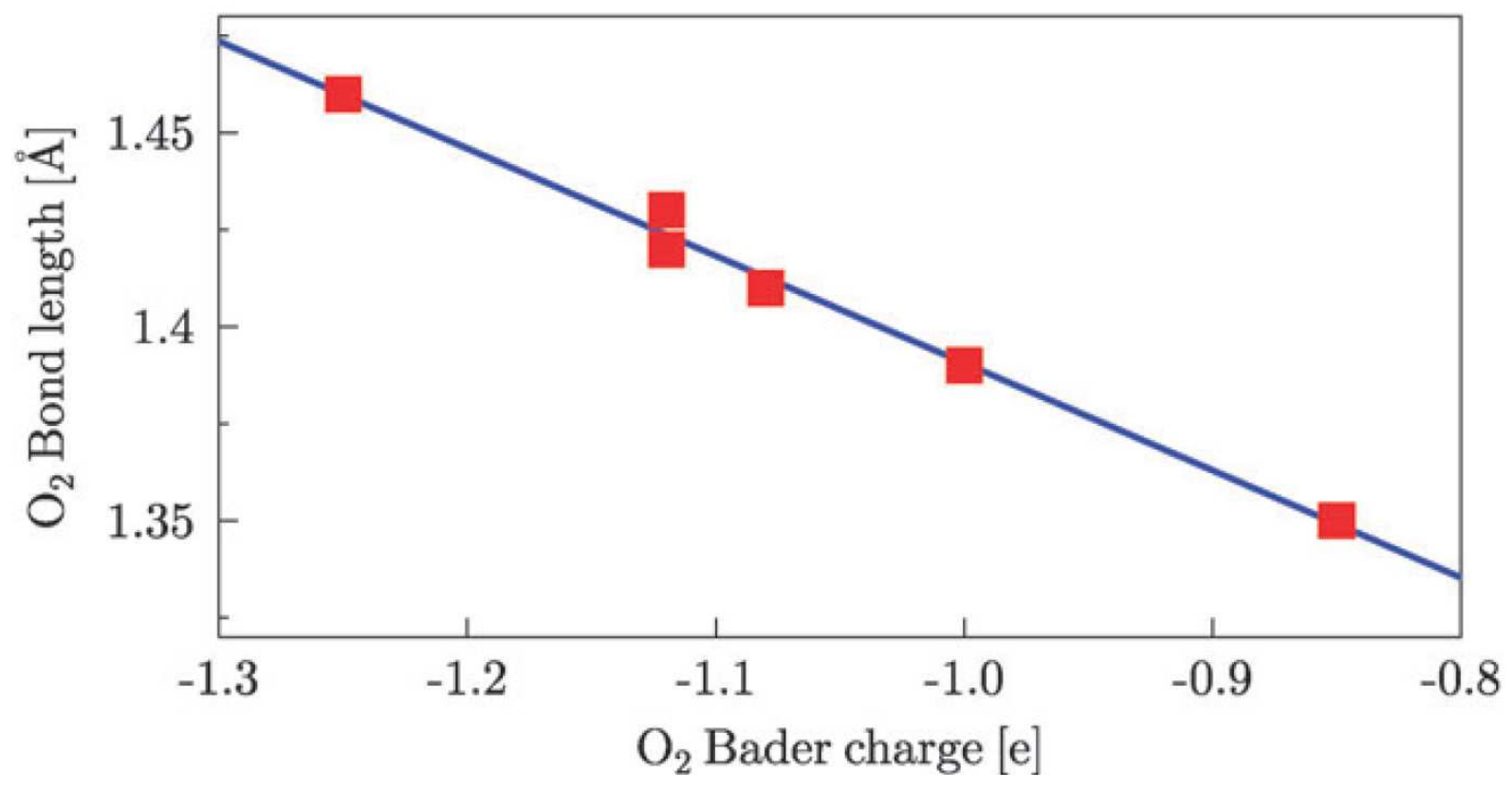

FIG. 12: The $\mathrm{O}_{2}$ bond length as a function of the $\mathrm{O}_{2}$ Bader charge for $\mathrm{O}_{2} / \mathrm{Au}_{1-6} / \mathrm{MgO} / \mathrm{Mo}$. Figure adapted with permissions from Ref. ${ }^{111}$.

\begin{tabular}{|c|c|c|c|}
\hline mode & O-O $(\AA)$ & Bader $(\mathrm{e})$ & $\mu_{B}$ \\
\hline \hline parallel & $1.44-1.53$ & $-1.0--1.3$ & 0 \\
\hline perpendicular & $1.31-1.37$ & -0.7 & 1 \\
\hline
\end{tabular}

TABLE I: The calculated O-O bond length in $\AA$, a calculated Bader charge, and magnetic moment for an $\mathrm{O}_{2}$ molecule adsorbed either on the parallel or perpendicular fashion at the perimeter of the $\mathrm{Au}_{14}$ cluster over $\operatorname{MgO}(2 \mathrm{ML}) / \operatorname{Ag}(100)^{19}$.

relative to the orientation as shown in Table I.

All the analyses support an interpretation that in the perpendicular mode the electronic state of $\mathrm{O}_{2}$ resembles superoxo, while the parallel mode corresponds to the peroxo-like species. At low coverage $\mathrm{O}_{2}$ favours parallel adsorption mode at the perimeter of cluster. With increasing $\mathrm{O}_{2}$ coverage, the perpendicular mode becomes dominating and it is the only possibility to accommodate 10 molecules to the perimeter of $\mathrm{Au}_{14}$. Interestingly, the differential adsorption energy of tenth $\mathrm{O}_{2}$ is still considerable being $-0.75 \mathrm{eV}$ exothermic and highlights the ability of $\mathrm{MgO} / \mathrm{Ag}$-supported $\mathrm{Au}_{14}$ to bind and activate simultaneously 


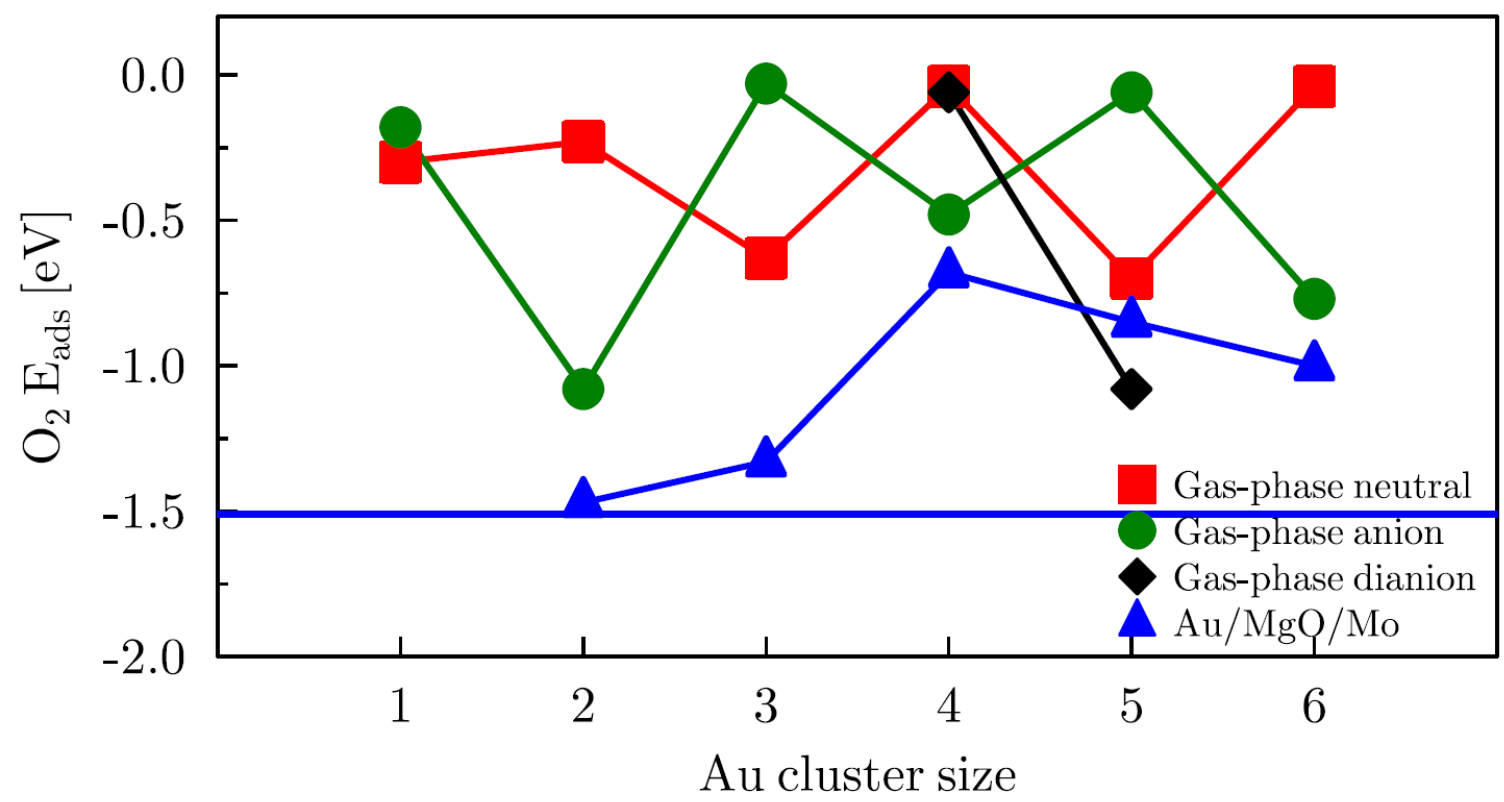

FIG. 13: The adsorption energy of molecular $\mathrm{O}_{2}$ on chain-like clusters on $\mathrm{MgO}(3 \mathrm{ML}) / \mathrm{Mo}$ (blue triangles) as well as on selected neutral (red squares) ${ }^{133}$, anionic (green circles) ${ }^{133}$, and dianionic (black diamonds) gas-phase clusters. The horizontal blue line gives the adsorption energy on the bare substrate. Figure adapted with permissions from Ref. ${ }^{111}$.

multiple oxygen molecules. This theoretical prediction is yet to be experimentally verified on thin film supported Au cluster. While for a $\mathrm{MgO} / \mathrm{Mo}$ supported Au cluster this might be impossible as $\mathrm{O}_{2}$ prefers to adsorb on a bare film to the cluster, from the thermodynamic aspect experimental verification should be possible for the $\mathrm{MgO} / \mathrm{Ag}(100)$ support, where the $\mathrm{O}_{2}$ species clearly favour cluster edges over the bare support. The adsorption of multiple oxygen molecules is not possible on gas-phase anionic clusters, since the adsorption of a single oxygen molecule consumes the extra electron and makes the cluster inactive for further oxygen adsorption ${ }^{134}$. In addition to strong adsorption and activation of oxygen molecules, the perimeter of $\mathrm{Au}_{14}$ cluster also dissociates oxygen readily. The calculated barrier is 0.5 $\mathrm{eV}$ with respect to the adsorbed oxygen molecule. The final, dissociated state is markedly exothermic by $1.8 \mathrm{eV}$ compared to the initial molecular state and shows a formation of a linear O-Au-O configuration at the edge of the cluster displayed in Figure 15.

A strong thermodynamic driving force for dissociation is seen e.g., for four oxygen 


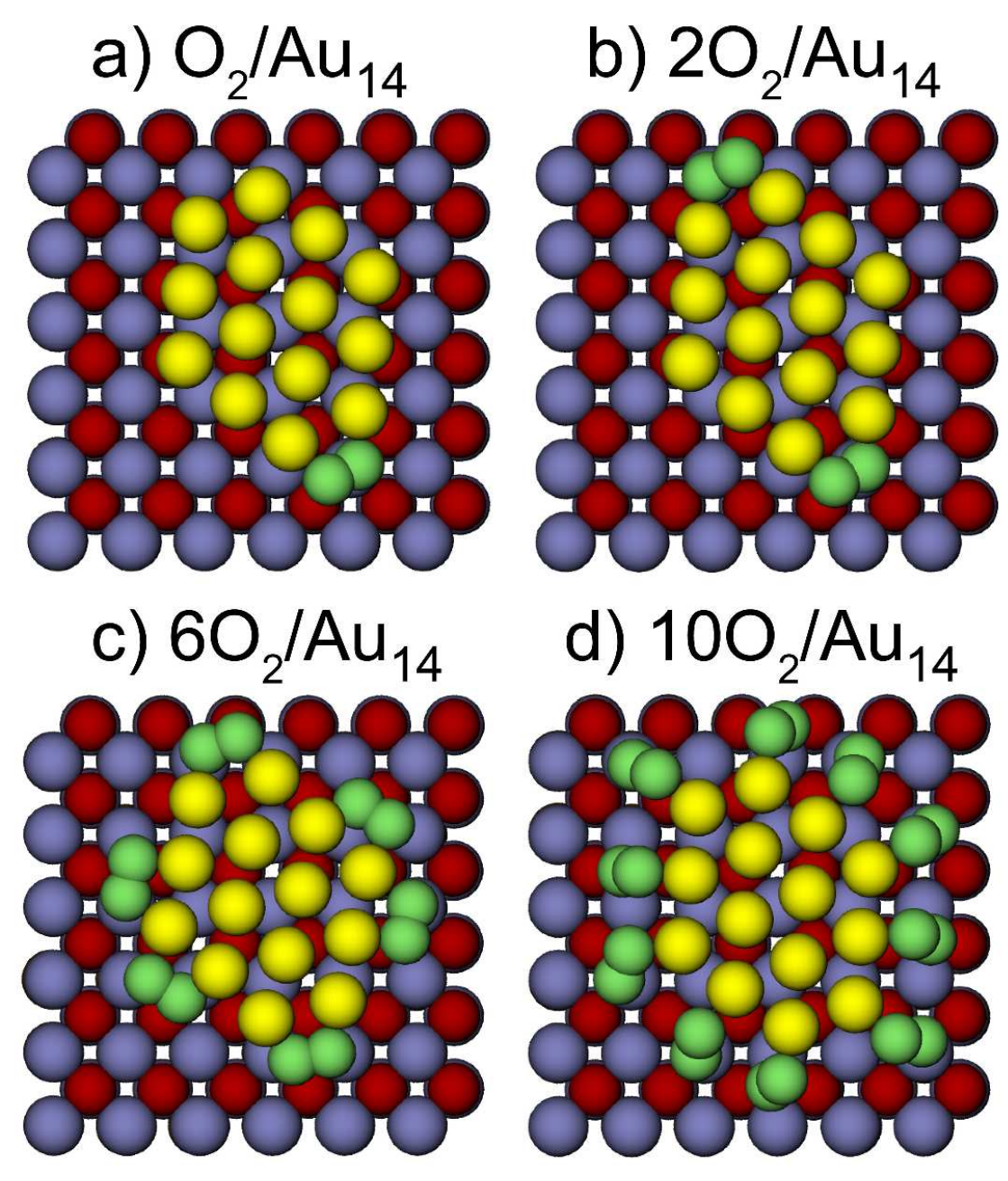

FIG. 14: Optimal adsorption geometries of one, two, six, and ten oxygen molecules on Ag-supported $\mathrm{Au}_{14}$ cluster identified in ref. ${ }^{119}$. Color code: red oxygen in $\mathrm{MgO}$, blue $\mathrm{Mo}$, yellow $\mathrm{Au}$, and green $\mathrm{O}$ in $\mathrm{O}_{2}$. Figure adapted with permissions from Ref. ${ }^{19}$.

molecules, which is exothermic by $1.2 \mathrm{eV} /$ molecule. The binding of atomic oxygen to the perimeter of the cluster leads to a considerable structural distortion of the cluster and formation of linear $\mathrm{Au}-\mathrm{O}-\mathrm{Au}$ chains. The $\mathrm{Au}$ atoms in $\mathrm{Au}-\mathrm{O}-\mathrm{Au}$ chains are chemically different, while in the absence of $\mathrm{O}_{2}$ perimeter $\mathrm{Au}$ atoms have excess negative charge of -0.2 to $-0.3|e|$ in the chains they become positively charged by $0.3|e|$. This is further supported by the LDOS analysis showing different electronic structure. All these factors indicate the oxidation of $\mathrm{Au}$ atoms in the presence of atomic oxygen. Recent DFT calculations predict $\mathrm{Au}$ oxidation at the interface to a $\mathrm{TiO}_{2}$ support ${ }^{135}$. Conversely, on a bulk $\mathrm{Au}$ surface $\mathrm{O}_{2}$ ad- 


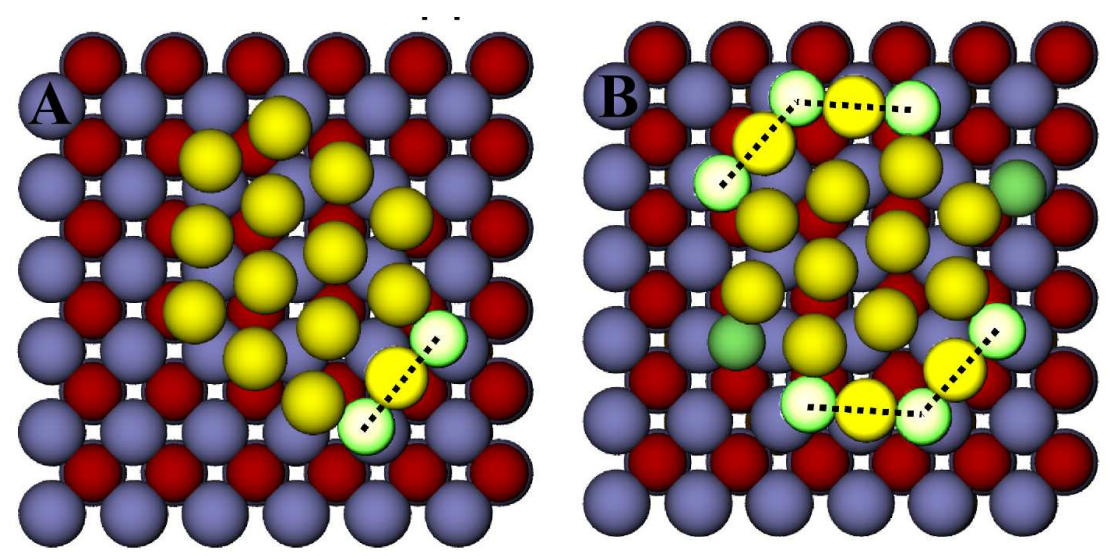

FIG. 15: Optimal adsorption geometries for two and eight $\mathrm{O}$ atoms at the perimeter of the $\mathrm{Au}_{14}$ cluster supported on $\mathrm{MgO}(2 \mathrm{ML}) / \mathrm{Ag}(100)$. Color code: red oxygen in $\mathrm{MgO}$, blue $\mathrm{Mo}$, yellow $\mathrm{Au}$, and green $\mathrm{O}$ in $\mathrm{O}_{2}$. Figure adapted with permissions from Ref. ${ }^{19}$.

sorption is endothermic even on low coordinated sites ${ }^{94,136}$ and $\mathrm{O}_{2}$ adsorption on $\mathrm{Au}$ clusters supported on $\mathrm{MgO}$ shows weak binding and mildly exothermic dissociative adsorption ${ }^{94}$.

The strong thermodynamic driving force together with the low dissociation barrier, 0.5 $\mathrm{eV}$, renders the dissociation accessible on the supported $\mathrm{Au}_{14}$ even at low temperatures. First principles atomistic thermodynamics ${ }^{137}$ was applied to calculate the Gibbs free energy of oxygen adsorption to asses the relative stability of different structures under ambient conditions of oxygen atmosphere. Figure 16 displays free energy plots as a function of $\mathrm{O}_{2}$ chemical potentials, where temperature and pressure effects were calculated from first principles with appropriate partition functions.

Among the calculated structures $\mathrm{Au}_{14} \mathrm{O}_{8 \text {,diss }}$ is thermodynamically the most stable one being nearly $4 \mathrm{eV}$ more favourable than the second best structure, $\mathrm{Au}_{14} \mathrm{O}_{2 \text {,diss }}$ at $\mathrm{T}=300 \mathrm{~K}$ and $\mathrm{O}_{2}$ pressure of 1 bar. Metastable bulk and surface forms of gold(III) oxide $\mathrm{Au}_{2} \mathrm{O}_{3}$ are known to form under special conditions ${ }^{138,139}$. DFT coupled with atomistic thermodynamics calculations has indicated that atomic oxygen on the $\mathrm{Au}(111)$ surface can induce the formation of a two-dimensional gold(I) oxide network as an overlayer on $\mathrm{Au}(111)$, predicted to be stable up to $420 \mathrm{~K}$ at atmospheric pressure ${ }^{140}$.

Sensitivity of oxygen adsorption and activation on a planar or tetrahedral structure of a $\mathrm{Au}$ cluster was computationally addressed via $\mathrm{Au}_{20}$ supported on a $\mathrm{MgO}(1 \mathrm{ML}) / \mathrm{Mo}(100)$ surface $^{132}$. In both cases oxygen adsorbs to the perimeter of the cluster at the parallel 


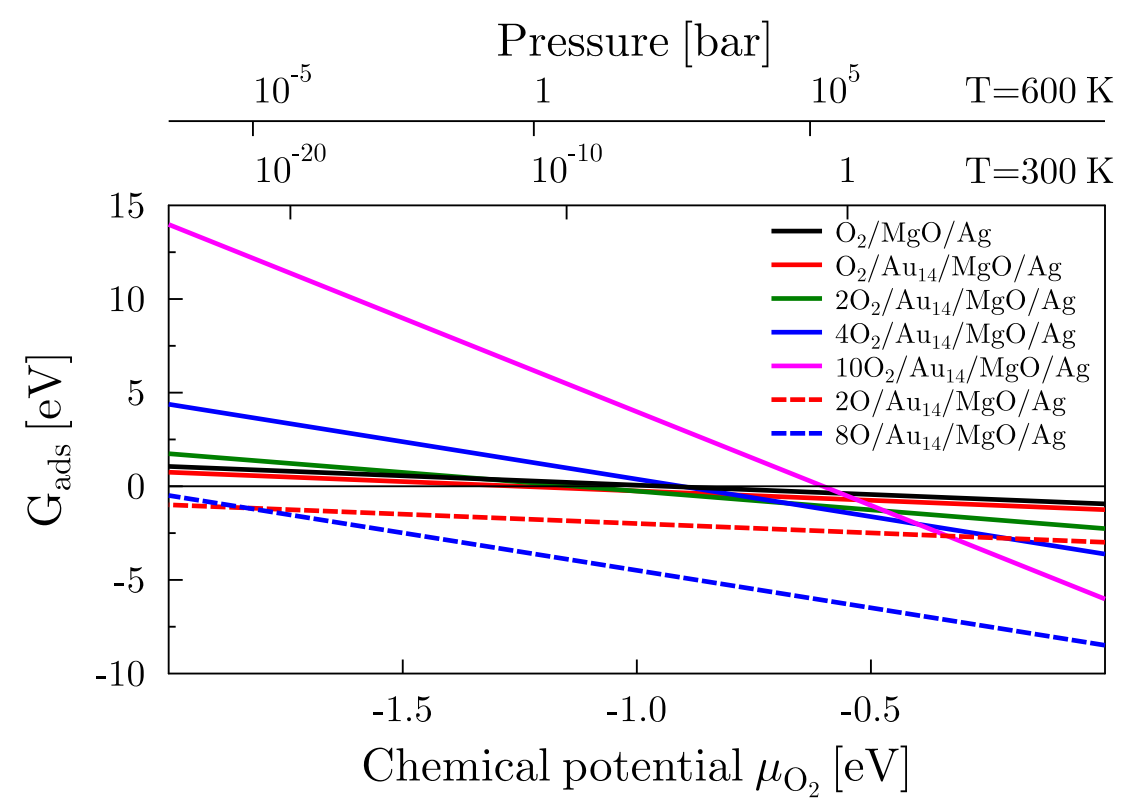

FIG. 16: The free energy of oxygen adsorption, $\Delta G_{a d s}$, as a function of oxygen chemical potential, $\mu_{O_{2}}$. Figure adapted with permissions from Ref. ${ }^{19}$.

configuration, activates to a peroxo state, and dissociates with a barrier of about $0.3 \mathrm{eV}$ with respect to the molecularly adsorbed oxygen. A slight difference of $0.2 \mathrm{eV}$ in $\mathrm{O}_{2}$ dissociation barrier heights on $\mathrm{Au}_{14}$ and $\mathrm{Au}_{20}$ potentially originates from different metal supports as oxygen binding on $\mathrm{MgO} / \mathrm{Mo}$ is stronger than on $\mathrm{MgO} / \mathrm{Ag}$, or from different $\mathrm{MgO}$ film thicknesses.

$\mathrm{CO}$ adsorption has been computationally addressed on $\mathrm{Au}_{3-7}, \mathrm{Au}_{12}$, and $\mathrm{Au}_{22}$ clusters on $\mathrm{MgO} / \mathrm{Ag}$ surfaces ${ }^{123}$. The adsorption energies range from -0.5 to $-1 \mathrm{eV}$ depending on the cluster size and are more exothermic than on the bare $\mathrm{MgO} / \mathrm{Ag}$ surface. $\mathrm{CO}$ does not bind to the high coordinated Au atoms of 1D and 2D Au clusters or the central area of the larger islands but favours solely the low-coordinated sites at the edge of these structures forming a tilted orientation at the cluster boundary. Vibrational frequency analysis displays a red-shift of $\sim 50-60 \mathrm{~cm}^{-1}$ in $\omega(\mathrm{CO})$ for $\mathrm{MgO} / \mathrm{Ag}$ supported Au clusters compared to same clusters on bulk $\mathrm{MgO}$ or in gas-phase counterparts. The shift is ascribed to the charge transfer to the cluster agreeing nicely with experimental results, which also indicate that $\mathrm{CO}$ exclusively binds to $\mathrm{Au}$ atoms at the island perimeter ${ }^{141}$. Similar to $\mathrm{O}_{2}$ adsorption, the favouring of low-coordinated boundary sites means that for larger 2D clusters only a minority of $\mathrm{Au}$ atoms bind $\mathrm{CO}$; in addition, $\mathrm{CO}$ and $\mathrm{O}_{2}$ may exhibit mutual competition of these sites. 
The formation of adsorbed $\mathrm{CO}_{2}$ on planar $\mathrm{Au}_{20} / \mathrm{MgO} / \mathrm{Ag}$ is essentially a non-activated process involving a negligible barrier of $0.07 \mathrm{eV}$ according to DFT calculations and the desorption energy of $\mathrm{CO}_{2}$ is $0.27 \mathrm{eV}^{132}$. Among the calculated barriers, the rate determining step is the dissociation of the molecular oxygen, which is suggested to correspond to the low temperature $\mathrm{CO}$ oxidation in experiments ${ }^{132}$. High temperature $\mathrm{CO}_{2}$ formation was proposed to originate from the reaction of $\mathrm{CO}$ with an activated, peripherally adsorbed but undissociated $\mathrm{O}_{2}$ with an activation energy of $0.66 \mathrm{eV}^{132}$. A completely different reaction mechanism was put forward for bulk $\mathrm{MgO}$ supported $\mathrm{Au}$ nanoparticles for which calculations suggest that $\mathrm{CO}$ oxidation follows an Eley-Rideal mechanism, where CO adsorbs on the nanoparticle and reacts with the coming oxygen molecule with activation energy of $\sim 0.2-$ $0.4 \mathrm{eV}^{94}$. Similar activation energies are computed on flat $\mathrm{Au}$ surfaces ${ }^{94}$ and $\mathrm{TiO}_{2}$ supported $\mathrm{Au}_{10}{ }^{100}$. On defected bulk $\mathrm{MgO} \mathrm{Au}_{8}$ was found to be the smallest cluster capable for $\mathrm{CO}$ oxidation with the calculated barrier of $0.5 \mathrm{eV}^{88}$. In conclusion, regardless of the support used in calculations, the activation barriers for $\mathrm{CO}$ oxidation have about the same order of magnitude but different reaction mechanisms.

\section{Dissociative adsorption of water}

Water is the most abundant natural resources and a candidate for generating hydrogen. Under realistic reaction conditions many oxides are hydroxylated in air ${ }^{142}$ and surface hydroxyl groups may strongly impact on the chemical characteristics of oxide surfaces ${ }^{143}$. Water dissociation on bulk $\mathrm{MgO}$ surfaces has been extensively studied both experimentally and theoretically. Ab initio molecular dynamics has been applied to compare water adsorption on flat and stepped $\mathrm{MgO}$ surface at low coverage ${ }^{144,145}$. The simulations show that water merely physisorbs on bulk $\mathrm{MgO}(100)$ while on coordinately unsaturated step sites dissociation takes places readily ${ }^{144,145}$. All DFT calculations indicate that water dissociation is thermodynamically unfavourable due to fragment separation on $\mathrm{MgO}(100)$ at low coverage $\mathrm{e}^{146-149}$, but at $1 \mathrm{ML}$ coverage calculations suggest a collective dissociation process such that one third of water molecules break down ${ }^{150-152}$. Experimentally, LEED and HAS measurements revealed that water adopts a $(3 \times 2)$ superstructure $^{153}$ and the combined HREELS and UPS study demonstrated a partially dissociated water layer ${ }^{154}$. The first experimental studies on submonolayers of water on a $\mathrm{MgO} / \mathrm{Ag}(100)$ system employing spectroscopic methods 
showed evidence of facile hydrolysis ${ }^{155-157}$, where the active site was proposed to be at the metal-oxide interface. This was further supported by the DFT study of the system ${ }^{158}$.

DFT calculations ${ }^{148}$ followed by a combined experimental and theoretical study ${ }^{23}$ on water adsorption and dissociation on $\mathrm{MgO} / \mathrm{Ag}(100)$ display many interesting features. Figure 17 compares the optimal adsorption structures of a molecular water on $\mathrm{MgO}(100)$ and $\mathrm{MgO}(2 \mathrm{ML}) / \mathrm{Ag}(100)$ surfaces. On the metal-supported thin film the oxygen atom of a water molecule is favourably located above a Mg cation, which is in line with STM results, ${ }^{23}$, where one hydrogen atom points asymmetrically towards a neighbouring surface anion ${ }^{23,148}$. The adsorption energy is about $-0.5 \mathrm{eV}$ and indicates that the metal support does not enhance the adsorption. Interestingly, calculations predict that in the presence of an Au cluster a water molecule prefers to sit over the oxide to the Au cluster ${ }^{159}$. The bottom two figures in Figure 17 depict adsorption structures for a dissociated water on both bare and Agsupported MgO. Energetics show that water dissociation is endothermic on both cases that is again in agreement with observations in STM measurements. The calculated adsorption geometries of dissociated water differ since on bare $\mathrm{MgO}$ both $\mathrm{OH}$ and $\mathrm{H}$ species reside on top positions and on supported film OH prefers a bridge geometry between two Mg cations.

STM experiments give evidence for two distinct dissociation channels ${ }^{23}$ depending on the film thickness. On the $2 \mathrm{ML}$ film the dissociation probability increase rapidly when bias and tunneling current dependent threshold energy exceeds $0.48 \mathrm{eV}$ that corresponds the asymmetric $\mathrm{O}-\mathrm{H}$ stretching mode energy. This strongly supports interpretation that vibrationally induced excitation is responsible for dissociation to $\mathrm{OH}$ and $\mathrm{H}$. The $\mathrm{MgO}$ film plays a central role to facilitate vibrationally induced dissociation due to decoupling allowed by the insulating $\mathrm{MgO}$ film therefore on the 2ML-thick film the dissociation barrier of water is reduced below the energy of the doubly excited $\nu_{O H}$ mode. On the 3ML film higher, 1.5 $\mathrm{V}$, bias voltage is needed to initiate dissociation, which is suggested to proceed via electronic excitation forming adsorbed oxygen. This is in line with spectroscopic experiments, which indicate that under low relative humidity conditions water dissociates on 4-5.5 ML thick MgO films at defect sites $^{160}$ as predicted also by DFT calculations ${ }^{148}$. The DFT calculations reveal the pivotal role of film thickness on barrier height ${ }^{23}$, which is about $1 \mathrm{eV}$ on $\mathrm{MgO}(3 \mathrm{ML}) / \mathrm{Ag}(100)$ and bare $\mathrm{MgO}$ reducing to to $0.56 \mathrm{eV}$ on $\mathrm{MgO}(1 \mathrm{ML}) / \mathrm{Ag}(100)$. The presence of under-coordinated step sites impacts substantially as they dissociate water spontaneously on both $\mathrm{MgO}$ and $\mathrm{MgO} / \mathrm{Ag}$ surfaces $^{148}$. 


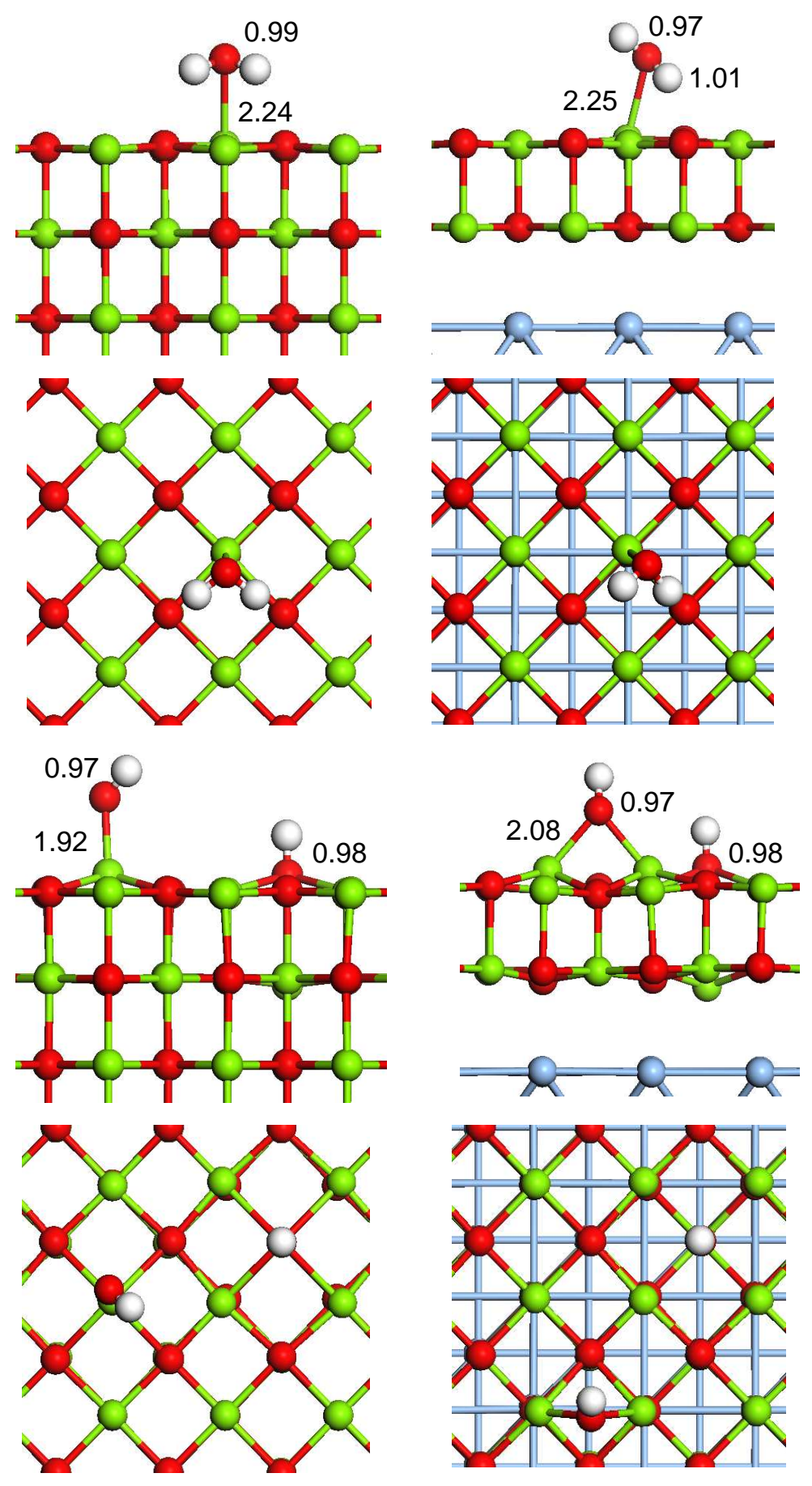

FIG. 17: The most favourable adsorption geometries on $\mathrm{MgO}(100)$ and $\mathrm{MgO} / \mathrm{Ag}(100)$ surfaces. The selected distances are given in angstroms. The colour coding is $\mathrm{Ag}$ atoms are blue, $\mathrm{Mg}$ atoms green, $\mathrm{O}$ atoms red, and $\mathrm{H}$ atoms white. Figure adapted with permissions from Ref. ${ }^{148}$. 
Interestingly, calculations show that isolated H-bonded water dimers facilitate barrierless water dissociation on a bare and $\mathrm{Ag}$-supported $\mathrm{MgO}(100)$ surface $^{161}$. Dissociation is further stabilised on $\mathrm{MgO}$ ultra-thin films, which is attributed to two factors. The presence of metal support stabilizes the final state of charged fragments owing to structural relaxations in oxide that induce a strong corrugation of the film. Furthermore, based on the analysis of interaction energies the ion-ion interaction is suggested to change to a dipole-dipole type interaction ensuing a weakly bound ion pair ${ }^{161}$. At monolayer water coverages different structural motifs corresponding to surface cells with different sizes have been employed in calculations ${ }^{148}$. An example applied structural model is given in Figure 18. The optimized structures show that a part of monolayer is dissociated and molecular water adsorbs on $\mathrm{Mg}^{2+}$ sites with one $\mathrm{H}$ pointing toward $\mathrm{OH}_{a d s}$. The adsorption energies are more exothermic by about 0.3 $\mathrm{eV} / \mathrm{H}_{2} \mathrm{O}$ than those obtained at low coverage. For comparison, on $\mathrm{FeO}(111)(1 \mathrm{ML}) / \mathrm{Pt}(111)$ the enhancement in water adsorption is even more pronounced according to calculations since one water molecule barely binds to the substrate, while the presence of the second water molecule stabilizes the average adsorption energy by $\sim-0.5 \mathrm{eV}^{16}$. In both systems enhanced adsorption is attributed to the formation of strong hydrogen bonds. Recent STM experiments on a water tetramer on $\mathrm{NaCl}(001) / \mathrm{Au}(111)$ reveal directionality of the hydrogen bonds at the orbital level ${ }^{162}$. The calculated fraction of dissociated water molecules is $1 / 3$

on $\mathrm{MgO} / \mathrm{Ag}$ that is in line with previous calculations on bare $\mathrm{MgO}^{150,151}$ and independent of the computational surface cell used. This can be rationalized as follows: Upon dissociation of one water molecule two strong $\mathrm{HOH}-\mathrm{OH}_{a d s}$ bonds are formed (a spare $\mathrm{H}$ is at the O-top site) and the number of such bonds is maximized for a dissociation ratio of one-third.

\section{MODIFICATIONS AT THE OXIDE-SUPPORT INTERFACE: OXYGEN VA- CANCIES AND DOPANTS}

The properties of metal supported ultra-thin oxide films can be tuned without varying the film thickness via engineering the interface between the metal support and the oxide. This can be achieved by introducing impurity atoms into the metal oxide interface and by varying the species, which in turn has been predicted to modify the electronic characteristics of the system and can be seen as changes in the work function ${ }^{163-165}$. Also, interfacial vacancies can be induced in the supported oxide films. In these systems kinetic effects have been 

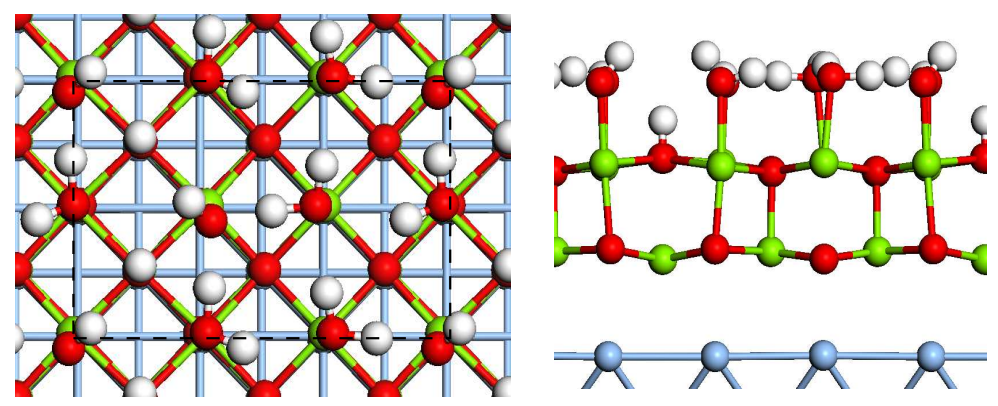

FIG. 18: The structural model of a $(3 \times 2)$ unit cell with a monolayer of water on $\mathrm{MgO} / \mathrm{Ag}(100)$ from top (left) and side (right). The surface cell is indicated as dashed line and the coloring code is as follows: Ag blue, $\mathrm{Mg}$ green, $\mathrm{O}$ red, and $\mathrm{H}$ white. Figure adapted with permissions from Ref. ${ }^{148}$.

identified to be important for reducing vacancies from the buried interface ${ }^{70}$. Figure 19 displays a structural representation of surface, central, and interfacial oxygen vacancies and the interfacial dopant. Recent experimental studies demonstrate how to incorporate $\mathrm{Mg}$ atoms to the $\mathrm{MgO}(100) / \mathrm{Ag}(100)$ interface and identify the mechanism behind the work function decrease $(\Delta \Phi)$ during $\mathrm{Mg}$ exposure ${ }^{166}$. The work function decrease can be, as large as $0.5 \mathrm{eV}$, attributed to to Fermi level pinning and band bending effects. For non-modified $\mathrm{MgO} / \mathrm{Ag}(100)$ systems measured $\Delta \Phi$ values ranging from 1.1 to $1.4 \mathrm{eV}^{61}$ and from 0.7 to 0.8 $\mathrm{eV}^{55}$ have been reported; they depend both on film preparation and the method to measure the work function. DFT studies unravel that oxygen vacancies decrease the work function but $\Delta \Phi$ depends sensitively on the charge state and the position of the vacancy ${ }^{52}$, and therefore a direct comparison to experimental value -which is an average value- is difficult.

According to DFT results, oxygen vacancies are preferentially located at the interface between the oxide and the support metal in $\mathrm{MgO}_{1-x} / \mathrm{Ag}$ and $\mathrm{MgO}_{1-x} /$ Mo systems ${ }^{42,47,167,168}$. The calculated formation energy of the vacancy on the surface of supported $\mathrm{MgO}$ is about 6 $\mathrm{eV}$ bur for an interfacial vacancy it is about $1 \mathrm{eV} \operatorname{less}^{42,48,167,168}$. Therefore in thermodynamic equilibrium, interfacial vacancies constitute the majority of vacancies in the oxide. In this case, an electron is transferred from the vacancy to an underlying metal, creating a singly charged $\mathrm{F}^{+}$center ${ }^{47,169}$. Calculations show that while regular $\mathrm{MgO}$ layers bind weakly to the Ag substrate, the buried vacancies increase the adhesion energy between the metal and the support ${ }^{42,47}$ as shown in Figure 20. The interaction between the regular $\mathrm{MgO}$ and Mo is stronger, owing to on one hand the larger covalency contribution of the oxygen anions and 

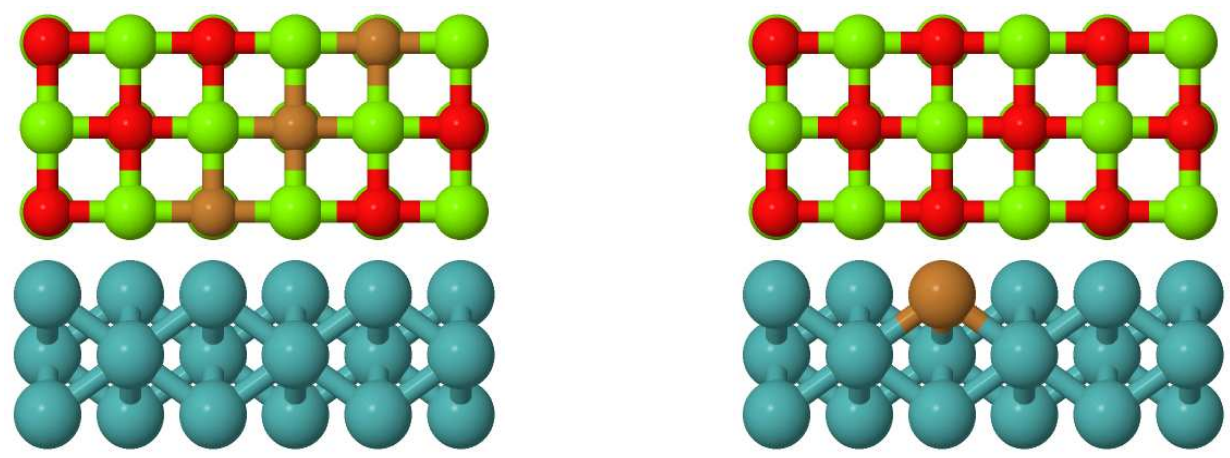

FIG. 19: The schematic representation of an interfacial, central, and surface oxygen vacancy (on the left) and the interfacial impurity atom (on the right) on a metal supported $\mathrm{MgO}(3 \mathrm{ML})$. Color code: red spheres stand for oxygen, blue is for Mo, green corresponds Mg and brown stands for an impurity or an oxygen vacancy.

Mo (Figure 20) and on the other hand to the increase of the interaction in the presence of an interfacial oxygen vacancy.

The charge state of the interfacial vacancy has been addressed employing different functionals, variable film thickness, and structure models ${ }^{47,52,169}$. The studies agree that the $\mathrm{F}^{+}$center is the most stable defect charge state for the interfacial vacancy. The analysis of structural variations of surrounding ions show a distinct structural response to the vacancy charge state. While negligible distortion is seen around $\mathrm{F}^{0}$, the nearest neighbour $\mathrm{Mg}$ ions are displaced outward by $7 \%$ around the $\mathrm{F}^{+}$center and by $13 \%$ around the $\mathrm{F}^{++}$ center $^{52}$. The metal-oxide interface can also contain spare $\mathrm{Mg}$ and $\mathrm{O}$ atoms. The calculated formation energies of interface impurities $\mathrm{Mg}_{i m p}$ and $\mathrm{O}_{\text {intr }}$ are only $0.45 \mathrm{eV}$ and $1.49 \mathrm{eV}$, respectively, highlighting the stabilization effect of the oxide and making them energetically more favourable interfacial defects than oxygen vacancies ${ }^{168}$. Moreover, the chemical composition and structure can also be modified by substituting an Ag atom at the topmost layer of the (100) surface with e.g., 3d TM atoms (Sc-Zn). Calculations render these structures thermodynamically favourable for all other atoms except Zn, demonstrating the fact that the $\mathrm{MgO}$ film stabilizes the interface dopants ${ }^{31}$. The overall amount of stabilization decreases when moving along in the $3 \mathrm{~d}$ series from Ti to $\mathrm{Zn}$.

Extensive DFT calculations were employed to investigate the role of an interfacial oxygen vacancy, $\mathrm{Mg}$ and $\mathrm{O}$ impurity atoms ${ }^{168}$, and the 3'rd row transition metal dopants ${ }^{31}$ on water 


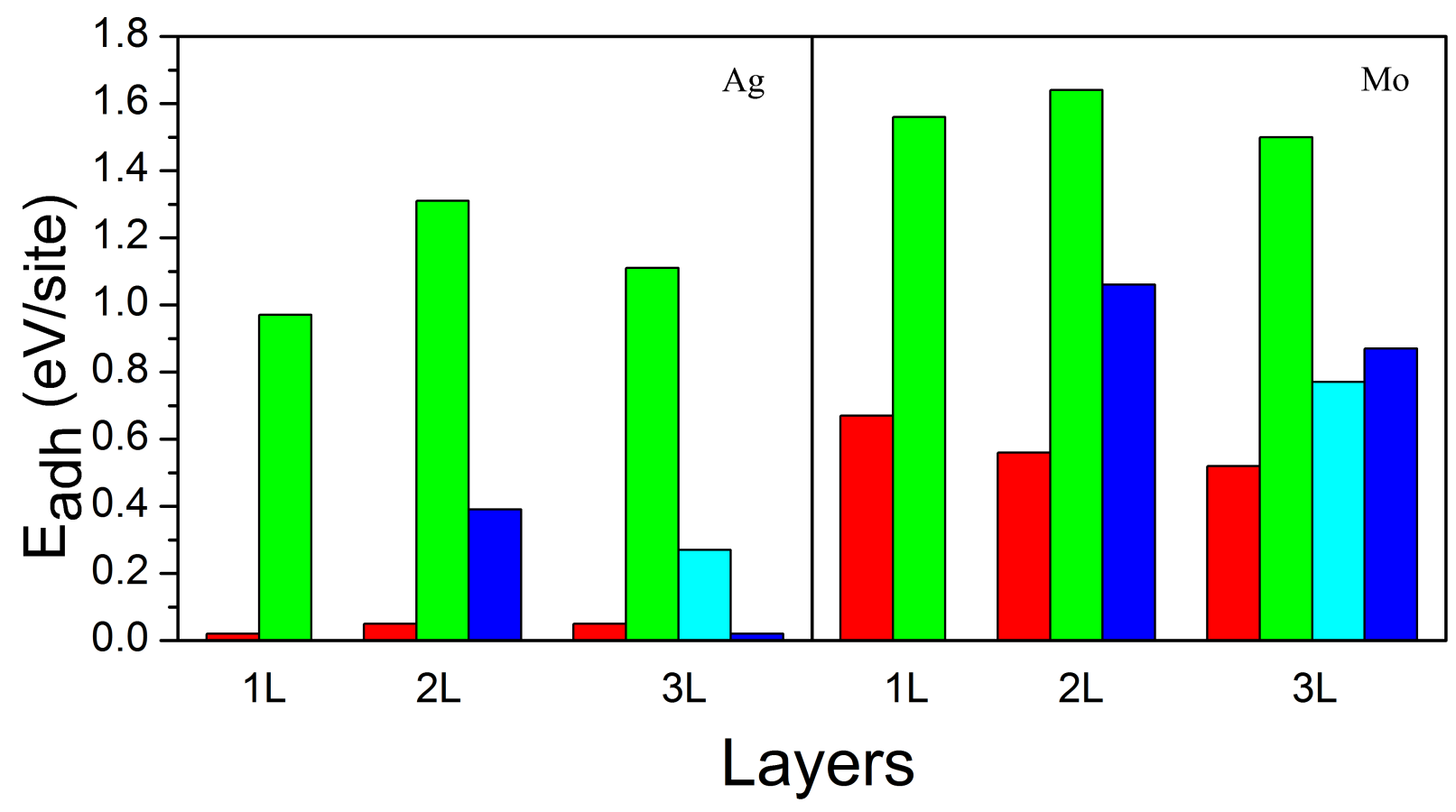

FIG. 20: Panel on the left (right) displays adhesion energy of the MgO film on the $\operatorname{Ag}(\mathrm{Mo})$ surface.Color coding: red non-defective film, green stands for an interfacial vacancy, cyan is for a vacancy in the central layer, and blue corresponds the vacancy at the surface. Adhesion energy is calculated as follows for a non-defective film $E_{a d h, u}=\left(E_{M g O / M}-E_{M g O}-E_{M}\right) / N$, where $N$ is an interfacial $\mathrm{MgO}$ unit and for a defective film as $E_{a d h, d}=E_{M g O_{1-x} / M}-E_{M g O_{1-x}}-E_{M}-N E_{a d h, u}$. The positive values indicate exothermic adsorption. Figure adapted with permissions from Ref. ${ }^{47}$.

adsorption and dissociation on $\mathrm{Ag}$-supported $\mathrm{MgO}$. In the latter two cases, an $\mathrm{Ag}$ atom in the topmost Ag layer is replaced with either an impurity atom or a dopant atom. The oxidemetal interface modifications change neither the reaction mechanism, nor the adsorption geometries of the water molecule, nor the dissociation products $\mathrm{OH}^{-}$and $\mathrm{H}^{+}$; they remain similar to those on the ideal $\mathrm{MgO}(100) / \mathrm{Ag}(100)$ surface discussed in chapter IV C. Instead, any kind of the interface defects introduce changes in energetics: smaller for the adsorption energy of water and larger for the transition and final states. The transition state strongly resembles the final state and actually describing it as a transition state is a controversial issue since the $\mathrm{H}-\mathrm{OH}$ bond is clearly already broken at this state. Comparison of the influence of an interfacial oxygen vacancy and $\mathrm{O} / \mathrm{Mg}$ impurity atoms shows that the vacancy introduces 
the largest stabilization effect: the barrier height drops $42 \%$ compared to the ideal $\mathrm{MgO} / \mathrm{Ag}$ system. Actually, the dissociation does not require external thermal energy atall to proceed, which means that even a small number of hidden vacancies is sufficient to enhance water dissociation substantially. Among the studied 3d TM dopants, the Ti atom is the most reactive one, and it stabilises the initial, transition and final states by $0.17,0.51$, and 0.48 $\mathrm{eV}$, respectively ${ }^{31}$. This corresponds to the reduction of barrier height by $44 \%$ compared to the ideal $\mathrm{MgO} / \mathrm{Ag}$ system. The variation of reaction and activation energies show non-linear, double-humped-type behaviour along the $3 \mathrm{~d}$ TM series, where the second most reactive dopant is iron. The detailed analysis of the doped systems shows that the impurity atom increases adhesion between $\mathrm{MgO}-\mathrm{Ag}$ as well as rumpling at the interface, but decreases the oxygen-impurity distances. The reactivity and adhesion are correlated in such a way that the stronger adhesion corresponds to higher reactivity. The variation of adhesion energy was shown to reflect the local hybridization between electronic states of the TM dopant and the oxide film and was rationalized with the help of ligand field theory. The extend of dstate splitting of the TM dopant originating from the ligand field of the oxide was shown to fully correlate with the variation of chemical reactivity ${ }^{31}$. The example of water dissociation highlights the fact that a chemical reaction can be controlled by interfacial defects even in the case where the activation of the reactant is not driven by charge transfer. However, the transition state resembles the final state, which consists of charged species.

The second system, for which the influence of interfacial modifications has been computationally studied, is $\mathrm{Au}$ adsorption on $\mathrm{Mo} / \mathrm{Ag}$ supported $\mathrm{MgO}$ films in the presence of buried oxygen vacancies. Figure 21 compares $\mathrm{Au}$ binding energies on metal-supported ideal and defected $\mathrm{MgO}$ films; positive energies refer to exothermic binding. On defected $\mathrm{MgO} / \mathrm{Ag}(\mathrm{Mo})$ surfaces $\mathrm{Au}$ adsorption strength depends on the position of the vacancy in the system: the strongest adsorption is found for a surface vacancy and the weakest for the interface vacancy ${ }^{47}$. While on $\mathrm{MgO} / \mathrm{Ag}(100) \mathrm{Au}$ binding is always stronger on a 2-3 $\mathrm{ML}$ thick film with a buried vacancy than on the ideal surface, this is not the case for Mo. The finding indicates that on $\mathrm{MgO}(100) / \mathrm{Ag}(100)$ gold would preferentially decorate sites with underlying buried vacancies. This offers a possible explanation why isolated Au atoms on $\mathrm{MgO} / \mathrm{Ag}(100)$ terraces have been identified as almost immobile species in STM images ${ }^{109}$. Similar preference is not seen for Mo due to more covalent Mo-oxide anions interaction, which locks the electron density in the interface. The extensive electronic structure analysis 


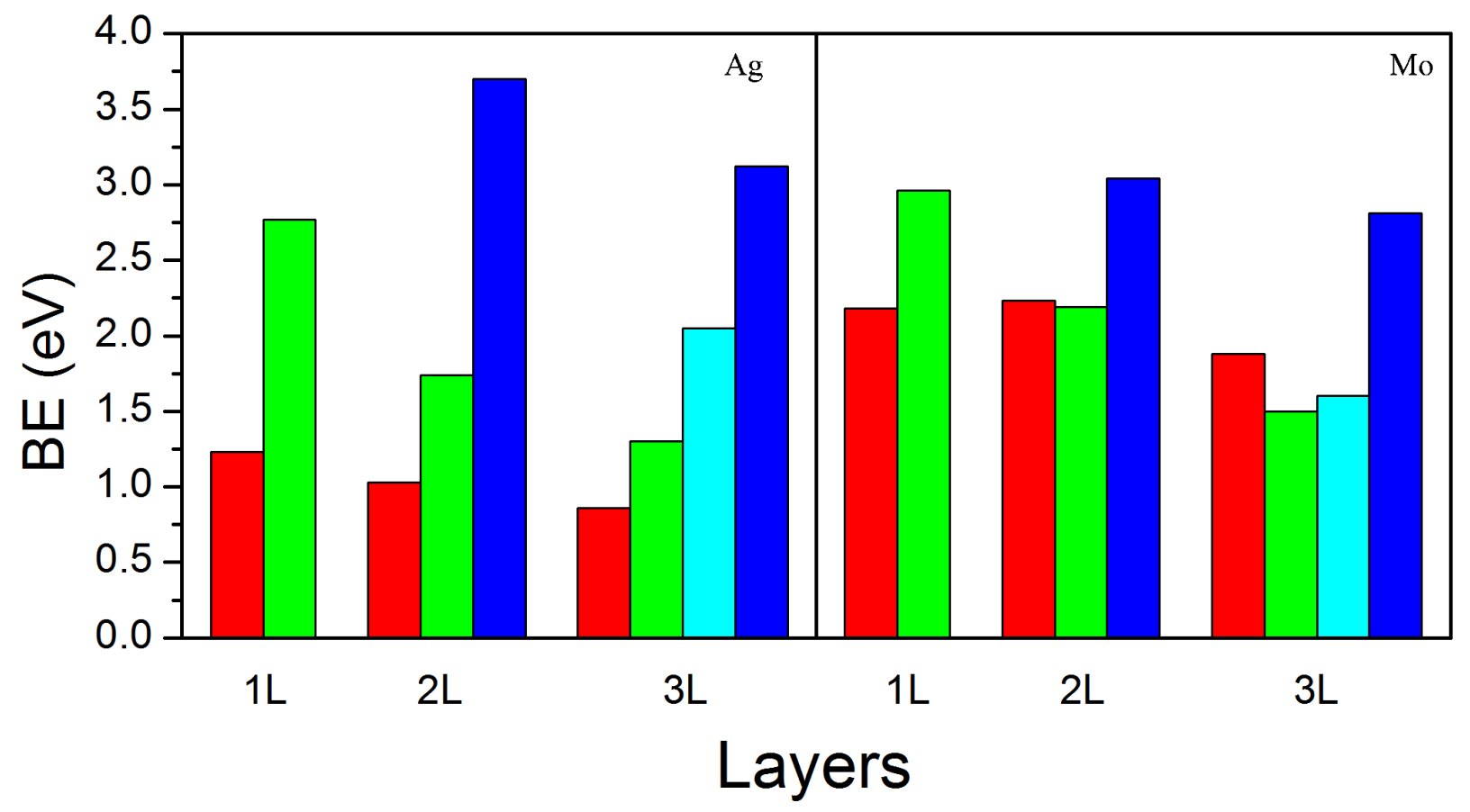

FIG. 21: The binding energy of $\mathrm{Au}$ to the $\mathrm{Ag}$ (Mo)-supported ultra-thin MgO films in panel $\mathrm{a}(\mathrm{b})$. Color coding: red a non-defective film, green an interfacial vacancy, cyan a central-layer vacancy, and blue a surface vacancy. Positive values indicate exothermic adsorption. Figure adapted with permissions from Ref. ${ }^{47}$.

including the plane average density analysis, the electronic localization function, and the Bader charge analysis, unravel that while one vacancy electron stays in a support metal atom under the vacancy, the second electron goes to a $\mathrm{Au}$ atom; thus the vacancy is more like a $\mathrm{F}^{++}$center. The simple thermodynamic analysis -with charge transfer and electrostatic terms- renders the formation of $\mathrm{F}^{++}$thermodynamically possible. According to the calculations, the electron transfer process is independent of the film thickness (at the range of 1-3 layers), and takes place similarly on both Ag and Mo support metals.

The fact that $\mathrm{Au}$ binding energy to the surface vacancy is always more exothermic than to the site with a buried vacancy, leads to the thermodynamic driving force to extract the vacancy from the metal-oxide interface to the surface. Despite thermodynamic preference, the vacancy extraction from the interface to the oxide surface can be hindered by kinetic factors, that is, too high diffusion barriers. The diffusion pathway of an oxygen vacancy consists of jumps between two nearest neighbour sites. In bulk MgO this has been reported 
to be highly demanding with activation energy of $\sim 4.25 \mathrm{eV}^{170}$. On two or three layers thick, unsupported $\mathrm{MgO}$ slabs the barrier is markedly reduced being still, however, $\sim 2.5$ $\mathrm{eV}^{167}$. On 2 or $3 \mathrm{ML}$ thick $\mathrm{Mo} / \mathrm{Ag}$ supported $\mathrm{MgO}$ films the barrier height ranges from 1.7 to $2.6 \mathrm{eV}$, where the highest barrier corresponds to vacancy diffusion to/from the central $\mathrm{MgO}$ layer. DFT calculations show that the presence of an Au adatom strongly reduces diffusion barriers, which means enhanced diffusion by a factor of two at room temperature. Altogether, the calculations suggest that the extraction of oxygen vacancies in ultra-thin $\mathrm{MgO}$ films is both thermodynamically and kinetically feasible. To further rationalize the obtained results, the existence of a Brønstead-Evans-Polanyi (BEP) relationship, introduced by Nørskov et al. ${ }^{136}$, was tested. The BEP relationship relates an activation energy for a given reaction or an elementary step to its corresponding reaction energy in a linear manner, and provides a way to identify thermodynamic-kinetic dependencies. Numerous DFT studies show how the results fall on the BEP line for different reactions on metal surfaces ${ }^{136,171-174}$ and nanoparticles ${ }^{175}$, and for diffusion processes in oxide systems ${ }^{170,176}$. In the present case, plotting the activation energy for oxygen vacancy diffusion as a function of the energy difference between two vacancy positions, two BEP-type of relationships appear (Figure 22) and the direction of the diffusion is from the support toward the adsorbate. The observed two lines arise from high barrier values corresponding to vacancy diffusion in $\mathrm{MgO}_{1-x} / \mathrm{Ag}$ and $\mathrm{MgO}_{1-x} / \mathrm{Mo}$, and from lower values for $\mathrm{Au} / \mathrm{MgO}_{1-x} / \mathrm{Ag}$ and $\mathrm{Au} / \mathrm{MgO}_{1-x} / \mathrm{Mo}$ systems. The reasons behind two BEP lines can be understood by analyzing the transition states for vacancy diffusion. The ELF (electron localization function) and Bader analysis for diffusion pathways give a constant, 2e charge for moving oxygen, while the charge left into the vacancy depends on the system. It is one unit charge for the $\mathrm{F}^{+}$-like defect in $\mathrm{MgO} / \mathrm{Ag}$ and $\mathrm{MgO} / \mathrm{Mo}$ systems and zero for $\mathrm{F}^{++}$in $\mathrm{Au} / \mathrm{MgO}_{1-x} / \mathrm{Ag}$ and $\mathrm{Au} / \mathrm{MgO}_{1-x} / \mathrm{Mo}$. The activation energy, that is the energy difference between the initial and transitions state, is solely determined by electrostatic terms, which on the other hand depend on the vacancy position and the distances between charged species. Thus, the appearance of the two BEP lines implies two differently charged species. 


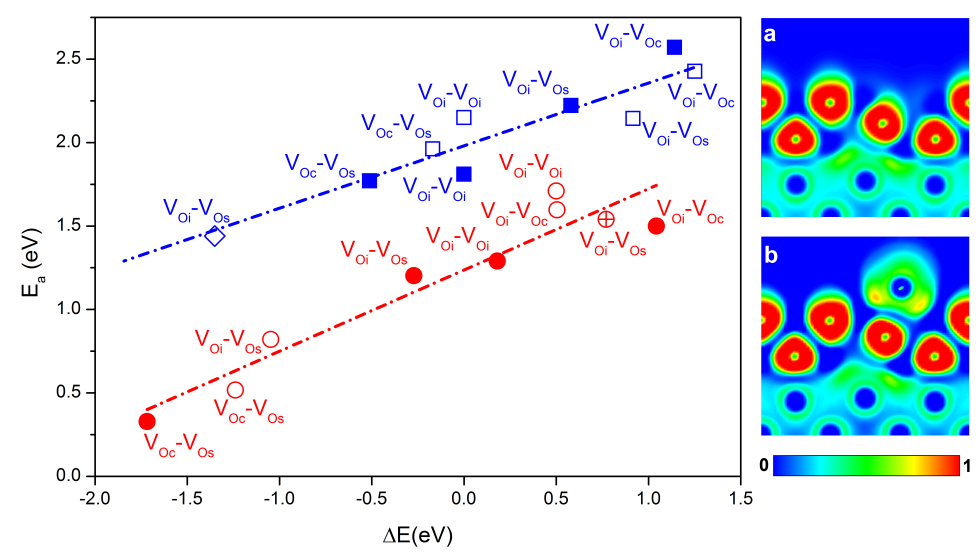

FIG. 22: Left: a Brønsted-Evans-Polanyi plot. Energy barrier for diffusion, $E_{a}$, as a function of the energy difference between two vacancy positions, $\Delta E$. Blue (red) symbols correspond to $(\mathrm{Au}) / \mathrm{MgO} / \mathrm{M}$, and open (filled) symbols stand for $\mathrm{Ag}$ (Mo). The thickness of the $\mathrm{MgO}$ film varies from one to three monolayers. The crossed circles refer to vertical diffusion far away from Au in the $\mathrm{Au} / \mathrm{MgO}(2 \mathrm{ML}) / \mathrm{Ag}$ system. $\mathrm{V}_{o_{i}}$ stands for an interfacial vacancy, $\mathrm{V}_{o_{c}}$ corresponds a vacancy in the center of the slab, and $V_{o_{s}}$ is a vacancy at the surface. Right: panels a and b display ELF (electron localization function) plots for the transition states with and without $\mathrm{Au}$ on the $\mathrm{MgO}(2 \mathrm{ML}) / \mathrm{Ag}$ substrate, respectively. Figure adapted with permissions from ref. ${ }^{47}$.

\section{DOPING}

Metal-supported simple oxide systems can be understood as an extreme case of doped oxides having high concentration of extra electrons detectable in STM measurements. In principle, a dopant has a similar effect as it can provide extra electrons into the oxide. However, in doped oxides the concentration of spare electrons is lower than in supported films and they are also more localized. Furthermore, the distribution of these electrons might be uneven. Altogether, this means that understanding the properties of doped oxides is challenging but the knowledge gained from metal-supported thin-film systems give insight on the characteristics of doped oxides. Calculations help to determine the composition and morphology of oxide material since those are highly challenging to experimentally resolve under working conditions. Simple ionic oxides are auspicious materials to probe the modifications introduced by dopants to characteristics of a host oxide. Possible dopant atoms 
can be divided into two groups: guest cations capable of providing less electrons than the host cations and those that can provide more. Note, that one can not neglect the role of the host oxide either: e.g., $\mathrm{CaO}$ is more reactive than $\mathrm{MgO}$ because of its larger lattice parameter and the smaller Madelung potential. Moreover, its band gap is smaller and ions more polarizable. According to DFT calculations, transition metal dopants Mo and $\mathrm{Cr}$ adopt a formal $2+$ charge state in an ideal and neutral $\mathrm{MgO}$ and $\mathrm{CaO}$ slabs, reproducing the nature of a host cation $^{38}$. STM experiments on the other hand reveal, that it is possible to induce charging and decharging of a Mo dopant sitting at the vicinity of the $\mathrm{CaO}$ surface with a STM tip, hence making $\mathrm{Mo}^{3+}$ cations $^{177}$. The presence of high valent dopants can also introduce structural modifications to an oxide matrix, as they are known to increase the number of cation vacancies. This is clearly seen in DFT calculations, where the vacancy formation energy drops from $8 \mathrm{eV}$ to 1 and $1.7 \mathrm{eV}$ for $\mathrm{MgO}_{\mathrm{Cr}}$ and $\mathrm{CaO}_{\mathrm{Mo}}$, respectively, and leads to a loss of another electron to a host oxide ${ }^{38}$. This, naturally, has implications to other possible electron transfer processes. Topographic STM images unambiguously show, that high valent TM substitute doping of $\mathrm{CaO}$ leads to the formation of $2 \mathrm{D} \mathrm{Au}$ islands ${ }^{37}$, similar to a metal supported ultra-thin oxide film. DFT calculations highlight the enhanced binding of an $\mathrm{Au}$ atom on Mo-doped $\mathrm{CaO}$ with adsorption energy nearly three times as large as computed on the ideal $\mathrm{CaO}$ surface, despite the absence of a direct contact between the $\mathrm{Au}$ and dopant atoms ${ }^{37}$. On pristine $\mathrm{CaO}$, the $\mathrm{Au}$ is preferentially located on the oxygen ion with adsorption energy of $-1.35 \mathrm{eV}$, while the adsorption energy as large as -3.90 (-3.50) $\mathrm{eV}$ is found when the Mo dopant is in the second (third) layer directly below the adsorbate. The enhanced bonding was ascribed to charge transfer from Mo to Au, leading to strong electrostatic interactions and concomitant lattice relaxations near the dopant ${ }^{37}$. Additional DFT studies were performed to understand the thermodynamic factors determining $\mathrm{Au}$ adsorption energy on high-valence doped $\mathrm{CaO}^{40}$.

To rationalize the variation of adsorption strength as a function of a Au-dopant distance, we employed the concept of acid-base interaction, where a high-valence dopant Mo acts as a base donating charge and $\mathrm{Au}$ is the acid accepting charge ${ }^{40}$. In these calculations, the 10 ML:s layer-thick slab was used and the dopant was placed into the 3'rd layer or deeper leaving at least $2 \mathrm{ML}$ of ideal $\mathrm{CaO}$ for a protective capping as in experiments ${ }^{37}$. While DFT studies in both references show that Au favours adsorption on an oxygen anion being neutral, Andersin et al. reported that, according the Bader charge analysis, an Au atom 


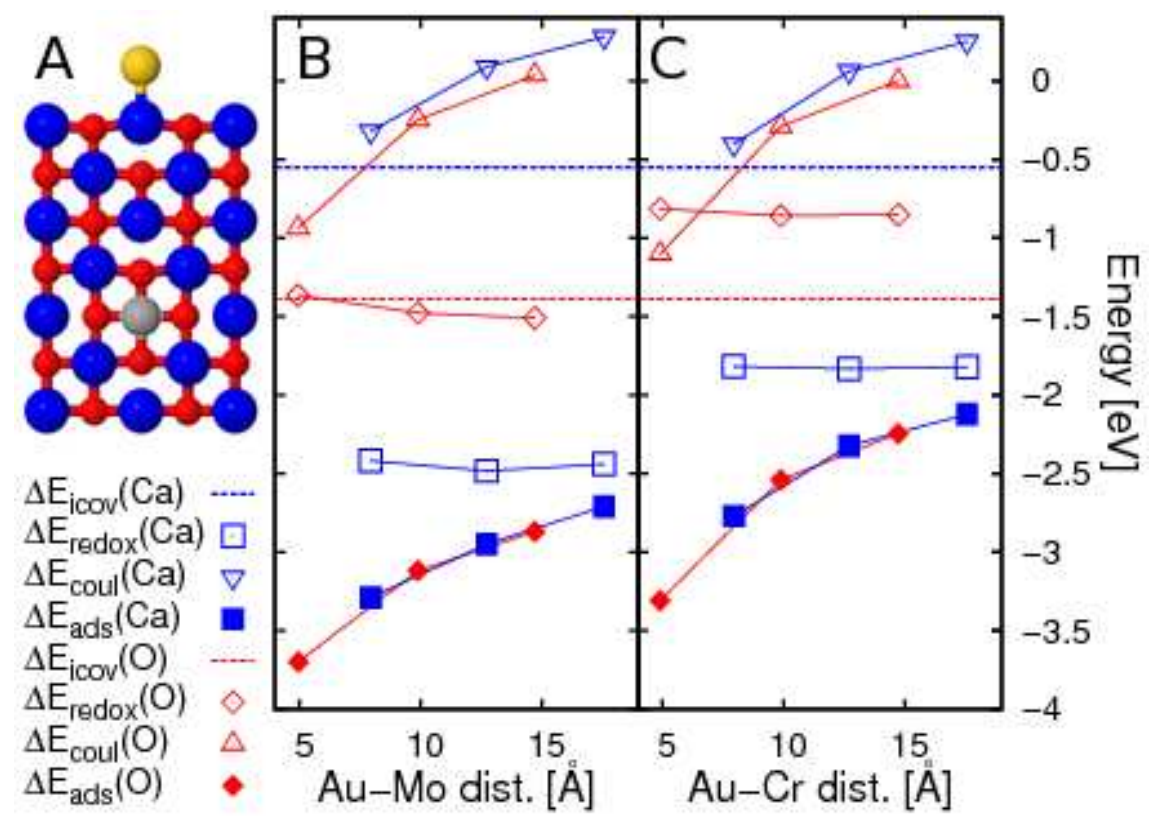

FIG. 23: A) displays the side view of the 7 topmost layers of $10 \mathrm{ML}$ layer thick computational unit cell, which was used to model Au adsorption on TM-doped CaO. The color coding as as follows blue stands for Ca atoms, red is for oxygens, while yellow and gray are for a Au atom and a dopant, respectively. Panels B) and C) The adsorption energy of a Au atom as a function of dopant depth together with the different energy contributions. Figure adapted with permissions from Ref. ${ }^{40}$.

becomes negatively charged on a Ca-site over an pristine $\mathrm{CaO}(100)$. Moreover, the PDOS analysis reveals that both 6 s spin levels become occupied together with vanishing magnetic moment, but the adsorption energy of $\mathrm{Au}$ is only $-0.55 \mathrm{eV}$, which is $\sim 0.8 \mathrm{eV}$ less exothermic than found for $\mathrm{Au}$ on the O-top site. These results indicate that charging of Au cannot alone be responsible for the increase in adsorption energy upon doping the oxide. Au adsorption was further analyzed employing a Born-Haber cycle, where the Au-CaMoO interaction is broken down to the three contributions shown in Fig. 24.

The first contribution is a direct iono-covalent interaction between the $\mathrm{Au}$ and the surface ion on the pristine $\mathrm{CaO}$, which involves direct orbital overlapping and charging on the top of Ca-atom. The energy change related to this term is called $\Delta E_{i c o v}$. The Au-dopant interaction is divided into two terms: (a) the redox process between the $\mathrm{Au}$ and the dopant $\left(\Delta E_{\text {redox }}\right)$ containing an electron transfer from the overvalent dopant to the Au atom and (b) 


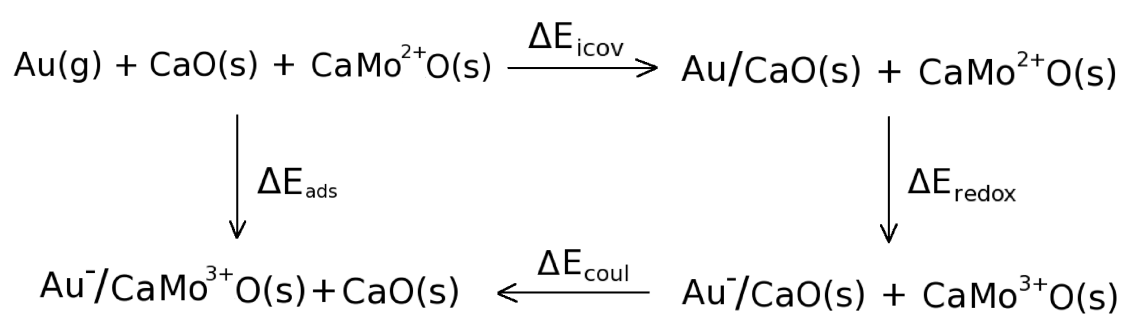

FIG. 24: The Born Haber cycle for Au adsorption on Mo-doped CaO. Au adhesion on the substrate (=adsorption energy $\left.\Delta E_{a d s}\right)$ is divided into three contributions: $\Delta E_{i c o v}$ stands for the iono-covalent bonding of a $\mathrm{Au}$ atom onto the pristine $\mathrm{CaO}$ surface, $\Delta E_{\text {redox }}$ is the redox interaction between $\mathrm{Au}$ and Mo leading to charge species infinitely far apart, and $\Delta E_{\text {coul }}$ corresponds the screened electrostatic interaction between $\mathrm{Au}$ and Mo. Figure adapted with permissions from Ref. ${ }^{40}$.

the electrostatic interaction between the $\mathrm{Au}^{-1}$ and a positively charged dopant $\Delta E_{\text {coul }}$. Figure $23 \mathrm{~B}$ ) and C) display adsorption energies together with above-described site-dependent contributions on both Mo- and Cr-doped surfaces as a function of the Au-dopant distance. Clearly, adsorption becomes weaker with the increasing distance between the Au and the dopant. The term $\Delta E_{\text {coul }}$ demonstrates approximately $1 / \mathrm{r}$ behaviour, where $\mathrm{r}$ is the $\mathrm{Au}$ dopant distance proving further support that energy change $\Delta E_{\text {coul }}$ describes electrostatic interaction. Owing to strong screening by the polarized oxide, the Coulomb interaction is significant only at very short distances. In experiments the capping region is typically a few undoped $\mathrm{CaO}$ layers $^{37}$. If the $\mathrm{Mo}$ is in the third layer the Au-Mo distance is approximately $8 \AA$ which corresponds the contribution of only $\sim-0.5 \mathrm{eV}$ while the adsorption energy is -3.0 $\mathrm{eV}$, thus the electrostatic contribution to Au adsorption is minor on this oxide. The adsorption energy is dominated by the other two terms. The iono-covalent term is independent of a dopant as it describes the interaction between $\mathrm{Au}$ and ions in the oxide matrix but depends on the adsorption site. The $\Delta E_{\text {redox }}$ term represents energy gain related to the electron exchange between $\mathrm{Au}$ and the dopant and corresponds to the dominant energy contribution in adsorption energy. It can be divided into two cases. Since the Au gains charge already upon the adsorption on a Ca-site of pristine $\mathrm{CaO}$, the redox energy change is assigned to the system stabilization due to Mo oxidation as the more cationic dopant binds stronger 
to anionic $\mathrm{O}^{2-}$. This is manifested as decreased distance between the dopant and the surrounding oxygens. Since this is a local effect, it does not depend on the depth of the dopant as seen in Figure 23. On an O-top site $\mathrm{Au}$ is initially neutral and thus the redox process includes charge transfer and stabilization due to structural relaxations around the dopant; again, the redox energy saturates quickly to a constant value. The redox energies differ by 1 $\mathrm{eV}$ such that the less exothermic value is found for the O-top site. This is due to Coulomb repulsion between negatively charged $\mathrm{Au}$ and negatively charged $\mathrm{O}$, manifested also in a Au-O bond length, which increases $~ 0.6 \AA$ upon Au charging. Figures $23 \mathrm{~B}$ ) and $\mathrm{C}$ ) show that the above discussion is independent of the dopant as both Mo and Cr display similar behaviour. The comparison of $\mathrm{Au}$ adsorption energies on $\mathrm{Mo}$ and $\mathrm{Cr}$ doped $\mathrm{CaO}$ surfaces show smaller stabilization on the Cr-doped than on the Mo-doped surface. The difference is ascribed to smaller redox energy on $\mathrm{CaO}_{\mathrm{Cr}}$. While according to the Bader charges and magnetic moments $\mathrm{Cr}$ donates altogether 3 electrons ( 2 to the oxide and 1 to the $\mathrm{Au}$ ) and geometric differences are minor, the smaller redox energy originates from higher 3rd ionization energy. Actually, on the ideal $\mathrm{CaO}$ surface the redox energy correlates with ionization energies of different high-valent transition metal dopants near Mo and $\mathrm{Cr}$ in the periodic table as illustrated in Figure 25. The higher the 3rd ionization energy, the less exothermic is the redox energy, which indicates that the cost of electron removal from the dopant increases with increasing ionization energy. In real systems, the ideal correlation shown in Figure 25 is not achievable due to the presence electron traps, such as cation vacancies, that compete with adsorbates for electrons. In addition, the host oxide can affect electron transfer unfavourably via crystal field splitting, which stabilizes the donor states too much and hampers the electron transfer ${ }^{178}$. Calculations show that on a $\mathrm{Mo}^{3+}-\mathrm{MgO}$ surface with one cation vacancy the adsorption is only $0.2 \mathrm{eV}$ more exothermic than on pristine $\mathrm{MgO}$, whereas $0.75 \mathrm{eV}$ energy difference is seen between $\mathrm{Mo}^{3+}{ }_{-} \mathrm{CaO}$ and $\mathrm{CaO}$ systems ${ }^{72}$. Molecular oxygen is also a strong acid and thus it is not surprising that enhanced binding on Mo-doped $\mathrm{CaO}$ is demonstrated in STM experiments, which is further supported by DFT calculations featuring $0.8 \mathrm{eV}$ increase in $\mathrm{O}_{2}$ adsorption energy and the formation of a superoxo species ${ }^{179}$. The Born-Haber cycle analysis for $\mathrm{O}_{2}$ renders the redox energy as a main contribution in adsorption energy on Mo-doped $\mathrm{CaO}^{180}$. While DFT calculations have so far mainly focused on high-valence doped $\mathrm{MgO}$ and $\mathrm{CaO}$ systems, understanding undervalent doped oxides is also essential. Particularly important is Li-doped $\mathrm{MgO}$, which is an active catalyst for ox- 
idative coupling of methane ${ }^{34}$. The reaction has not been thoroughly understood yet and for example, an active site for a homolytic $\mathrm{CH}_{3}-\mathrm{H}$ bond breaking step has remained elusive. In the case of undervalent doped systems, the Born-Haber cycle analysis can also be applied to unravel the relevance of different energy terms for e.g., Au adsorption, which has been experimentally studied ${ }^{39}$. STM experiments show that depending on Li concentration on Mo-doped $\mathrm{CaO}$ the $\mathrm{Au}$ growth mode is either 2D or 3D. On bare and Li-doped $\mathrm{CaO}, \mathrm{Au}$ aggregates favour 3D structures whereas on Mo-doped 2D structures are preferred ${ }^{39}$. The observed changes can be explained with electron transfer from a dopant to a Au particle, which takes place on Mo-doped $\mathrm{CaO}$ but which is not possible on bare or Li-doped $\mathrm{CaO}$. Adding Li to Mo-doped $\mathrm{CaO}$ will neutralize the impact of a Mo dopant and prevent the charge transfer from Mo to Au.

The combined STM-DFT study illustrates that charge transfer strongly depends on the nature of a dopant and an oxide: while $\mathrm{Au}$ becomes negatively charged on Mo-doped $\mathrm{CaO}$ it stays neutral on Cr-doped $\mathrm{MgO}$. This is manifested in the growth mode of Au, which 2D for charged species and 3D for neutral ones ${ }^{38}$. Addition of Li dopants to Mo-doped CaO leads to decrease in fraction of 2D $\mathrm{Au}$ islands with respect to 3D aggregates indicating that electron transfer happens from Mo to Li atoms and not to adsorbed $\mathrm{Au}^{39}$. The shape of an $\mathrm{Au}$ cluster has been computationally addressed on $\mathrm{Al}$-doped $\mathrm{MgO}$, where planar and tetrahedral $\mathrm{Au}_{20}$ configurations were compared ${ }^{181}$. Calculations demonstrate that with increasing dopant concentration the binding energy of a cluster increases. The binding energy depends on the position of the dopant being more exothermic when the dopant is in the second layer of the oxide and under the cluster. In the all studied dopant concentrations a planar geometry is more favourable than the tetrahedral one and the energy difference between these two geometries depends linearly on dopant concentration displaying a larger difference at higher concentrations. The electronic structure analysis shows substantial charge transfer from the substrate to the cluster, which also increases with increasing dopant concentration.

The comparison of $\mathrm{Au}$ adsorption energies on doped $\mathrm{MgO}$ and $\mathrm{CaO}$ surfaces calculated with different functionals (PBE, PBE0, HSE0 and PBE+U) shows that absolute values of adsorption energies are functional dependent but charge transfer trends are similar in all cases. On $\mathrm{Cr}^{2+}-\mathrm{MgO}$ and $\mathrm{Mo}^{2+}{ }_{-} \mathrm{CaO} \mathrm{Au}$ becomes negatively charged, whereas on $\mathrm{Cr}^{3+}{ }_{-}$ $\mathrm{MgO}$ it stays neutral ${ }^{72}$. To separate the role of a guest cation from that of the oxide, Au adsorption on two selected surfaces namely $\mathrm{Mo}^{3+}-\mathrm{MgO}$ and $\mathrm{Cr}^{3+}{ }_{-} \mathrm{CaO}$ were calculated. The 


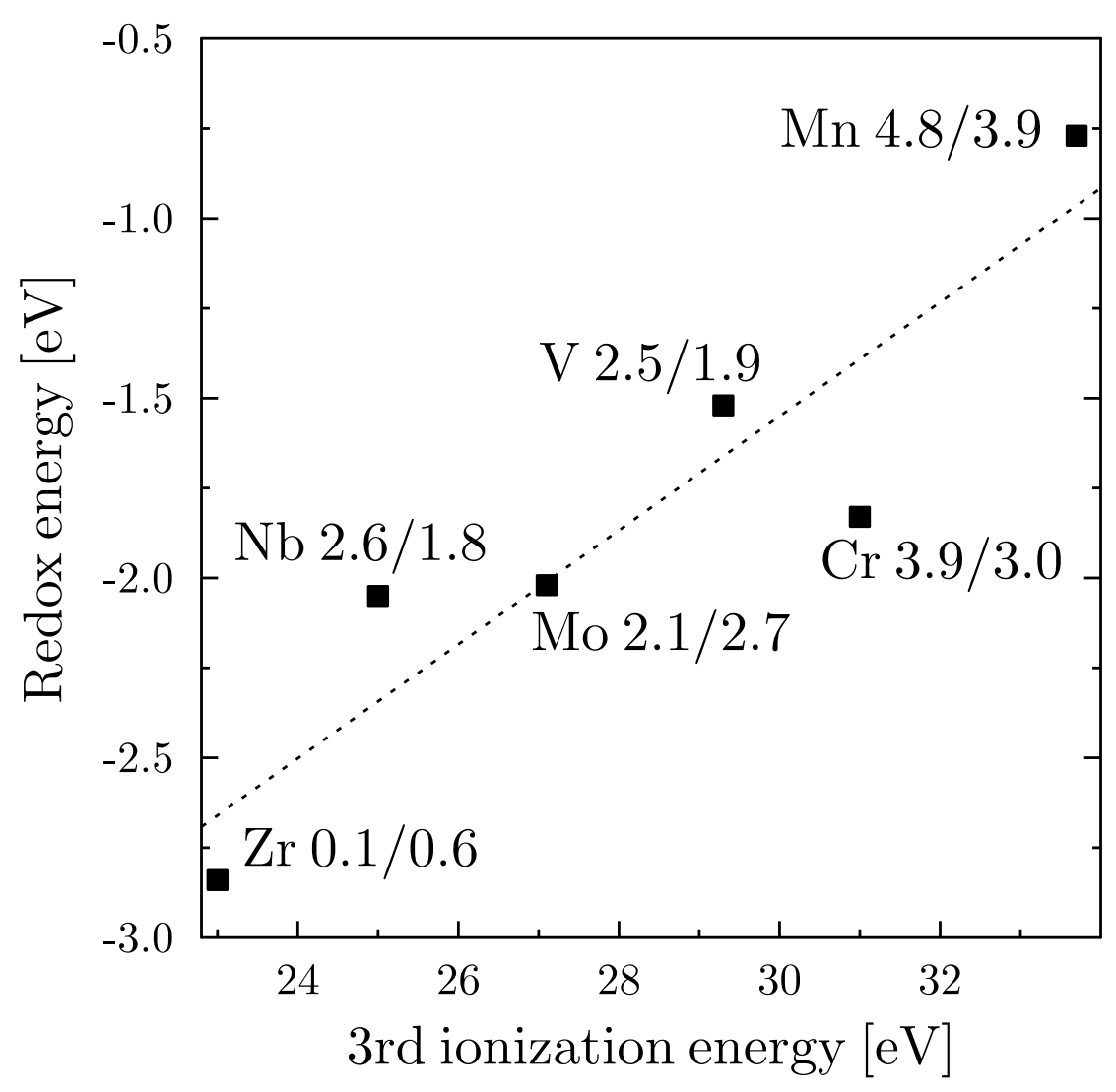

FIG. 25: The calculated redox energy in the TM-doped $\mathrm{CaO}(100)$ surface as a function of the measured $3^{\text {rd }}$ ionization energy of the different dopants. The notations $\mu(2+)$ and $\mu(3+)$, given after the name of the element, refer to the magnetic moments of double and triple cations of the dopants, respectively. Figure adapted with permissions from Ref. ${ }^{40}$

results show that even in $\mathrm{CaO} \mathrm{Cr}^{3+}$ is unable to donate an electron to $\mathrm{Au}$ regardless of smaller crystal field splitting leading to favourable position of donor states. For comparison, $\mathrm{Au}$ becomes negatively charged on $\mathrm{Mo}^{3+}{ }_{-} \mathrm{MgO}$ as well as on $\mathrm{Mo}^{3+}{ }_{-} \mathrm{CaO}$. All these together further support the suggestion ${ }^{40}$ that ionization energy, which stands for the cost of oxidation of the TM ion, determines the dopant's efficiency to transfer an electron to an acceptor in the system. 


\section{CONCLUSIONS}

Over the past years significant advances have been made in the preparation and experimental studies of tailored oxides as well as in the modeling their properties. These modified oxides have emerged as materials with unique properties, not encountered in their bulk counterparts. The selected examples discussed highlight the potential of simple oxides. They can be made chemically active and can operate as active catalysts or act as supports for catalyst particles. Two different schemes to modify the properties of simple oxides are addressed, namely growing oxides as ultra-thin films over metal supports and doping them with metal impurities. The discussion mainly focuses on theoretical studies for metal supported $\mathrm{MgO}$ films and in doped oxides on $\mathrm{CaO}$ and $\mathrm{MgO}$ systems, while other oxides are occasionally brought in attention for comparison. All the reviewed systems underline the potential and importance of density functional theory calculations and their role to unravel experimentally seen features but even more importantly to predict material properties, especially activity. Despite the fact that computational methods have their limitations, for certain cases, such as buried vacancies, they are almost irreplaceable in addressing the characteristics and impact of hidden defects on adsorption.

The key adsorbates elaborated include electronegative species such as Au atoms and clusters, molecular oxygen, and $\mathrm{NO}_{2}$. The adsorption and dissociation of molecular oxygen is considered both on a bare metal-supported ultra-thin $\mathrm{MgO}$ and on an Au cluster over Ag-supported $\mathrm{MgO}$. Interestingly, the calculations predict that the presence of the support metal facilitates simultaneous activation of several oxygen molecules. The adsorption and dissociation of non-electronegative water on ideal $\mathrm{MgO} / \mathrm{Ag}$ is discussed both at low and high water coverages. In the latter case, the formation of strong hydrogen-hydrogen bonds leads to dissociation of a fraction of adsorbed water molecules. In addition, the modifications at the oxide-support interface are addressed in the two cases; on $\mathrm{Au}$ adsorption on a $\mathrm{MgO} / \mathrm{Ag}(\mathrm{Mo})$ surface with an interfacial oxygen vacancy and water adsorption on $\mathrm{MgO} / \mathrm{Ag}$ with an interfacial dopant. The role of thin-film systems is not limited to model systems but they have a variety of applications including catalysis, solid oxide fuel cells, gas sensors, corrosion protection, and biocompatible materials, just to mention a few. The spectrum and composition of oxide materials developed for different application is broad; some of these oxides are simple while there is an increasing number of fairly complex oxides. In the 
future, we need to compute the electronic structure of these complex oxides reliably, which potentially have a variety of different defects, and simultaneously get a description for weak van der Waals interactions. In particular, calculation of line defects increases the system size, which in turn poses challenges for calculations.

On doped $\mathrm{CaO}$ and $\mathrm{MgO}$ oxides, the adsorption of an $\mathrm{Au}$ atom and an $\mathrm{O}_{2}$ molecule is discussed. While the film thickness is an adjustable parameter in metal-supported thin film systems, in doped oxides the corresponding parameter is the dopant concentration. Moreover, unlike the metal support, dopants can be mobile and they are also predicted to introduce vacancies into oxide. However, calculations indicate that the impact of over-valent dopants on electronegative adsorbates such as $\mathrm{Au}$ atoms and $\mathrm{O}_{2}$ molecules, is similar to the metal support. Thus adsorption is enhanced, the species become negatively charged, and on both supports Au clusters favour planar geometries. With the help of the Born-Haber cycle the enhanced binding is attributed to energy gain owing to simultaneous electron transfer and lattice relaxations. In an idealized system, the ionization energy of the TM dopant explains the variation of $\mathrm{Au}$ adsorption energy from one dopant to the other but in reality dopant induced vacancies have an influence on electron transfer processes and modify this ideal rule. While in metal-supported ultra-thin oxide films systems one can gain better control over structural and electronic characteristics, the atomic structure of doped oxides displays larger plasticity and uncertainty. The model system studies of these materials make the basis to identify the key factors determining the function of the material, which paves the way for examination of less-defined oxides.

Doped oxides also have a variety of applications ranging from catalysis and photovoltaic to chemical sensing, solid oxide fuel cells, and coatings. In many cases the doped oxide is in the thin-film arrangement. The presence of dopants typically affects a number of point defects, such as oxygen vacancies, which then strongly impact on surface chemistry of an oxide. From the theoretical point of view, the concentration and distribution of dopants and vacancies substantially enhance the computational burden and add complexity. Although possible, special care must be taken when the Born-Haber cycle is applied to rationalize chemical reactions on complex, doped oxide surfaces. This is because sufficiently accurate description of the electronic structure is needed and because the impact of vacancies must be included to the analysis. Furthermore, the identification of an active site is usually more demanding than on metal surfaces and nanoparticles owing to a larger number of different 
factors such as dopant and vacancy concentration, which might influence the nature and characteristics of the active site. One more thing that makes DFT calculations particularly challenging, is the lack of experimental methods, that could reveal the morphology and composition of oxides under reaction conditions. Therefore, there is an urgent need to develop computational methods and concepts to simulate oxide characteristics and establish their key descriptors to advance in one of the most challenging areas of Material Science.

\section{ACKNOWLEDGEMENTS}

I would like to thank my colleagues, collaborators and former and present PhD students and post docs including in particular Prof. H. Häkkinen, Prof. A. Hellman, Prof. H. Grönbeck, Prof. H.J. Freund, Dr. P. Frondelius, Dr J. Andersin, Dr L. Bellarosa and MSc J. Nevalaita. Dr A. Clayborne and Dr V. Apaja are acknowledged for carefully reading the manuscript. The computing resources provided by CSC -IT Center for Science (Espoo) and Nanoscience Center in the University of Jyväskylä, and financial support from the Academy of Finland are greatly acknowledged.

1 V. Heinrich, P. Cox, The surface science of metal oxides, Cambridge university press, 1994.

2 D. Woodruff (Ed.), The chemical physcis of solid surfaces, volume 9, oxide surfaces, Elsevier, 2001.

3 M. Ganduglia-Pirovano, A. Hofman, J. Sauer, Surf. Sci. Rep. 62 (2007) 219.

4 H. J. Freund, H. Kuhlenbeck, V. Staemmler, Rep. Prog. Phys. 59 (1996) 283-347.

5 H. J. Freund and G. Pacchioni, Chem. Soc. Rev. 37 (2008) 2224-2242.

6 N. Nilius, Surf. Sci. Rep. 64 (2009) 595-659.

7 L. Giordano, G. Pacchioni, Acc. Chem. Res. 44 (2011) 1244.

8 G. Pacchioni, H. Freund, Chem. Rev. 113 (2013) 4035.

9 S. Schintke, S. Messerli, M. Pivetta, F. Patthey, L. Liboulle, M. Stengel, A. D. Vita, W. Schneider, Phys. Rev. Lett. 87 (2001) 276801.

10 C. Lamberi, E. Groppo, C. Prestipino, S. Casassa, A. M. Ferrari, C. Pisani, C. Giovanardi, P. Luches, S. Valeri, F. Boscherini, Phys. Rev. Lett 91 (2003) 046101. 
11 X. Shao, P. Myrach, N. Nilius, H.J. Freund, J. Phys. Chem. C 115 (2012) 8784.

12 G. Kresse, M. Schmid, E. Napetsching, M. Shishkin, L. Köhler, P. Varga, Science 308 (2005) 1440.

13 A. Hellman, H. Grönbeck, Phys. Rev. Lett. 100 (2008) 116801.

14 Y. Sun, Z. Qin, M. Lewandowski, E. Carrasco, M. Sterrer, S. Shaikhutdinov, H. Freund, J. Catal. 266 (2009) 359.

15 Y. N. Sun, L. Giordano, J. Goniakowski, M. Lewandowski, Z. H. Qin, C. Noguera, S. Shaikhutdinow, G. Pacchioni, H. J. Freund, Angew. Chem. Int. Ed 49 (2010) 4418.

16 F. Ringleb, Y. Fujimori, H. F. Wang, H. Ariga, E. Carrasco, M. Sterrer, H. Freund, L. Giordano, G. Pacchioni, J. Goniakowski, J. Phys. Chem. C 115 (2011) 19328.

17 Y. D. Kim and T. Wei and D. W. Goodman, Langmuir 19 (2003) 354.

18 S. Surnev, A. Fortunelli, F. P. Netzer, Chem. Rev. 113 (2013) 4314.

19 P. Frondelius, H. Häkkinen, K. Honkala, Angew. Chem. Int. 49 (2010) 7913.

20 A. Hellman, S. Klacar, H. Grönbeck, J. Am. Chem. Soc. 131 (2009) 16636.

21 Y. Lei, Y. M. Lewandowski, Y. Fujimori, Y. Martynova, I. M. N. Groot, R. J. Meyer, L. Giordano, G. Pacchioni, J. Goniakowski, C. Noguera, S. Shaikhutdinov, H.J. Freund, ChemCatChem 3 (2011) 671-674.

22 H. Y. T. Chen, L. Giordano, G. Pacchioni, J. Phys. Chem. C 117 (2013) 10623.

23 H.J. Shin, J. Jung, K. Motobayashi, S. Yanagisawa, Y. Morikawa, Y. Kim, M. Kawai, Nat. Mat. 9 (2010) 442.

24 J. Repp, G. Meyer, F.E. Olsson, M. Persson, Science 305 (2004) 493.

25 L. Gross, F. Mohn, P. Liljeroth, J. Repp, F. J. Giessibl, G. Meyer, Science 324 (2009) 1428.

26 L. Gross, F. Mohn, N. Moll, P. Liljeroth, G. Meyer, Science 325 (2009) 1110.

27 K. Muller, D. Torres, J.B. Park, P. Liu, D. Stacchiola, D. E. Starr, J. Phys. Chem. C 117 (2013) 280-287.

28 G. Pacchioni, L. Giordano, M. Baistrocchi, Phys. Rev. Lett. 94 (2005) 226103.

29 M. Sterrer, T. Risse, U. M. Pozzoni, L. Giordano, M. Heyde, H. P. Rust, G. Pacchioni, H.J. Freund, Phys. Rev. Lett. 98 (2007) 096107.

30 L. Giordano, U. Martinez, S. Sicolo, G. Pacchioni, J. Chem. Phys. (2007) 144713.

31 J. Jung, H. Shin, Y. Kim, M. Kawai, J Am. Chem. Soc 134 (2012) 10554-10561.

32 H. Metiu, S. Chretien, Z. Hu, B. Li, X.Y. Sun, J. Phys. Chem. C 116 (2012) 439. 
33 E. W. McFarland, H. Metiu, Chem. Rev. 113 (2013) 4391-4427.

34 C. Hammond, S. Conrad, I. Hermans, ChemSusChem 5 (2012) 1668-1686.

35 M. Gharibi, F. T. Zangeneh, F. Yaripour, S. Sahebdelfar, Appl. Catal. A 443-444 (2012) 8-26.

36 S. Arndt, G. Laugel, S. Levchenko, R. Horn, M. S. M. Baerns, R. Schlögl, R. Schomäcker, Catal. Rev. Sci. and Eng. 53 (2011) 424.

37 X. Shao, S. Prada, L. Giordano, G. Pacchioni, N. Nilius, H. J. Freund, Angew. Chem. Int. Ed. 50 (2011) 11525-11527.

38 F. Stavale, X. Shao, N. Nilius, H. J. Freund, S. Prada, L. Giordano, G. Pacchioni, J. Am. Chem. Soc 134 (2012) 11380.

39 X. Shao, N. Nilius, H. J. Freund, J. Am. Chem. Soc. 134 (2012) 2532.

40 J. Andersin, J. Nevalaita, K. Honkala, H. Häkkinen, Angew. Chem. Int. Ed 52 (2013) 1424.

41 L. Giordano, J. Goniakowski, G. Pacchioni, Phys. Rev. B 67 (2003) 045410.

42 N. Lopez, S. Valeri, Phys. Rev. B 70 (2004) 125428.

43 P. Frondelius, H. Häkkinen, K. Honkala, New. J. Phys. 9 (2007) 339.

44 S. Benedetti, H. M. Benia, N. Nilius, S. Valeri, H. J. Freund, Chem. Phys. Lett. 430 (2006) 330.

45 S. Benedetti, P. Torelli, S. Valeri, H. M Benia, N. Nilius, G. Renaud, Phys.Rev. B 78 (2008) 195411.

46 K. P. McKenna and A. L. Shluger, Nat. Mater. 7 (2008) 859.

47 L. Bellarosa, N. Lopez, K. Honkala, J. Phys. Chem. C 117 (2013) 23806.

48 K. Honkala, H. Häkkinen, J. Phys. Chem. C 111 (2007) 4319.

49 C. Giovanari, A. di Bona, T. S. Moia, S. Valeri, C. Pisani, M. Sgroi, M. Busso, Surf. Sci 505 (2002) L209-L214.

50 P. Luches, S. D’Addato, S. Valeri, E. Groppo, C. Prestipino, C. Lamberti, F. Busso, Phys. Rev. B 69 (2004) 045412.

51 P. Guenard, G. Renaud, B. Villette, Phys. B Condens. Matter. 221 (1996) 205-209.

52 S. Ling, M.B. Watkins, A.L. Shluger, J. Phys. Chem. C 117 (2013) 5075.

53 J. Goniakowski, C. Noguera, Phys. Rev. B 79 (2009) 155433.

54 T. Koenig, G. H. Simon, H.-P. Rust, G. Pacchioni, M. Heyde, H.-J. Freund, J. Am. Chem. Soc. 131 (48) (2009) 17544-17545.

55 T. Jaouen, G. Jezequel, G. Delhaye, B. Lepine, P. Turban, P. Schieffer, Appl. Phys. Lett. 100 
(2012) 022103.

56 M. T. Greiner, L. Chai, M. G. Helander, W. M. Tang, Z. H. Lu, Adv. Funct. Mater. 22 (2012) $4557-4568$.

57 J. Goniakowski, C. Noguera, Interface Sci. 12 (2004) 93.

58 L. Giordano, G. Pacchioni, Phys. Chem. Chem. Phys. 8 (2006) 3335.

59 L. Sementa, G. Barcaro, F. R. Negreiros, I. O. Thomas, F.P. Netzer, A. M. Ferrari, A. Fortunelli, J. Chem. Theory Comput. 8 (2012) 629-638.

60 S. Prada, U. Martinez, G. Pacchioni, Phys. Rev. B 78 (2008) 235423.

61 T. König, G. H. Simon, H. P. Rust, M. J. Heyde, J. Phys. Chem. C 113 (26) (2009) 1130111305.

62 T. Jaouen, G. Jezequel, G. Delhaye, B. Lepine, P. Turban, P. Schieffer, Appl. Phys. Lett. 100 (2012) 022103.

63 L. Giordano, F. Cinquini, G. Pacchioni, Phys. Rev. B 73 (2005) 045414.

64 U. Heiz, W. D. Schneider, J. Phys.D:Appl. Phys. 33 (2000) R85-R102.

65 M. Sterrer, E. Fischbach, M. Heyde, N. Nilius, H.P. Rust, T. Risse, H.J. Freund, J. Phys. Chem. B 110 (2006) 8665.

66 J. Kramer, W. Ernst, C. Tegenkamp, H. Pfnür, Surf. Sci. 517 (2002) 87.

67 J. Kramer, C. Tegenkamp, H. Pfnür, Phys. Rev. B 67 (2003) 235401.

68 T. Berger, M. Sterrer, O. Diwald, E. Knözinger, J. Phys. Chem. B 108 (2004) 7280.

69 M. Sterrer, M. Heyde, M. Novicki, N. Nilius, T. Risse, H.P. Rust, G. Pacchioni, H.J. Freund, J. Phys. Chem. B 110 (2006) 46.

70 V. Maurice, G. Despert, S. Zanna, M. P. Bacos, P. Marcus, Nat. Mater. 3 (2004) 687.

71 X. Shao, P. Myrach, N. Nilius, H. F. Freund, J. Phys. Chem. C 115 (2011) 8784.

72 S. Prada, L. Giordano, G. Pacchioni, J. Phys. Chem. C 117 (2013) 9943.

73 C.G. Bond, D.T. Thompson, Catal. Rev. Sci. Eng. 41 (1999) 319.

74 R. Meyer, C. Lemire, S.K. Shaikhutdinov, H.J. Freund, Gold Bull. 27 (2004) 72.

75 G. J. Hutchings, M. Haruta, Appl. Cat. A 291 (2005) 2.

76 D.T. Thompson, Top. Catal. 38 (2006) 231.

77 M. Haruta, T. Kobayashi, H. Sano, N. Yamada, Chem. Lett. 16 (1987) 405.

78 G. J. Hutchings, J. Catal. 96 (1985) 292.

79 B. Nkosi, N. J. Coville, G. J. Hutchings, M. D. Adams, J. Friedl, F. Wagner, J. Catal. 128 
(1991) 366.

80 T. Hayashi, K. Tanaka, M. Haruta, J. Catal. 178 (1998) 566.

81 M. Haruta, Cattech 6 (2002) 102, and references therein.

82 A. Corma, P. Serna, Science 313 (2006) 332.

83 L. Prati, M. Rossi, J. Catal. 176 (1998) 552.

84 B. Zope, D. D. Hibbitts and M. Neurock and R. J. Davis, Science 330 (2010) 74.

85 D. Andreeva, Gold Bull. 35 (2002) 82.

86 M. Valden, X. Lai, D.W. Goodman, Science 281 (1998) 1647.

87 N. Lopez, J. K. Nørskov, J. Am. Chem. Soc. 124 (2002) 11262.

88 A. Sanchez, S. Abbet, U. Heiz, W. Schneider, H. Häkkinen, R. Barnett, U. Landman, J. Phys. Chem. A 103 (1999) 9573.

89 H. Häkkinen, S. Abbet, A. Sanchez, U. Heiz, U. Landman, Angew. Chem. Int. 42 (2003) 1297.

90 Q. Fu, H. Saltsburg, M. Flytzani-Stephanopoulos, Science 301 (2003) 935.

91 M. Haruta, M. Date, Appl. Catal. A 222 (2001) 427.

92 M. Haruta, S. Tsubota, T. Kobayasi, H. Kageyama, N. Genet, B. Delmon, J. Catal. 144 (1993) 175.

93 M. Turner, V. B. Golovko, O. P. H. Vaughan, P. Abdulkin, A. Bergenguer-Murcia, M. S. Tikhov, B. F. G. Johnson, R. M. Labert, Nature 454 (2008) 981-984.

94 L. M. Molina, B. Hammer, Phys. Rev. B 69 (2004) 155424.

95 B. Yoon, H. Häkkinen, U. Landman, A. Worz, J. Antonietti, S. Abbet, K. Judai, U. Heiz, Science 307 (2005) 403.

96 S. Lee, C. Fang, T. Wu, S. L. Anderson, J. Am. Chem. Soc. 126 (2004) 5682.

97 I. X. Green, W. Tang, M. Neurock, J. T. Yates, Jr, Science 135 (2011) 19336.

98 L. Li, Y. Gao, H. Li, Y. Zhao, Y. Pei, Z. Chen, X. C. Zeng, J. Am. Chem. Soc. 135 (2013) 19336.

99 I. N. Remediakis, N. Lopez, J.K. Nørskov, Angew. Chem. Int 44 (2005) 1824.

100 I.N. Remediakis, N. Lopez, J.K. Nørskov, Appl. Catal. A 291 (2005) 13-20.

101 M. Sterrer, T. Risse, M. Heyde, H.P. Rust, H.J. Freund, Phys.Rev. Lett. 98 (2007) 206103.

102 P. Frondelius, A. Hellman, K. Honkala, H. Häkkinen, H. Grönbeck, Phys. Rev. B 78 (2008) 085426.

103 R. Bader, Atoms in Molecules, Oxford University Press, 1990. 
104 G. Henkelman, A. Arnaldsson, H. Jónsson, Comp. Mat. Sci. 36 (2006) 354.

105 V. Musolino, A. Selloni, R. Car, J. Chem. Phys. 108 (1998) 5044.

106 C. J. Nelin, B. S Bagus, M. A. Brown, M. Sterrer, H.J. Freund, Angw. Chem. Int. Ed 50 (2011) 10174.

107 D. Ricci, A. Bongiorno, G. Pacchioni, U. Landman, Phys. Rev. Lett 97 (2006) 036106.

108 P. Frondelius, H. Häkkinen, K. Honkala, Phys. Rev. B 76 (2007) 073406.

109 V. Simic-Milosevic, M. Heyde, X. Lin, T. Koenig, H. P. Rust, M. Sterrer, T. Risse, N. Nilius, H. J. Freund, L. Giordano, G. Pacchioni, Phys. Rev. B 78 (2008) 235429.

110 V. Simic-Milosevic, M. Heyde, N. Nilius, T. Konig, H. P. Rust, M. Sterrer, T. Risse, H. J. Freund, L. Giordano, G. Pacchioni, J. Am. Chem. Soc 130 (2008) 7814.

111 P. Frondelius, H. Häkkinen, K. Honkala, Phys. Chem. Chem. Phys. 116 (2010) 4266.

112 A. D. Vitto, G. Pacchioni, F. Delbecq, P. Sautet, J. Phys. Chem. B 109 (2005) 8040.

113 M. Walter, H. Häkkinen, Phys. Rev. B 72 (2005) 205440.

114 H. Häkkinen, U. Landman, Phys. Rev. B 62 (2000) R2287.

115 I. Yudanov, G. Pacchioni, K. Neyman, N. Rösch, J. Phys. Chem. B 101 (1997) 2786.

116 P. Frondelius, Electronic, structural and chemical properties of gold clusters on ultra-thin oxide films, Ph.D. thesis, University of Jyväskylä (2009).

117 N. Nilius, M. V. Ganduglia-Pirovano, V. Brazdova, M. Kulawik, J. Sauer, H.J. Freund, Phys. Rev. Lett. 100 (2008) 096802.

118 M. Walter, P. Frondelius, K. Honkala, H. Häkkinen, Phys. Rev. Lett. 99 (2007) 096102.

119 X. Lin, N. Nilius, H. Freund, M. Walter, P. Frondelius, K. Honkala, H. äkkinen, Phys. Rev. Lett. $102(2009) 20680$.

120 X. Lin, N. Nilius, M. Sterrer, P. Koskinen, H. Häkkinen, H. J. Freund, Phys. Rev. B 81 (2010) 153406.

121 C. Stiehler, Y. Pan, W. D. Schneider, P. Koskinen, H. Häkkinen, N. Nilius, H. J. Freund, Phys. Rev. B 88 (2013) 115415.

122 L. Giordano, G. Pacchioni, J. Goniakowski, N. Nilius, E. D. L. Rienks, H. J. Freund, Phys. Rev. Lett. 101 (2008) 026102.

123 S. Sicolo, L. Giordano, G. Pacchioni, J. Phys. Chem. J 113 (2009) 10256.

124 P. Barbaro, C. Bianchini (Eds.), Catalysis for Sustainable Energy Production, Wiley-VCH, 2009. 
125 W. F. Schneider, J. Phys. Chem 108 (2004) 273.

126 P. Broqvist, H. Grönbeck, Surf. Sci. 600 (2006) L214.

127 H. Grönbeck, J. Phys. Chem. B 110 (2006) 11977.

128 P. Broqvist, H. Grönbeck, Surf. Sci. 600 (2006) L214-L218.

129 A. Gonchar, T. Risse, H.J. Freund, L. Giordano, C. D. Valentin, G. Pacchioni, Angew. Chem. Int. Ed. 50 (2011) 2635.

130 A. Eichler, J. Hafner, Phys. Rev. B 59 (1999) 5960-5967.

131 B. Hammer, J.K. Nørskov, Nature 376 (1995) 238.

132 C. Harding, V. Habibpour, S. Kunz, A. N. S. Farnbacher, U. Heiz, U. Landman, J. Am. Chem. Soc 131 (2008) 538-548.

133 L. M. Molina, B. Hammer, J. Chem. Phys. 123 (2005) 161104.

134 B. Yoon, H. Häkkinen, U. Landman, J. Phys. Chem. A 107 (2003) 4066.

135 L. Vilhelmsen, B. Hammer, J. Chem. Phys. 139 (2013) 204701.

136 J. Nørskov, T. Bligaard, A. Logadottir, S. Bahn, L. Hansen, M. Bollinger, H. Bengaard, B. Hammer, Z. Sljivancanin, M. Mavrikakis, Y. Xu, S. Dahl, C. Jacobsen, J. Catal. 209 (2002) $275-278$.

137 K. Reuter, M. Scheffler, Phys. Rev. B 65 (2001) 035406.

138 P. G. Jones, Acta Crystallogr. Sect. B 35 (1979) 1435.

139 L. K. Ono, B. Roldan Cuenya, J. Phys.Chem. C 112 (2008) 4676.

140 H. Shi, C. Stampfl, Phys. Rev. B 76 (2007) 075327.

141 X. Lin, B. Yang, H. M. Benia, P. Myrach, M. Yulikov, A. Aumer, M. A. Brown, M. Sterrer, O. Bondarchuk, E. Kieseritzky, J. Rocker, T. Risse, H. J. Gao, N. Nilius, H. J. Freund, J. Am. Chem. Soc 132 (2010) 7745.

142 M. A. Henderson, Surf. Sci. Rep. 46 (2002) 1-308.

143 S. Kouva, J. Andersin, K. Honkala, J. Lehtonen, L. Lefferts, J. Kanervo, Phys. Chem. Chem. Phys. 16 (2014) 20650.

144 W. Langel, M. Parrinello, Phys. Rev. Lett. 73 (1994) 504.

145 W. Langel, M. Parrinello, J. Chem. Phys. 103 (1995) 3240.

146 M. I. McCarthy, G. Schenter, C. A. Scamehorn, J. B. Nicholas, J. Phys. Chem. 100 (1996) 16989-16995.

147 J. Carrasco, F. Illas, N. Lopez, Phys. Rev. Lett. 100 (2008) 016101. 
148 K. Honkala, A. Hellman, H. Grönbeck, J. Phys. Chem. C 114 (2010) 7070.

149 R. S. Alvim, I. Borges, D. G. Costa, A. A. Leitao, J. Phys. Chem. C 116 (2012) 738.

150 L. Giordano, J. Goniakowski, J. Suzanne, Phys. Rev. Lett. 81 (1998) 1271.

151 M. Odelius, Phys. Rev. Lett. 82 (1999) 3919.

152 L. D. Site, A. Alavi, R. M. Bell, J. Chem. Phys. 113 (2000) 3344.

153 D. Ferry, S. Picaud, P. N. M. Hoang, C. Girardet, L. Giordano, B. Deirdjian, J. Suzanne, Surf. Sci. 409 (1998) 101.

154 Y. Yu, Q. Guo, S. Liu, E. Wang, P. J. Moller, Phys. Rev. B 68 (2003) 115414.

155 L. Savio, E. Celasco, L. Vattuone, M. Rocca, J. Chem. Phys. 119 (2003) 12053.

156 L. Savio, E. Celasco, L. Vattuone, M. Rocca, J. Phys. Chem. B 108 (2004) 7771.

157 S. Altieri, S. F. Contri, S. Valeri, Phys. Rev. B 76 (2007) 205413.

158 A. M. Ferrari, C. Roetti, C. Pisani, Chem. Phys. Phys. Chem. 9 (2007) 2350.

159 Z. Ding, S. Meng, Phys. Rev. B 86 (2012) 045455.

160 J. T. Newberg, D.E. Starr, S. Yamamoto, S. Kaya, T. Kendelewicz, E. R. Mysak, S. Porsgaard, M. B. Salmeron, G. E. Brown, A. Nilsson, H. Bluhm, J. Phys. Chem. C 115 (2011) 12864.

161 L. Giordano, A. M. Ferrari, J. Phys. Chem. C 116 (2013) 20349-20355.

162 J. Guo, X. Meng, J. Chen, J. Sheng, X. Z. Li, L. Xu, J. R. Shi, E. Wang, Y. Jiang, Nat. Mat. $13(2014) 184$.

163 U. Martinez, L. Giordano, G. Pacchioni, J. Chem. Phys. 128 (2008) 164707.

164 U. Martinez, J. F. Jerratsch, N. Nilius, L. Giordano, G. Pacchioni, H. J. Freund, Phys. Rev. Lett. 103 (2009) 056801.

165 R. Wlodarczyk, M. Sierka, J. Sauer, D. Löffler, J. J. Uhlrich, X. Yu, B. Yang, I. M. N. Groot, S. Shaikhutdinov, H. J. Freund, Phys. Rev. B 85 (2012) 085403.

166 T. Jaouen, S. Tricot, G. Delhaye, B. Lepine, D. S. G. Jezequel, P. Schieffer, Phys. Rev. Lett. 111 (2013) 027601.

167 J. Carrasco, N. Lopez, F. Illas, H. J. Freund, J. Chem. Phys. 125 (2006) 074711.

168 J. Jung, H. J. Shin, Y. Kim, M. Kawai, J. Am. Chem. Soc. 133 (2011) 6142.

169 L. Giordano, U. Martinez, G. Pacchioni, M. Watkins, A. L. Shluger, J. Phys. Chem. C 112 (2008) 3857.

170 J. Carrasco, N. Lopez, F. Illas, Phys.Rev. Lett 93 (2004) 225502.

171 T. R. Munter, T. Bligaard, C. H. Christensen, J. K. Nørskov, Phys. Chem. Chem. Phys. 10 
(2008) 5202-5206.

172 P. Ferrin, D. Simonetti, S. Kandoi, E. Kunkes, J. A. Dumesic, J. K. Nørskov, M. Mavrikakis, J. Am. Soc. Chem. 131 (2009) 5809-5815.

173 J. Andersin, N. Lopez, K. Honkala, J. Phys. Chem. C 113 (2009) 8278-8286.

174 L. Nykänen, K. Honkala, ACS Catal. 3 (2013) 3026-3030.

175 H. Falsig, B. Hvolbæk, I.S. Kristensen, T. Jiang, T. Bligaard, C.H. Christensen, J.K. Nørskov, Angew. Chem. Int 47 (2008) 4835.

176 N. Lopez, J. Daniel Prades, F. Hernandez-Ramirez, J. R. Morante, J. Pan, S. Mathur, Phys. Chem. Chem. Phys. 12 (10) (2010) 2401-2406.

177 Y. Cui, N. Nilius, H. J. Freund, S. Prada, L. Giordano, G. Pacchioni, Phys. Rev. B 88 (2013) 205421.

178 A. R. West, Basic Solid State Chemistry, John Wiley \& Sons, LTD, 2004.

179 Y. Cui, X. Shao, M. Baldofski, J. Sauer, N. Nilius, H. J. Freund, Ang. Chem. Int. Ed 52 (2013) 11385.

180 J. Nevalaita, H. Häkkinen, K. Honkala, to be submitted.

181 N. Mammen, S. Narasimhan, S. de Gironcoli, J. Am. Chem. Soc. 133 (2011) 2801-2803. 